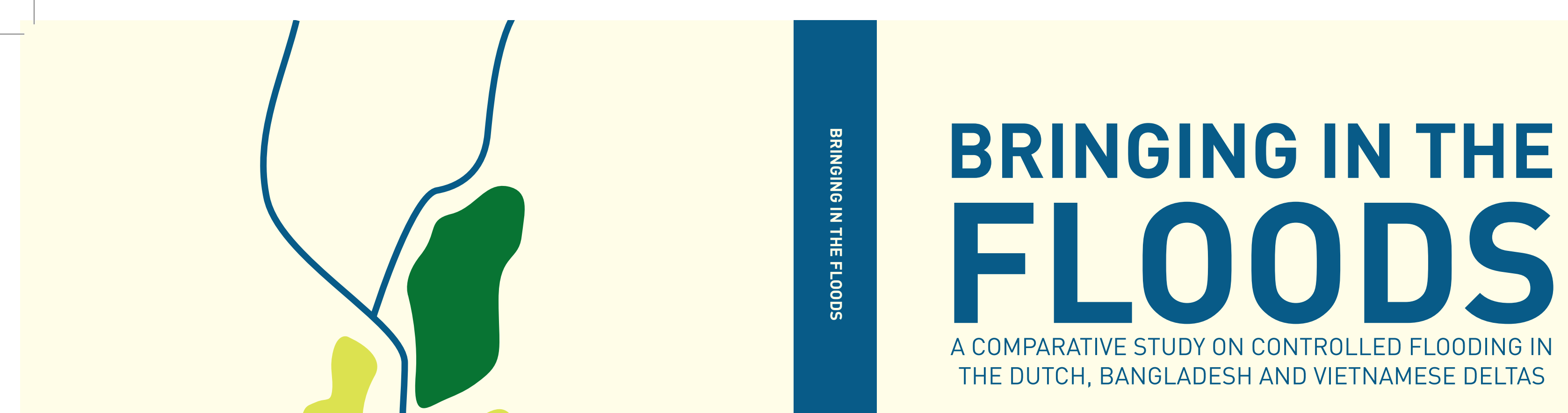




\section{Propositions}

1. Understanding flooding as being harmful obscures thinking about the potential benefits it can bring. (this thesis)

2. Flood management challenges lie in the future, solutions can be found in the past. (this thesis)

3. The need in science to publish unique material invokes academic protectionism.

4. The use of infographics to improve the dissemination and uptake of research findings is compromised by word count 'penalties' and color printing charges as is common practice among scientific journals.

5. Completing a PhD with delay is a proxy of perseverance.

6. Comparing the Netherlands, Bangladesh and Vietnam is like comparing soccer, cricket and table tennis: all ball sports but the number of players, the size of the field, and the rules of the game are different.

Propositions belonging to the thesis, entitled

'Bringing in the floods. A comparative study on controlled flooding in the Dutch, Bangladesh and Vietnamese deltas.'

Martijn Floris van Staveren

Wageningen, 8 November 2017 
Bringing in the floods

A comparative study on controlled flooding in the Dutch, Bangladesh and Vietnamese deltas 


\section{Thesis committee}

\section{Promotor}

Prof. Dr J.P.M. van Tatenhove

Personal chair at the Environmental Policy Group

Wageningen University \& Research

\section{Co-promotors}

Dr J.F. Warner

Associate professor, Sociology of Development and Change Group

Wageningen University \& Research

Dr P. Wester

Chief Scientist Water Resources Management

International Centre for Integrated Mountain Development (ICIMOD)

Affiliated researcher Water Resources Management Group

Wageningen University \& Research

\section{Other members}

Prof. Dr F. Ludwig, Wageningen University \& Research

Dr F.G. Renaud, United Nations University, Bonn, Germany

Prof. Dr W.A.H. Thissen, Delft University of Technology

Prof. Dr P. van der Zaag, IHE Delft Institute for Water Education

This research was conducted under the auspices of the Wageningen School of Social Sciences. 
Bringing in the floods

\title{
A comparative study on controlled flooding in the Dutch, Bangladesh and Vietnamese deltas
}

\author{
Martijn F. van Staveren
}

Thesis

submitted in fulfilment of the requirements for the degree of doctor

at Wageningen University

by the authority of the Rector Magnificus,

Prof. Dr A.P.J. Mol,

in the presence of the

Thesis Committee appointed by the Academic Board

to be defended in public

on Wednesday 8 November 2017

at 1:30 p.m. in the Aula. 
Martijn F. van Staveren

Bringing in the floods. A comparative study on controlled flooding in the Dutch, Bangladesh and Vietnamese deltas

174 pages

PhD thesis, Wageningen University, Wageningen, the Netherlands (2017)

With references, with summary in English

ISBN: 978-94-6343-703-5

DOI: $10.18174 / 423239$ 


\section{Table of Contents}

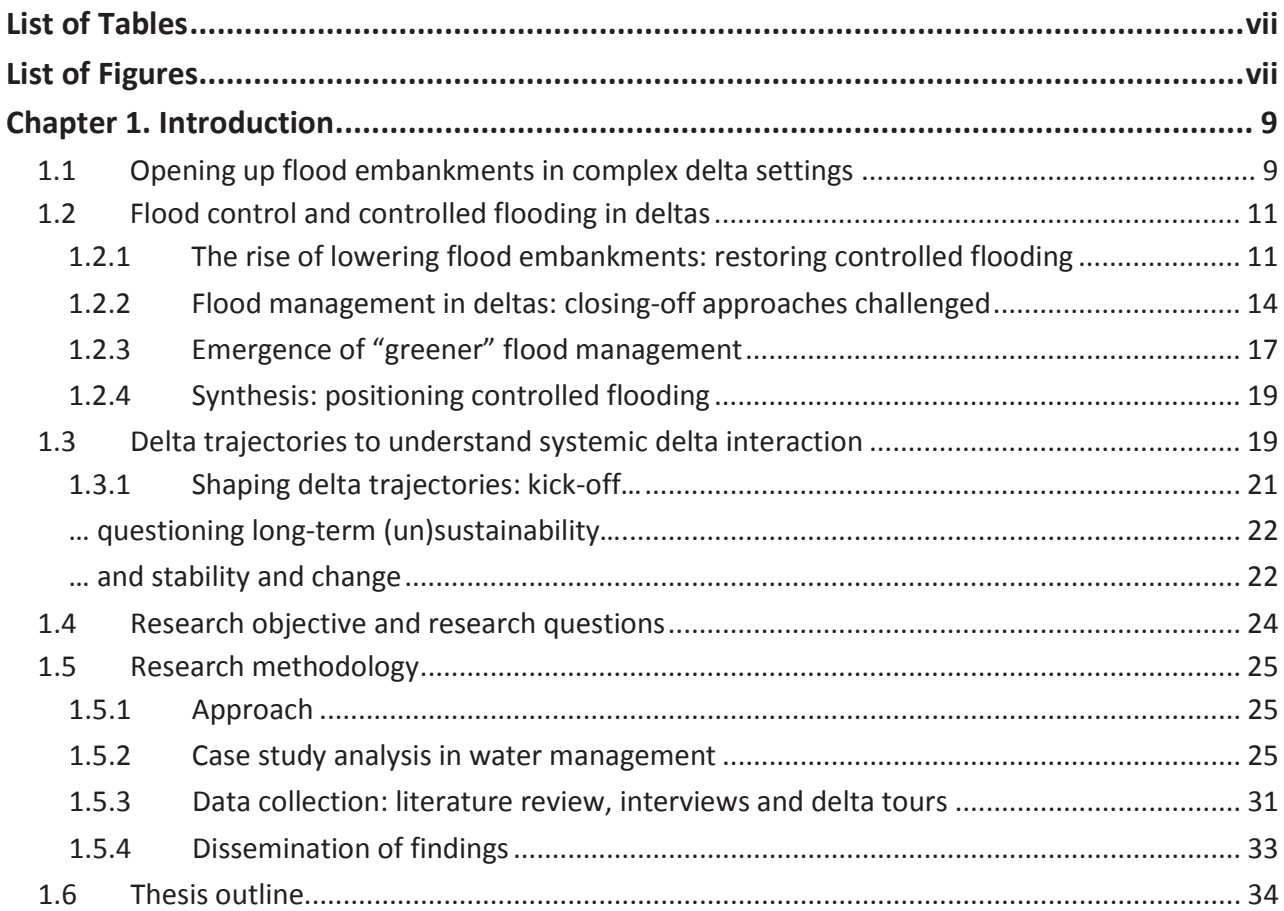

Chapter 2. Hydraulic engineering in the social-ecological delta: understanding the interplay between social, ecological, and technological systems in the Dutch delta by means of "delta

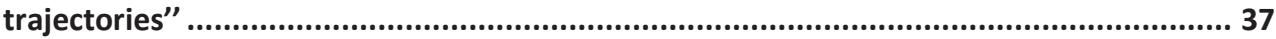

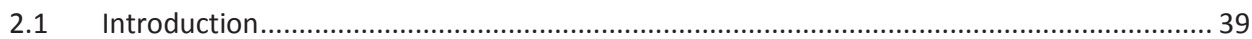

2.2 Technology in human-environment conceptualizations.................................................. 40

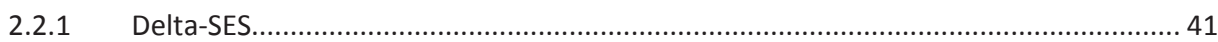

2.2.2 Into technology: hydraulical engineering systems in deltas .......................................42

2.2.3 Pathways to the future: delta trajectories ......................................................... 43

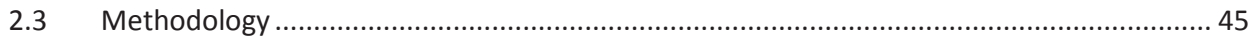

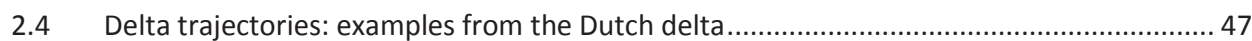

2.4.1 Oosterschelde storm surge barrier: pivotal in delta decisions and initiating path

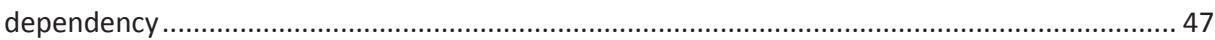

2.4.2 River embankments and impoldering: initiating a technological lock-in ..................... 48

2.4.3 Analysis and discussion: realigning unsustainable delta pathways ............................ 50

2.4.4 Realignment in the Dutch delta.......................................................................... 51

2.4.5 Realigning trajectories with adaptive delta management ..................................... 52

2.5 Conclusion .................................................................................................................... 53

Chapter 3. Let's bring in the floods: de-poldering in the Netherlands as a strategy for longterm delta survival? .......................................................................................55

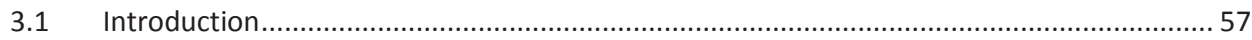




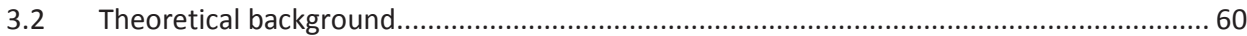

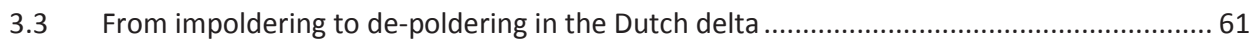

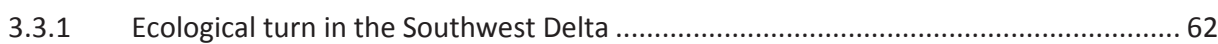

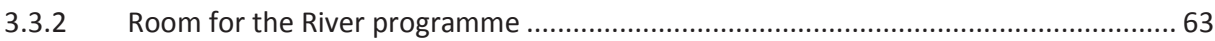

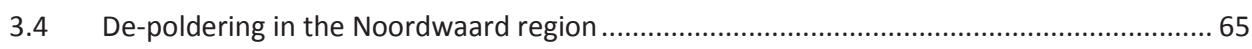

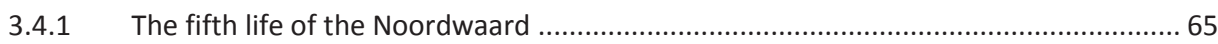

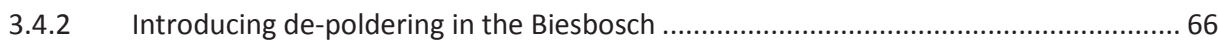

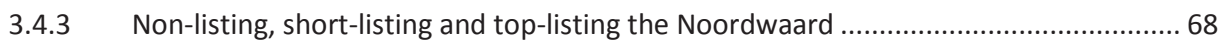

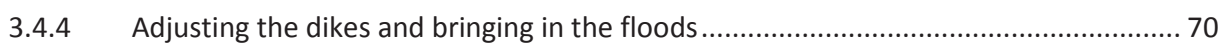

3.4.5 Bring in the floods - bringing in the sediment? ....................................................... 70

3.4.6 Continued de-poldering in the Noordwaard region? ................................................. 71

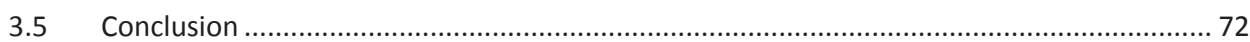

Chapter 4. Bringing in the tides. From closing down to opening up delta polders via Tidal River Management in the southwest delta of Bangladesh ............................................ 73

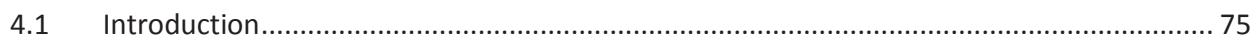

4.2 A brief social-ecological history of the southwest delta of Bangladesh ................................ 79

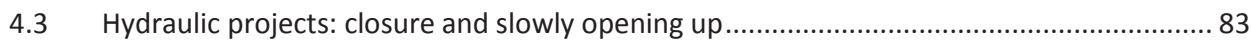

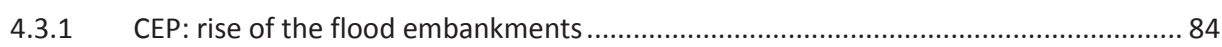

4.3.2 FAP: river engineering plans and compartmentalized controlled flooding pilots......... 85

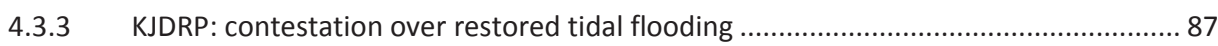

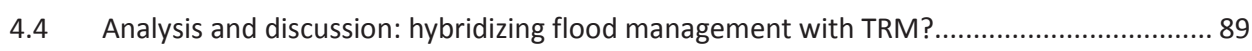

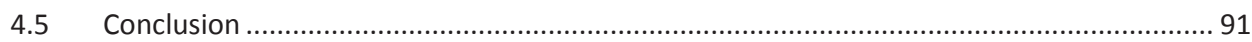

Chapter 5. The tenth dragon: controlled seasonal flooding in long-term policy plans for the

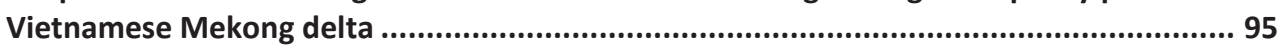

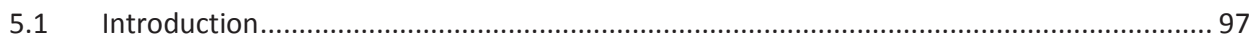

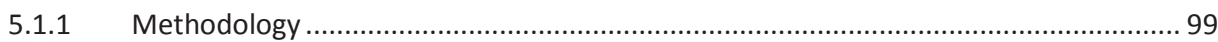

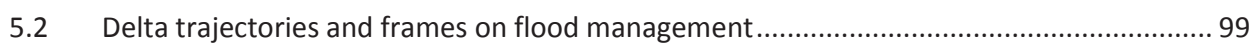

5.3 The Mekong's watery development trajectory: mastering the dragons ............................ 102

5.3.1 Initiating the Mekong's delta development trajectory .............................................. 104

5.4 Mekong delta long-term policy plans: changing frames on water and flood management105

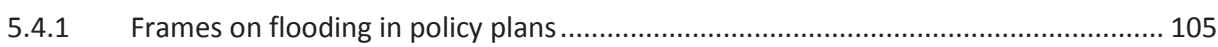

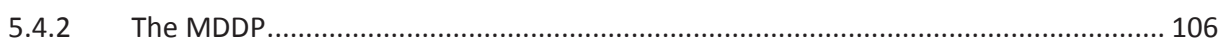

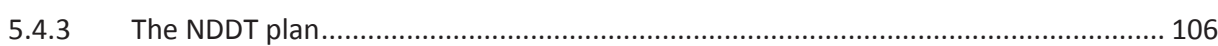

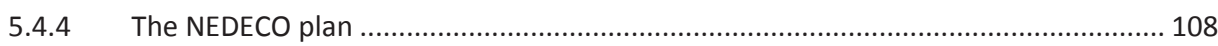

5.4.5 The Mekong Delta Plan ........................................................................................... 109

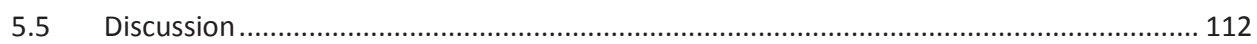

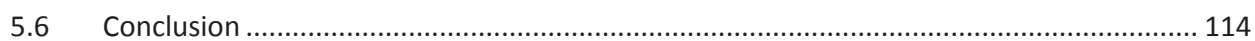

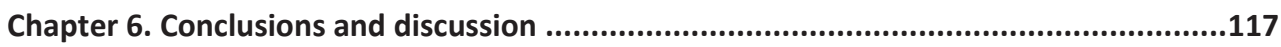

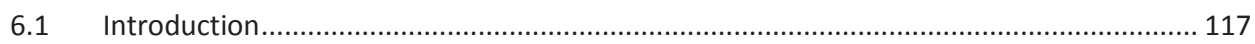

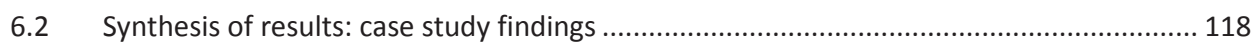

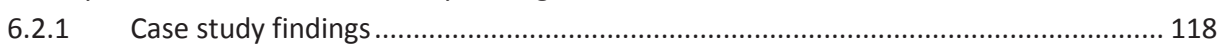

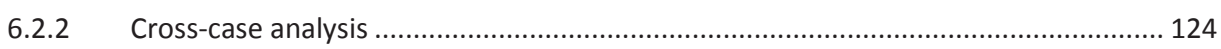

6.2.3 Controlled flooding in long-term delta planning .................................................... 127 
6.2.4 Controlled flooding and long-term delta trajectory realignment .......................... 129

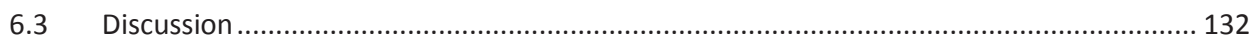

6.3.1 Engagement with the literature ................................................................. 132

6.3.2 Reflection on the conceptual framework........................................................ 135

6.3.3 Contribution of the research ....................................................................... 137

6.3.4 Future outlook: towards strategic controlled flooding in deltas?.......................... 138

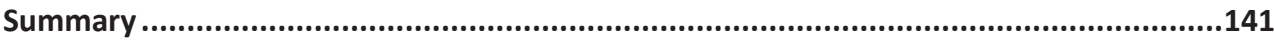

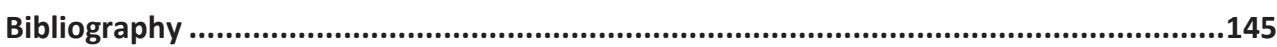

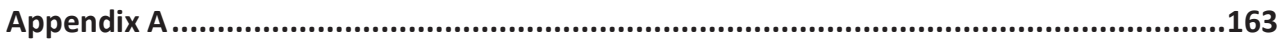

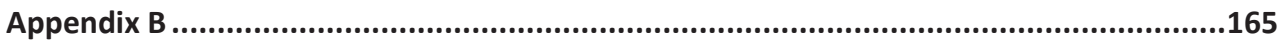

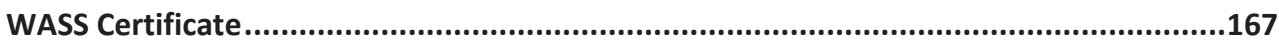

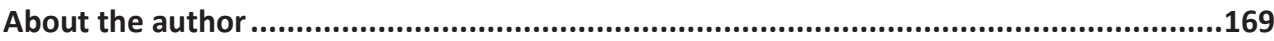

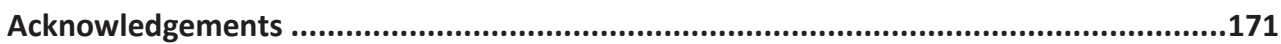

\section{List of Tables}

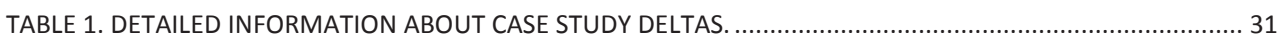

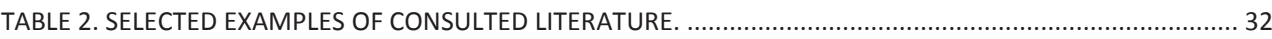

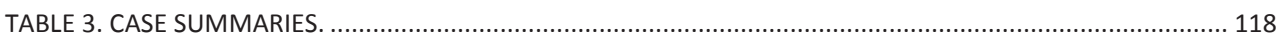

\section{List of Figures}

FIGURE 1. OPENING AN INTAKE POINT TO RESTORE FLOOD DYNAMICS ON DELTA LANDS. ............................. 10

FIGURE 2. DISTINCTION BETWEEN CONTAINED WATER FLOWS, “GOOD” FLOODS AND “BAD” FLOODS............ 13

FIGURE 3. TEMPORALITY OF CONTROLLED FLOODING INITIATIVES ............................................................ 14

FIGURE 4. SIMILAR TOPICAL CASES (CIRCLES) IN DIFFERENT DELTAS (TRIANGLES) ........................................ 27

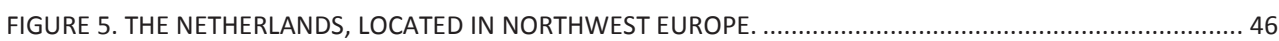

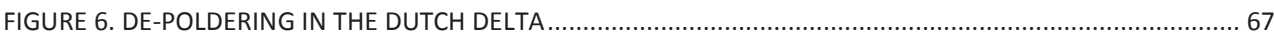

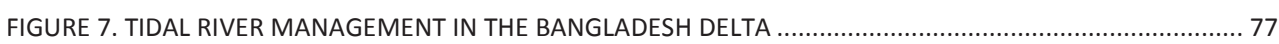

FIGURE 8. CONTROLLED SEASONAL FLOODING IN THE MEKONG DELTA .................................................. 103 
viii | 


\section{Chapter 1. Introduction}

\subsection{Opening up flood embankments in complex delta settings}

The Indian writer Amitav Ghosh showed grippingly in "Hungry Tide" (2004) how the Bengal delta is home to interactions: between land and water, between normal and extreme weather conditions, between history and future, and between local knowledge and modernist thinking. In "Quagmire" (2010), American historian David Biggs presented an environmental history of the Mekong delta, describing hydraulic interventions from early settlement in the delta, to the colonial period and to developments after the Vietnam War ended in 1975. Piet Nienhuis investigated in an "Environmental history of the Rhine-Meuse delta" (2008) how flood management approaches had shifted over the last decades in the Dutch and Belgium delta, emphasizing increased attention being paid to the delta's environmental processes.

While these delta regions are geographically far apart, each author chose to highlight waterrelated interactions. Recurrent saline tides, fresh river water discharge and occasional flooding figure prominently and in doing so the authors suggest that water and flooding are important carriers of delta histories, and, deductively, delta futures. At the same time they portray deltas as places of complexity and dynamic interaction between the environment, delta societies and engineered water management systems, which makes it increasingly difficult to manage delta water resources.

These environmental delta histories have served as inspirational sources and rich empirical accounts for this thesis, in which perennial debates about dealing with delta flooding (including its absence) are central. It is important to emphasize from the beginning that this study is different from most flood management research, which is characterized by a onedimensional understanding of flooding as only catastrophic and damaging. Such studies search for ways to adapt to climate change, to reduce flood vulnerability and disaster risk reduction, or to improve flood-related crisis management (Zevenbergen et al., 2013). While this thesis does aim to improve flood management in deltas, it has the restoration of flood dynamics as its object of analysis. This does not mean that it pursues large-scale flood restoration in deltas, but that it investigates how such "contradictory" interventions could emerge, within (and not necessarily conflicting with) contexts characterized by flood prevention strategies.

The following chapters explore such contested interventions, located in various deltas of the world, that consist of modifications to flood embankments to enable the (temporary) return 
of flooding on previously enclosed lands. Suggestions to relocate, lower or completely remove flood-preventive embankments have been noted in various deltas, so under various socioinstitutional settings, environmental conditions, and engineering capacities. Interestingly, they materialize in policy environments characterized by a paradigm, often dominant for decades, consisting of full flood prevention. This raises the question why and how the modification or even removal of embankments and restoration of flood dynamics, or in short restored controlled flooding, could emerge in such various places and under sometimes contrasting conditions. If Ghosh, Biggs and Nienhuis' messages are to be taken to heart, it takes a broad analytical perspective including social, environmental and technological dimensions, to answer these questions.

Besides an apparent interest among academics in controlled flooding initiatives (see Section 1.2.1), the societal relevance of the topic is flagged by novelists-researchers expressing their puzzlement with why policy makers decide to bring back water on often hard-won, reclaimed land (De Stoop, 2015; Westerman, 2015). They in particular note the political dimension of suggesting to re-flood delta lands, despite social agitation (De Stoop, 2015). At the same time the opposite has been observed: in places where controlled flooding has actually been stopped following policy makers' decisions, societal action has forcefully restored this form of flooding (A. Rahman, 1995). These authors popularly describe how such interventions are characterized by a fascinating melée of policy dynamics, politics and science. Taken together, this underscores that controlled flooding initiatives present interesting objects of analysis from an academic as well as societal perspective.

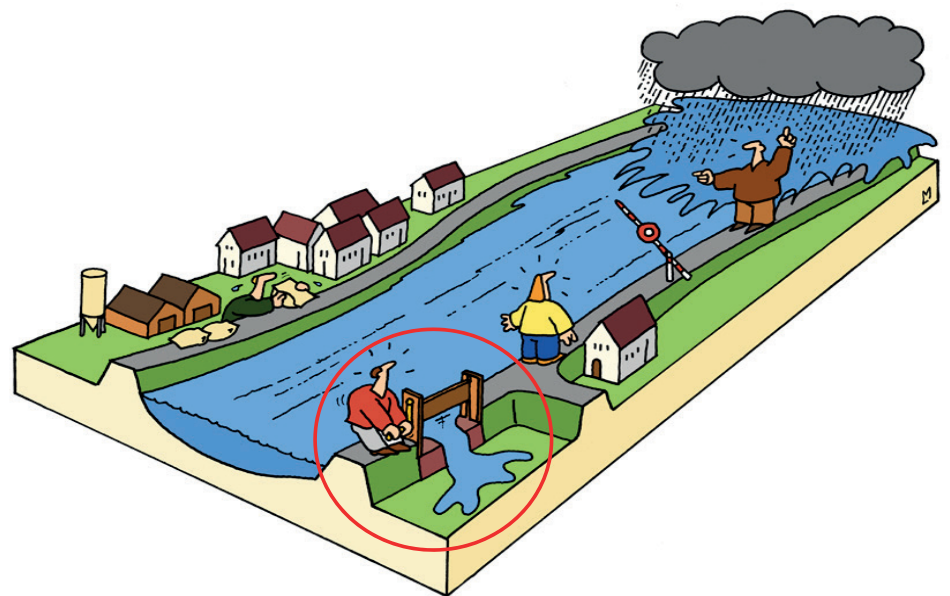

Figure 1. Opening an intake point to restore flood dynamics on delta lands. Courtesy Leven met Water/Loet van Moll. Circle added. 


\subsection{Flood control and controlled flooding in deltas}

\subsubsection{The rise of lowering flood embankments: restoring controlled flooding}

Over the last decades, initiatives to intentionally lower, relocate or remove flood-preventive embankments are mushrooming in various deltas of the world. For reasons of readability, with controlled flooding "initiatives" I collectively refer to conceptual ideas (proposed by ecoinspired engineers, for example), to formal policy plans suggesting embankment removal, or to implementation endeavors (formal projects or less formal initiatives). The following chapters will be more specific and go into the details of the respective initiative for restored controlled flooding under scrutiny. Controlled flooding initiatives have been identified and studied in, among other regions, the Rhine-Meuse delta (see for the Netherlands Van Staveren et al. [2014] and Warner [2008a], for Belgium Cox et al. [2006] and Maris et al. [2007], and for Germany Becker, Huitema, \& Aerts [2015] and Hartmann [2010]), the Sacramento-San Joaquin delta in California, United States (Bates \& Lund, 2013; Suddeth, 2011), the Thames delta in the United Kingdom (Eden \& Tunstall, 2006), the Bangladesh's Ganges-Brahmaputra-Meghna delta (Nowreen, Rashed Jalal, \& Khan, 2013; Van Staveren, Warner, \& Khan, 2017) and the Mekong delta in southern Vietnam (Socialist Republic of Vietnam and the Kingdom of the Netherlands, 2013).

Highlighting policy discussions on the topic in the Netherlands, the expectation that the modification of embankments would surface has been articulated earlier (Enserink, 2004; Wolff, 1992). This is not to say that embankment removal originates in the Netherlands - this study will go into various examples located in other deltas - but to sketch some of the earliest contributions to the debate in the Dutch delta between primarily environmentally concerned actors, engineers aiming for full flood protection, and the broader society. Henk Saeijs, one of the first biologists hired at Rijkswaterstaat (the organization responsible for the design, construction, management and maintenance of the main infrastructure facilities in the Netherlands) advocated an ecosystemic perspective on water management and opined that restoring controlled flooding is a logical consequence of impoldering since sediment deprivation is a downside of impoldering (Santbergen, 2015, p.211-225). In a rather pessimistic but not unrealistic future scenario, the Compendium on Polder Projects even expects that "In time, no doubt the country [the Netherlands] which gave the word polder to the world, will itself disappear when all the effort and cost of keeping it habitable is too high a price to pay" (Stoutjesdijk, 1982, p.17). While policy debates about a structural use of retention areas and controlled flooding came to a standstill in the Netherlands in the 1990s 
(Santbergen, 2015, p.211-225), partly because of societal protests against the intervention (Roth, Warner, \& Winnubst, 2006), by now dozens of projects have materialized in which flood dynamics are restored in reconnected floodplains or in polders (Van Staveren et al., 2014).

This thesis focusses on controlled flooding initiatives, consisting of modifications to embankments located in a delta's coastal zone or slightly more upstream in the riverine regions. ${ }^{1}$ It therefore concerns primarily riverine embankments, or embankments that make up individual polder units (to be discussed in section 1.2.2) along rivers. More strictly, in this thesis restoring controlled flooding is defined as the deliberate modification of embankments in order to enable flood dynamics on previously enclosed delta lands.

The definition implies the deliberate submersion of land. This seems paradoxical, given that flooding is typically characterized by its uncontrollability. It is not surprising that water overflowing embankments is instantaneously equated with situations of natural catastrophe, since flood disasters top the world's disaster statistics (IFRC, 2016, pp. 236-240), and this image makes (global) news headlines. ${ }^{2}$ But to widen the frame on floods, the figure below aims to distinguish between different types of flooding. It is informed by a definition of (river) floods proposed by Bandyopadhyay, who argues that "...river floods occur when the flow in a river channel exceeds its bank-full capacity, expelling the excess flow over the banks" (2009, p.50). This definition suggests that there is a threshold between water as contained in between (or on one side of) embankments, and water as overflowing embankments. The embankment height, or threshold, distinguishes between these two waterealities: a controlled, contained and "good" water flow, and a "bad" or intangible water flow (flooding).

\footnotetext{
${ }^{1}$ A slightly broader formulation, as in "the modification of water controlling infrastructure to enable flooding" could cover the removal of numerous dams in the United States (Fox, Magilligan, \& Sneddon, 2016) or the military practice of inundating lands for territorial defence (De Kraker, 2015; Lary, 2001). These kinds of interventions are outside the scope of this thesis. Similarly, coastal re-alignment (French, 2006; Pethick, 2002), or abandoning unproductive polders along coasts (Van Cruyningen, 2014) are regarded as being a permanent redefinition of the coastline.

${ }^{2}$ In "Before the Flood," a documentary issued by the United Nations, Leonardo di Caprio calls for attention to (water-related) climate change impacts. See https://www.beforetheflood.com/, accessed December 2016.
} 


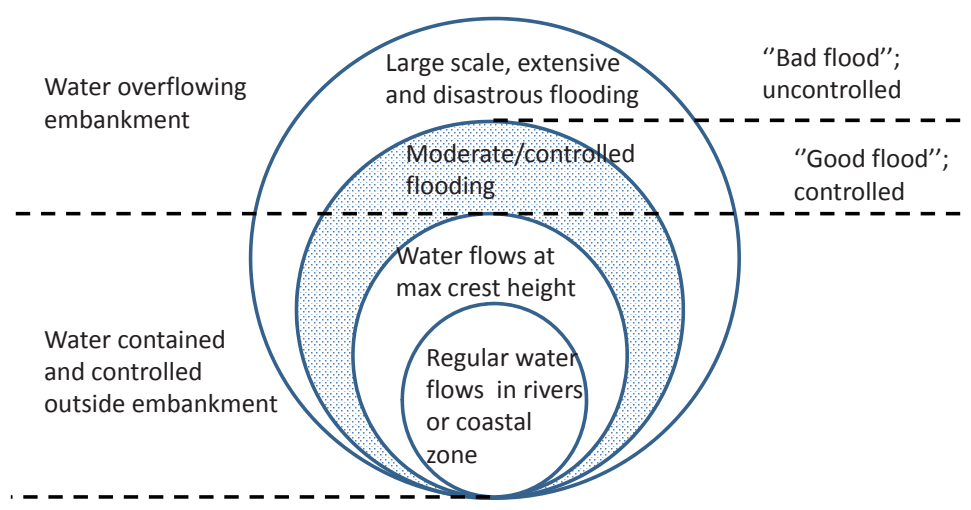

Figure 2. Distinction between contained water flows, "good" floods and "bad" floods.

The shaded ring, however, indicates that when water overflows an embankment, a further distinction can be made between moderate controlled overflow and extensive uncontrolled flooding. Moderate flooding is increasingly acknowledged for its positive impacts on some forms of agriculture, such as rice production, and the natural environment, such as wetlands. Controlling flood water for agricultural practices goes back to ancient delta cultures along the Nile and Indus, where overflow irrigation was practiced extensively to wet the lands (Kamal, 2006; Ozden, 2014; Saeed Khan, Nawaz, Van Steenbergen, Nizami, \& Ahmad, 2014). In hydrological terms, controlled flooding at one place can reduce peak water levels, and therefore flood risks, at another place. The view of flooding as solely harmful and uncontrollable obscures the awareness of different forms of flooding, which is more widely acknowledged in Asian settings (Nikula, 2008; Paul, 1984; Tuan, Hoanh, Miller, \& Sinh, 2007). Only when the volume of water overflowing an embankment unexpectedly exceeds the moderate flooding threshold, extreme flooding and catastrophic situations materialize.

In order to manage the threshold between contained water and water overflowing embankments, changes can be made to (1) the embankments themselves or (2) the volume of water discharged in between the embankments. Water discharges can be reduced by (temporary) storing flood peaks in upstream areas, for example in retention areas, via flood bypasses, behind dams or by means of purposefully using wetlands as flood buffers. Embankments can also be heightened, or placed further apart, to enable the river to discharge more water without overflowing its embankments. Modifications of embankments to restore flooding can consist of lowering a section of an embankment (which enables overflow via an intake structure), relocation (typically river widening, to reconnect floodplains to the main river) or full removal. In case of relocation or full removal, a second line of more inland 
embankments typically takes over the task of protecting the hinterland. In the Netherlands and Bangladesh, compartmentalization has been discussed (and tried) to provide multiple barriers to overflowing flood water (Warner, 2010). The threshold should therefore be understood both in a physical as well as in a socio-political or normative sense, since it reflects choices about which areas to be kept flood-free, and other areas to be liable to water overtopping embankments.

Controlled flooding initiatives can be classified based on the timing or duration of controlled flooding. Of interest in this research are initiatives that temporarily restore controlled flooding, which can be divided into (1) incidental, (2) seasonal and (3) multi-annual situations. Incidental controlled flooding can refer to the upstream storage of peak flows, for example by means of retention areas (Warner, 2008a). Also flood diversion (fully rerouting floods) or designating flood bypasses (floodplains parallel to a river spreading out flood water) are concepts that fit this category (Duel, Ellis Penning, Haasnoot, \& Klijn, 2003). Seasonal controlled flooding can be practiced for agricultural irrigation purposes (Ehlert, 2012), while multi-annual initiatives have been found where tidal flooding is pursued in conjunction with capturing sediment (Nowreen et al., 2013). Controlled flooding initiatives that are more permanent in nature (see footnote 1) are not considered here.

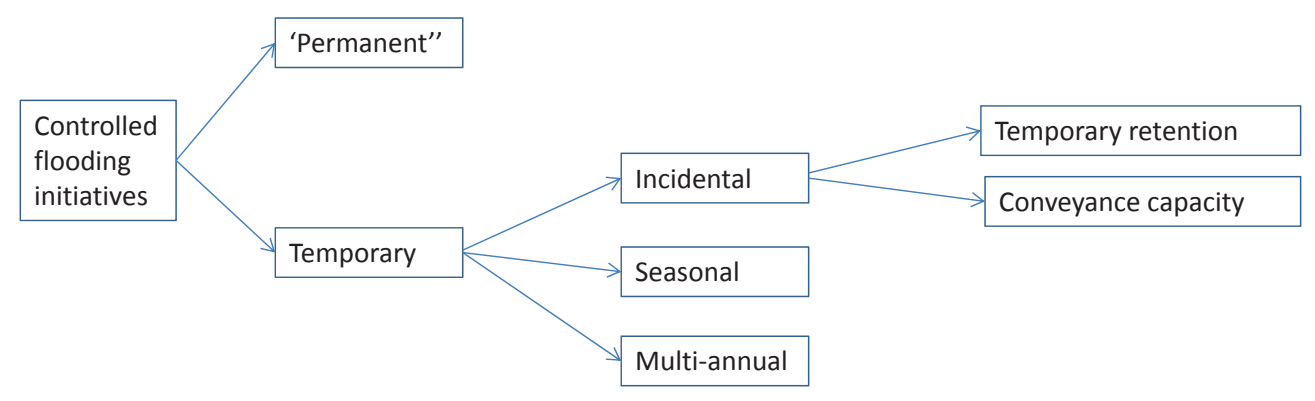

Figure 3. Temporality of controlled flooding initiatives

\subsubsection{Flood management in deltas: closing-off approaches challenged}

The controlled flooding initiatives investigated here are located in deltas. There are many ways to understand deltas, ranging from ontologically constructed realities (Zegwaard, 2016), to resourceful ecosystems providing certain goods and services (MEA, 2005), to objects of multidisciplinary scientific analyses (Collins, 2015), and to disappointingly large amounts of 
mud (Gerrits, 2008, p.1). In geographical terms, deltas are low-lying coastal ${ }^{3}$ regions, home to dynamic environmental interactions between land and water, and between rivers and seas (Meyer, 2009; Ramachandran, Ramachandran \& Lakshmi, 2010). Predominantly natural scientists have attempted to delineate and quantify environmental delta system process such as erosion, sedimentation, and flooding via geomorphological and hydrological models (Disco \& Van den Ende, 2003; Ludwig, van Slobbe, \& Cofino, 2014). This proves difficult since land and water movements are never stable: deltas are in constant flux. It is therefore argued that deltas should be conceptualized and studied as complex, interacting or adaptive systems (Dammers, Bregt, Edelenbosch, Meyer, \& Pel, 2013; Gerrits, 2008; Renaud, Syvitski, et al., 2013).

Because of the ever present water bodies, deltas are prone to coastal or riverine flooding. Flood risk management in deltas is a huge challenge, considering the high population densities and built-up economic value along the coasts, near rivers and in (urbanizing) cities (Hallegatte, Green, Nicholls, \& Corfee-Morlot, 2013; Schanze, 2012; Syvitski et al., 2009; Tessler et al., 2015; Zevenbergen et al., 2013). Delta inhabitants' flood avoidance strategies such as settling on higher grounds have increasingly been replaced by interventions aiming for flood control, caused by a general belief that science and technology would make development and mastery over nature possible (Blackbourn, 1997). Also, demands for increased food production and flood safety in support of urbanizing areas have strengthened this perspective (Nienhuis, 2008). Resulting closing-off policies and subsequent infrastructures in delta estuaries and along delta rivers therefore developed rapidly during the last century (Blackbourn, 1997; Disco, 2002; Van Heezik, 2008), although contrastingly, before that time irrigation and drainage canals were constructed to "open up" and reclaim delta lands (Biggs, 2010).

As an example, polder embankments have been built in the Dutch delta for several hundreds of years as unitary divisions between land and water (Van der Ham, 2009). Within the encircled polder, or impoldered area, water levels could be meticulously controlled by means of weirs and sluice gates, governed by means of institutional arrangements at polder scale. Polders were laid out to enable draining and reclamation of land, to subsequently protect these new agricultural units against (saline) flooding. After small-scale impoldering projects, an entrepreneurial perspective encouraged by innovations such as steam power and advanced steel mechanisms, scaled up polder construction in even lower-lying regions (Van

\footnotetext{
${ }^{3}$ Deltas can also be found inland, e.g. the Inner Niger delta in Mali (Zwarts et al., 2005).
} 
Cruyningen, 2014; Van Dam, 2002; Van der Ham, 2009). By now, over half of the Netherlands consists of impoldered, reclaimed land below mean sea level (Van de Ven, 2004). The polder concept has been replicated in many other deltas (Stoutjesdijk, 1982) and in that sense superseded local flood management infrastructure (Larkin, 2013). Constructing polders or river embankments was not always done irrevocably. Many breached unintentionally during construction, or when storms hit (Wolters, Bakker, \& Garbutt, 2005). Also riverine embankment suffered from instability, weakness in construction or lack of maintenance (Van Heezik, 2008). But when hydraulic infrastructure provides a reliable protection from flooding 4 , this presented immense opportunities: drained land and relatively flood free zones created the circumstances for rapid socio-economic development behind the embankments.

Planning for or construction of river closures, tidal dams and polders did not always proceed without scientific dispute, fierce societal protests or free from political interests (Bijker, 2007; D'Souza, 2006; Klingensmith, 2007b). Large scale, closing-off hydraulic infrastructure have become easy targets for societal protests (S. Islam \& Kibria, 2006; Klingensmith, 2007b). Although protests might be staged for political reasons, resistance against such plans generally resulted from (a mix of) concerns about the local environmental impacts of engineering works for example on fish stocks or water supply (A. Rahman, 1995), an uneasiness with top-down, unsolicited decision-making by distant hydrocrats (Benedikter, 2013), and an expanding stakeholder network (including environmentalists) for whom large- scale engineering presented more disadvantages than advantages (Benedikter, 2013; Bijker, 2002; Warner, 2008a).

Furthermore, scholars have increasingly flagged the negative environmental impacts of closing off estuaries and constraining river embankments (Awal, 2014; Le, Nguyen, Wolanski, Tran, \& Haruyama, 2007; Syvitski, 2008; Syvitski et al., 2009; Syvitski \& Saito, 2007). River and polder embankments not only prevent flooding, but also the deposition of sediment on the former floodplains. Sediment deposition in narrowed rivers instead of on former floodplains has led to silted up rivers, which surfaces almost instantaneously in deltas with high sediment concentrations (Awal, 2014). Sediment deprivation coupled with groundwater extraction and historic peat mining in some impoldered regions effectuated that in many deltas the

\footnotetext{
${ }^{4} \mathrm{~A}$ distinction can be made between flood prevention and flood protection. Although both expressions mean more or less the same, flood prevention highlights mostly the objective to prevent flooding. Flood protection has a similar objective, but places stronger emphasis on the "risk-dimension" of flooding, as in protection from disastrous events. In this thesis, both expressions are used interchangeably unless it is relevant to highlight a particular one.
} 
difference between the land and water levels in rivers and along the coasts are ever increasing (Syvitski et al., 2009). Cycles of embankment heightening have followed, but the long-term sustainability (socially, technologically and financially) of this practice has been questioned (Gerrits \& Marks, 2008; Wesselink, 2007). Since lands no longer receive sediments and nutrients, fertilizers need to be added to keep up with targeted agricultural production volumes (K. V. Nguyen, Vo, \& Huynh, 2015). Finally, potential climate change impacts have been used as arguments to question the long-term effectiveness of flood protection infrastructure (Ludwig et al., 2014; Syvitski, 2008).

\subsubsection{Emergence of "greener" flood management}

Against the background of increasing global concern about the environment in the 1970s and 1980s (Carson, 1962; Disco, 2002; World Commission on Environment and Development, 1987), also in the domain of flood and water management environmental considerations have contributed to (partial) paradigm shifts (Pahl-Wostl, Jeffrey, Isendahl, \& Brugnach, 2011; Wesselink et al., 2015; Wiering \& Arts, 2006). This resulted in, and is constituted by, questions of how to reduce the immediate negative environmental impacts of hydraulic engineering works, which profoundly modifies delta landscapes (Savenije, Hoekstra, \& Van Der Zaag, 2014; Syvitski et al., 2009), but also how to proactively make use of the potential benefits of water for the natural environment (Falkenmark, 2003), and in particular flooding (Ehlert, 2012; Nikula, 2008). In the water management sector since the 1970s, the environmental dimension was more strongly acknowledged and brought into water management policies via attention to environmental flows (Arthington, Bunn, Poff, \& Naiman, 2006; Falkenmark, 2003), ecological guidelines for river basin development (Marchand \& Toornstra, 1986) and (eco)systemic approaches to managing delta water systems (Disco, 2002; Saeijs, 2008). These developments were amplified by various global policy reports and concepts stressing the relevance of environmental considerations in integrated water resources management (Gleick, 2003). Adaptive and flexible flood management responses, both in policy and in material terms, are argued to be more capable of addressing future flood management challenge than full flood protection measures (Borsje et al., 2011; Kothuis \& Kok, 2017; Schanze, 2012).

New ideas about flood management infrastructure stimulated the development of a range of greener flood management concepts and functional designs ${ }^{5}$ (Janssen, 2015; Saeijs, 2008).

\footnotetext{
${ }^{5}$ Appendix A aims to create some order as to the extent to which these greener flood management concepts incorporate ecosystem dynamics.
} 
Ecosystem-thinkers promote flood management infrastructure that is less-impacting on delta environments and sometimes "works with" delta dynamics such as sea currents to contribute to coastal protection (Borsje et al., 2011; De Vriend \& Van Koningsveld, 2012; Janssen, 2015; Korbee, 2015; Waterman, 2008). Ecosystem-based flood management has been used to categorize approaches that proactively build on and include environmental processes in flood management interventions (Seidl \& Stauffacher, 2013). Eco-engineered interventions are increasingly being adopted to deal with flood challenges, as opposed to grey infrastructure only (Renaud, Sudmeier-Rieux, \& Estrella, 2013; World Bank, 2012). Distinct bodies of literature that go into such measures can be found for deltaic coastal zones (Borsje et al., 2011; French, 2006; Van Loon-Steensma, Slim, Decuyper, \& Hu, 2014; Van Wesenbeeck et al., 2014) and more riverine or inland regions (Duel et al., 2003). Related, the value of flexible or multifunctional flood defenses has been expressed (Anvarifar, Zevenbergen, Thissen, \& Islam, 2016; Kothuis \& Kok, 2017).

Besides incremental changes in water management thinking, large or near flood events have been instrumental in forcefully challenging dominant flood prevention paradigms (Barry, 1998; Käkönen, 2008; Sayers et al., 2015). Flooding and near flooding along the Rhine and Meuse rivers in the 1990s and most recently in 2013 (Merz et al., 2014) served as wake-up calls. This showed that the flood containment strategy has its technical limits (Warner, Van Buuren, \& Edelenbos, 2013), something that has been observed much earlier in Asian deltas where flooding occurs more frequently and in much larger volumes (N. Islam, 2001; Marchand, Pham, \& Le, 2014). Conceptual proposals to widen river beds, connecting floodplains to the main river in order to spread out flood peaks, were subsequently adopted in the Netherlands and Germany under Room for the River programmes (Duel et al., 2003; Warner et al., 2013).

The environmental benefits of moderate flooding are increasingly stressed (Ehlert, 2012; Nikula, 2008). In Bangladesh, farmers distinguish between barsha or good floods; annual inundation flushing canals and fertilizing soil that can be capitalized upon, and bonna floods; bad ones involving extreme and extensive flooding (Paul, 1984). In the Mekong delta, the flood season is referred to as mua nuoc noi (the taking advantage of the flood season [Trung, Tuan, Trieu, Bastakoti, \& Lebel, 2013, p.118]), anticipating its irrigation, flushing and sediment deposition capacities. In many (other) parts of the world, such benefits have largely been subdued by constructing flood-preventive embankments that protect against high water but also prevent the intake of nutrients and sediments. 


\subsubsection{Synthesis: positioning controlled flooding}

The above has demonstrated how attention to greener forms of flood management has gained traction, as opposed to pursuing closing-off infrastructure. Controlled flooding clearly rides this wave, but at the same time this raises the question how controlled flooding can (for now) be positioned in relation to existing flood prevention policies in deltas.

First, the manifestation of greener flood management approaches, including controlled flooding, does not imply that full flood prevention has completely fallen out of fashion. Controlled flooding in one place can contribute to overall flood risk reduction on a regional scale, by lowering peak flows or temporarily storing water. From this spatial perspective, controlled flooding in one place can be still defined as a flood prevention measure in relation to other areas. Related, letting floods back in has been argued to go hand in hand with tight forms of engineered control (Van Hemert, 1999). This stands out in detailed project designs where it is meticulously determined where, when and how much flood water is "allowed" to flood the land (Van Staveren et al., 2014).

Second, controlled flooding is often presented as an innovation, but a historical perspective learns that it resembles age-old practices (Ehlert, 2012; Willcocks, 1930). In the Netherlands, the re-invention of controlled flooding in combination with living on mounds (which had been practiced for hundreds of years), now attracts hundreds of visitors (including international delegations interested in the latest innovations in water management) per year to the site (Van Rooy, 2015; Warner, 2012).

\subsection{Delta trajectories to understand systemic delta interaction}

Building on Section 1.2.2, this study approaches deltas as interacting social-ecologicaltechnological systems, where the delta trajectory concept is used as "...an analytical tool, intended to understand and assess the dynamic coevolution and interplay of environmental dynamics, social processes, and hydraulic infrastructure in deltas over time" (Van Staveren \& van Tatenhove, 2016). ${ }^{6}$ Chapter 2 will develop the conceptual framework in more detail. The following sections highlight some of the most important elements, in particularly how delta trajectories take shape, and how they are subsequently remain stable or are liable to change.

\footnotetext{
${ }^{6}$ Inspirational examples on trajectories referring to technical-economic dimensions of hydraulic engineering (Haasnoot, 2013) or to the availability of water resources in depleting river basins (Molle, 2003) to underline (un)sustainable development paths. For related ideas about systemic interaction and pathways, see (Leach et al., 2007). Compared to those, the delta trajectory concept is more concerned with the (long-term) flood risk in deltas, and places this central in discussions about long-term environmental delta sustainability.
} 
In the conclusion (Section 6.2.4) the case study findings are positioned in relation to such delta trajectory dynamics.

Flood (2001) makes a distinction between systems thinking and systemic thinking. The former has been criticized for its implicit suggestion that the world is made up of functionalistic units, which systematically interact within a delineated environment. Rather, the point that systemic thinkers make, and on which this thesis builds, is that systems, composed of actors and processes, interact through relatively "open" boundaries, with other systems and thereby coevolve (Alessa, Kliskey, \& Altaweel, 2009; Flood, 2001; Gerrits, 2008; Norgaard, Kallis, \& Kiparsky, 2009). This position is also taken by Berkes et al. $(2008,2000)$ who developed a social-ecological systems (SES) perspective to study coupled interactions between the environment and social actors. Others have suggested to conceive of complex systems as interacting social-ecological-technological systems (Brugnach, Dewulf, Pahl-Wostl, \& Taillieu, 2008; Dammers et al., 2013; Kemp \& Rotmans, 2005; Leach, Scoones, \& Stirling, 2007), which addresses criticism about how to account for the influence of technological systems on the environment and society (A. Smith \& Stirling, 2010).

A social-ecological-technological perspective is applicable to delta settings, as dynamic environmental systems where high impacts from society on delta environments are felt by means of technological infrastructure, including hydraulic engineering (Dammers et al., 2013; Renaud, Syvitski, et al., 2013; Savenije et al., 2014; Syvitski et al., 2009). This analytical perspective is different from considering a delta and its water bodies as an (eco)system in itself (see Saeijs, 2008, for an example of this). Although scholars have developed a deep and broad interest in the place and consequences of modern technology in the socio-environment (Ellul, 1964; Feenberg, 2010; Giddens, 1990; M. R. Smith \& Marx, 1994), this thesis adopts a less specific perspective. The technological system will be analyzed on a par with socialecological system conceptualizations: for its systemic interaction with the human and environmental dimension of deltas. This keeps the systemic analysis at the same "depth" and allows for a balanced investigation of social, environmental and technological interaction. This perspective explains primarily how systemic interaction takes place, and is less specific about systems' internal dynamics.

Dynamics, processes and actors of the individual systems can be specified. The environmental system of deltas is typically highly unstable, involving a continuous interaction between land and water, including seasonal flooding, erosion, sedimentation and land formation processes. 
The technological or hydraulic engineering system refers to the network of (polder) embankments, estuarine barriers, canals, sluices and pumps that are all put in place to manage water flows (Carse, 2012; Van der Vleuten, 2013; Van Staveren, Warner, et al., 2017). Those account for the typical concrete and steel works, but also for "softer" forms such as clay dikes and wooden sluice gates that are part of hydraulic engineering systems. As Larkin (2013) argues, a systemic perspective also implies that non-tangible connections between related infrastructural networks (for example, the spread of the polder concept or water management policies to other delta countries) also play an important role in network formation. The social system comprises actors and networks that are discursively connected to water and flood management. This broad understanding implies that not only the "closed" circle of hydraulic engineers, economists and policy planners, but also the broader stakeholder network such as polder residents, local communities, environmentalists and international policy advisors, can influence how water policy evolves and how hydraulic interventions materialize.

\subsubsection{Shaping delta trajectories: kick-off...}

The delta trajectory concept describes how a certain development path has evolved by analyzing systemic interaction between social, environmental and technological factors. A delta trajectory is typically "kicked-off" by the introduction or networked expansion of hydraulic engineered works in support of socio-economic demands, such as water regulation for agriculture. An example is the construction of high flood embankments: they provide relatively flood-free zones which enables socio-economic developments and shapes agricultural practices behind the embankments. As analyzed by Wesselink (2007), the protected built-up areas at the same time turn into sediment deprived delta lands: they slowly start to subside, while siltation in rivers intensifies. Instigated by an increased difference between land height and water levels, societal demands for increased flood protection will follow. The initiated delta trajectory, characterized by successively heightening floodpreventive embankments, is reinforced and leads to a physical "lock-in." It is increasingly difficult to step away from lock-in situations (Perkins, 2003), due to the rigidity of hydraulic engineering works and increasing built-up value behind embankments. In the Netherlands, cycles of embankment reinforcement has led to embankments of more than $10 \mathrm{~m}$ high, with a difference of $8 \mathrm{~m}$ between the water level and the low-lying hinterland (Wesselink, 2007).

The kick-off of a trajectory in terms of hydraulic engineering works, and increasing scale on which large hydraulic networks are managed, is intertwined with the formation of central hydraulic institutions (Van Buuren, Ellen, \& Warner, 2016). Organizations such as the Dutch 
Rijkswaterstaat, the Bangladesh Water Development Board and the Vietnamese state's construction companies are powerful in terms of technical knowledge, making policy decisions, and implementing construction measures (Benedikter, 2013; Cook, 2010; Van den Brink, 2009). They often reinforce the delta's development path by repeating the storylines of flood prevention and calls for expanding or reinforcing hydraulic works (Benedikter, 2013). This is a form of institutional path dependency (Pierson, 2000), in addition to the physical lockin as outlined earlier.

Delta trajectories can be characterized based on differentiated geographies. The southwest delta in the Netherlands, for example, its characterized by its many estuarine closure dams and tidal dynamics. The Bangladesh delta's southwest is home to extensive polder works and high sedimentation rates. In the Mekong delta, different trajectories can be identified based on the exact location and timing of seasonal flooding. They add up to a composite delta trajectory, characterizing the development path on the scale of the entire delta.

\section{... questioning long-term (un)sustainability...}

The (un)sustainability of a certain delta trajectory in relation to (the absence of) its flood dynamics can be challenged or questioned by various social, environmental and technological yardsticks. Gerrits and Marks (2008), for example, argue that in the long run it is no longer possible to maintain the ever-growing difference between rivers and sea on the one hand, and the subsiding polders on the other. Potential climate change effects may also influence whether a delta trajectory, for example a water containment strategy in rivers, is capable of transporting peak discharges in the future (Ludwig et al., 2014). Farmers might formulate different demands on land use and associated forms of water management, when they notice that certain development trajectories (e.g. rice intensification) come with aggravating environmental downsides (K. V. Nguyen \& James, 2013).

\section{... and stability and change}

Resulting from the above, delta trajectories are relatively rigid, to a large extent based on the physical entrenchment of hydraulic works, and institutional path dependency. Such concepts have recently received more attention, as a way to understand policy change and stability in flood risk management (Van Buuren et al., 2016). Path dependency and institutional lock-in do not imply, however, that trajectories are set in stone forever. Its stability might be challenged or influenced from various directions, which relates to the systemic perspective as central to this conceptual framework. For a system to change, more forces need to be present, and need to act synergistically upon the system (Frantzeskaki et al., 2016). 
First, from a more "internal" social systems perspective, calls for reorienting an existing trajectory by means of new, less-rigid flood management approaches can be formulated due to new insights and ideas among water policy makers, also called policy learning (Ingram \& Fraser, 2006; Van Buuren et al., 2016). Those ideas can gradually evolve among the network of professional engineers, but can also be sparked by other developments. The increasing attention paid to ecosystem processes and the increasing involvement of environmental engineers in water management (Disco, 2002), for example, has stimulated thinking along the lines ecosystem-based flood management interventions (Borsje et al., 2011; Waterman, 2008). Also non-professional actors can press for "new" ways of flood management: in Bangladesh, local communities have enforced embankment removal to restore flooding (A. Rahman, 1995), in the Netherlands local farmers came up with the plan to live on mounds instead of being relocated (Van Rooy, 2015), and in the Mekong, farmers increasingly emphasize the need for seasonal flooding for sustainable agricultural production (K. V. Nguyen \& James, 2013).

Second, especially environmental dynamics may trigger calls for new policy directions. Flood disasters, such as the century flood in 1988 and cyclonic storms in 2007 and 2009 in Bangladesh, (near) floods in 1953 and in the mid-1990s in the Dutch delta, and extensive flooding in the early 2000s and 2011 in the Mekong delta, have rekindled fundamental policy debates about the effectiveness of the flood management strategy. While it does not exclude the possibility that the existing strategy is actually reinforced, this might (re)open policy windows for the development of new flood management approaches.

Reorienting delta trajectories towards more sustainable system states will take time (Leach et al., 2007; Rammel, Stagl, \& Wilfing, 2007). It will probably take shape as a gradual process, given the path dependency characteristics outlined above. The term realignment (in use in the United Kingdom to express the physical redesigning of coastal protection with environmental processes along the coast [French, 2006]) is borrowed to express how flood management policies and infrastructural engineering works can be modified over time in such a way that delta trajectories develop in more sustainable directions. On a policy level, this could happen by means of including ecosystem-based concepts in flood management policy, instead of full flood prevention approaches alone (Seidl \& Stauffacher, 2013). At the infrastructural level, this could materialize by way of eco-technological add-ons or modifications to embankments, in such a way that flooding and sedimentation are managed differently (for example, partly restored). 


\subsection{Research objective and research questions}

This thesis specifically investigates controlled flooding initiatives, which so far have received attention in a somewhat fragmented way from various scholars in the world. No extensive comparative study has been conducted on the topic so far, comparing insights from different delta settings. As a result, it is not clear how and why, under somehow similar but also very different conditions, controlled flooding initiatives could emerge and materialize in practice. In addition, it is unclear in which ways controlled flooding initiatives could contribute to longterm flood safety in deltas.

This thesis' primary objective is therefore to investigate how social, environmental and/or technical factors have contributed to the emergence of controlled flooding initiatives in different delta settings. Furthermore, these insights are placed in relation to long-term developments in deltas. To reach this objective, a main research question and four subquestions were formulated, which will be addressed in subsequent chapters.

\section{Main research question (MRQ)}

How can the emergence of controlled flooding initiatives in different deltas be explained, and how do these initiatives affect the development trajectories of different deltas?

\section{Sub research questions}

I Which analytical framework of complex delta interaction can help to explain how deltas evolve over time? (Chapter 2)

II Which socio-political, environmental and technological factors have been critical for the emergence of controlled flooding initiatives in different deltas? (Chapters 3-5)

III What are the similarities and differences between controlled flooding initiatives in these three deltas? How can these similarities and differences be explained? (Chapter 6)

IV How have ideas about controlled flooding been incorporated in long-term delta management plans for these three deltas? (Chapter 6)

Flood management is never-ending challenge in deltas (Hallegatte et al., 2013; Tessler et al., 2015), since it needs to be in line with continuously evolving social demands, environmental dynamics, and available technological means. It is for this reason that policy makers (re)formulate policy plans and (re)construct hydraulic engineering works, seemingly without 
an end (Biggs, 2010, p.37). It is therefore relevant to investigate and reflect on how such processes take shape, as well as on how new conceptual ideas may contribute to addressing contemporary or long-term social, environmental and technological challenges. Insights in controlled flooding initiatives can contribute to a better understanding of why and how policy change (or stability) with regard to flood management takes place. It delivers insights in where drivers for change come from, given the fact that hydraulic institutions are rather path dependent, meaning they may prefer to stick to "known" approaches.

\subsection{Research methodology}

\subsubsection{Approach}

Inspired by the environmental delta histories as highlighted in the introduction (Section 1.1), this thesis has pursued a particular interest in the historical background of flood management in the respective deltas. This historical background is essential in providing contextual as well as specific insights regarding environmental changes, historic institutionalization, past debates and practical interventions in the deltas under review. Only by means of an historical understanding of past plans and interventions, the evolution of flood management in dynamic delta environments can be meaningfully untangled. An historical analysis has the capacity to put the development of contemporary "new" ideas and policy debates into perspective, which in the case of the Mekong delta makes it possible to identify the seemingly cyclical appearance of long-term policy plans over the last four decades. Finally, this approach has helped to better understand not only "known" territory but also unknown delta settings.

\subsubsection{Case study analysis in water management}

Inspired by the emergence of controlled flooding in different delta settings, this thesis adopts a comparative, multiple case study approach. Such an approach is increasingly called for in the domain of water resources management (Mollinga \& Gondhalekar, 2014; Wescoat, 2009). According to Mollinga \& Gondhalekar (2014, p.182), "The inherently localized nature of water resources management as now set in a context of intensifying globalization, provides excellent ground for growing a new brand of comparative analysis." Mollinga and Gondhalekar suggest that this is driven by an acknowledgement of shared water-related challenges around the globe, a perceived need to integrate the knowledge base of different localized water studies, and to address the dichotomy between water policy theory and practice $(2014$, p.183). The domain of integrated water resources management in a broad sense (Wescoat, 2009), flood management more specifically (Van Alphen \& Lodder, 2006), and lately delta management 
(Bucx et al., 2014; Renaud, Syvitski, et al., 2013) have been the object of such kinds of analyses. The investigated controlled flooding cases add to this line of work.

Case studies are increasingly being employed as a research methodology in the social sciences (Yin, 2014). They are applicable to in-depth or detailed investigations of contemporary, reallife issues in complex contexts (Flyvbjerg, 2006; Geertz, 1972). This applies in particular to the controlled flooding cases that will be discussed here: they are characterized by complexity in terms of hydro-morphological processes, socio-economic and political developments, and they are contemporary issues that impact society.

Furthermore, in particular the use of case-oriented research for concept formation stands out. Case-oriented research allows for flexible analytic frames which can be modified in the course of the study as knowledge [insights] emerge, making case-oriented study especially wellsuited for concept formation and theory development (Mollinga \& Gondhalekar, 2012) referring to (Ragin, 1997).

\section{Comparative case study design}

Comparative case studies can serve exploratory, descriptive and explanatory purposes (Yin, 2014 p.187), while its explanatory power lies in illuminating why and how decisions about certain issues have been taken. Comparative case study research aims to, besides delivering detailed empirical case study material, develop cross-case insights in similarities or differences between cases (Yin, 2014). This makes it possible to identify commonalities and differences, which could lead to more generalizable conclusions. The comparative method is defined as neither a distinct methodology nor a particular theme, but rather a research design perspective, which "...aims to identify significant differences in structural configurations of different situations" (Mollinga \& Gondhalekar, 2012, p.4).

In this research the differences apply to the context in which the investigated cases materialize. The figure below visually demonstrates how the cases are similar thematically (circles) while their respective contexts are highly diverse (triangles) both in terms of environmental dynamics (triangle size representing such dynamics) and socio-institutional settings (patterns). "Comparison by contrast" (Mollinga \& Gondhalekar, 2014), for example in comparing irrigation in water abundant and water scarce conditions (Geertz, 1972) or similarly a "most different" research design (Landman, 2000) highlights specific outcomes per case, but may at the same time extract generalizable insights, taken into account the different contexts where findings have emerged from. The comparative method is based on replication of an 
analysis of similar or contrasting cases, instead of sampling where larger amounts of data are necessary for statistically grounded conclusions (Yin, 2014).
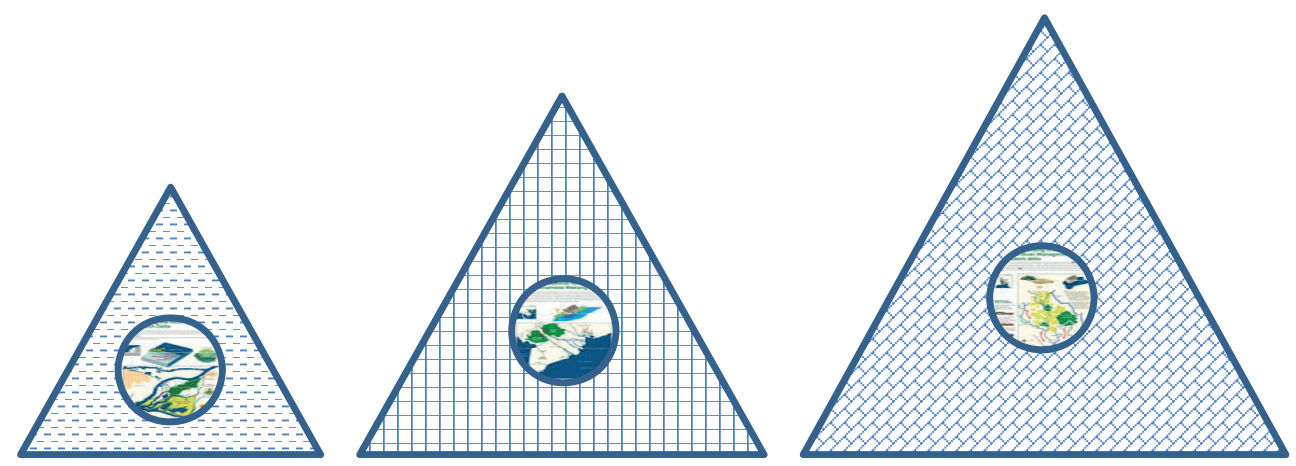

Figure 4. Similar topical cases (circles) in different deltas (triangles)

\section{Delta site and case study selection}

Three steps were taken to select a predefined number of in-depth controlled flooding case studies, each located in a different delta, so under different socio-institutional and environmental conditions.

An earlier, co-authored comparative delta study (Van der Most, Marchand, Bucx, Nauta, \& Van Staveren, 2009) made it possible to have a general acquaintance with ongoing flood management issues in those deltas, acting as a shortlist of eight potential case study deltas: the Yellow River delta in China, the Mekong River delta in Vietnam, the Ganges-BrahmaputraMeghna delta in Bangladesh, the Ciliwung river delta in Indonesia, the Nile river delta in Egypt, the Rhine river delta in the Netherlands, the Mississippi river delta in the United States, and the California Bay (Sacramento San Joaquin) delta in the United States.

As a second step, formulated as a criterion, controlled flooding should be discussed in contemporary policy debates about flood management. This would strengthen support for and relevance of the case study to be conducted, for policy and practice. Research findings from similar controlled flooding projects in one delta, may be used by stakeholders being involved in other cases which increases the uptake opportunities of research outputs; on two occasions (see Section 1.5.4). Based on literature review conducted in 2012/2013, several studies were retrieved that made explicit reference to this policy debate in the deltas of the Netherlands, Bangladesh, Vietnam and deltas in the US (Bates \& Lund, 2013; Day et al., 2007; N. Islam, 2001; Käkönen, 2008; Shampa \& Pramanik, 2012; Suddeth, 2011; Warner, 2008a). 
A third step consisted of three related considerations: (1) to account for the "comparison by contrast" method as outlined earlier and (2) to search for coherence in the shape of a meaningful connection between the cases (beyond the obvious shared thematic connection). Such a connection was easily found since in the Netherlands, Bangladesh and Vietnam longterm flood management policies have come to be reconsidered by so-called long-term delta processes. In addition, there is a "hydraulic connection" since in each of those deltas, polders (representative of aiming for flood prevention) have widely been constructed.

Via international development cooperation relations the Dutch government assists the governments of Bangladesh and Vietnam in formulating long-term delta plans (Government of the Netherlands, 2009; Seijger et al., 2016; Zegwaard, 2016). Long-term delta planning evolved as a policy approach to dealing with complex delta challenges (see footnote 55 and Seijger et al. [2016] for motivations and methodology). Especially its most recent interpretation was developed into an "exportable" policy tool. The effect of such a policy process is that stabilized policy debates are re-opened and scrutinized for its long-term sustainability. It provides a window of opportunity to propose new concepts and ideas.

Another hydraulic connection was encountered between the Netherlands, Bangladesh and Vietnam in the shape of polder construction, as outlined in Section 1.2.2. With a prominent role for Western engineers advocating closing-off infrastructure, the polder concept was distributed to various other delta areas (Stoutjesdijk, 1982; Van de Ven, 2004). The Dutch polder concept was introduced in Bangladesh in the 1960s: over a hundred polders were constructed in the southwest delta region and along the coastline towards the East (LeedshillDe Leuw Engineers, 1968). In the Mekong delta, the introduction of the polder concept was effectuated during the time of French colonial rule in the 1930s. French colonizers transferred the polder concept from the Red River delta in the North of Vietnam, where farmers had been constructing polder-like embankments for hundreds of years (Biggs, 2010; Jansen, 2015). Having a polder-rich background, studying those deltas from the perspective of flood restoration, or "de-poldering," presents opportunities for interesting analyses.

After considering the potential set of case studies in its entirety, cases were selected in the deltas of the Netherlands, Bangladesh and Vietnam. ${ }^{7}$ These deltas display varying degrees in

\footnotetext{
${ }^{7}$ There is a Dutch connection with the US deltas in terms of centuries of knowledge exchange (Bergsma, 2017), that there are polders (Suddeth, 2011), and that long-term delta visions are being formulated (Lund et al., 2008) - but all without the institutionalized Dutch assistance in developing long-term delta plans as figuring so prominently in the Asian deltas. As follow up on this research project, a comparative paper is being developed
} 
environmental dynamics, in terms of water discharge, peak flows, and sediment concentration (leading to faster environmental change) in which the Netherlands and Bangladesh fully "contrast," and with the Vietnamese Mekong delta positioned as an in-between case. For example, average discharge volumes in the Ganges-Brahmaputra are more than tenfold compared to average discharge of the Rhine, and the Mekong river is positioned in between. See Table 1 below for specifics about these environmental dynamics. While later chapters will in much more detail explore the individual controlled flooding case studies, the next section provides short introductions to the cases.

\section{De-poldering the Noordwaard polder in the Dutch delta}

In the Dutch delta, the Room for the River programme (2005-2015) was formulated after (near) flood events in the mid-1990s (Roth et al., 2006). It consists of over 30 interventions, including floodplain reconnection and river widening, along the main rivers in the Netherlands. A few controlled flooding restoration, or de-poldering projects, had been implemented in the mid-2000s, but during the course of this research project the Noordwaard polder was planned to be de-poldered. The project consisted of embankment lowering, which would enable the inflow of flood water during high water levels in the river Merwede, acting as a river bypass. The inflow of water reduces peak water levels in the river and supports the adjacent freshwater wetland by means of restored water dynamics. It is located at the junction of tides and rivers.

\section{Controlled flooding in beels/polders with Tidal River Management in the Bangladesh's delta}

The coastal zone of Bangladesh has been home to the construction of polders in the 1960s. Besides stimulating agricultural productive and providing safer places to live in, this caused increased sedimentation in the region's rivers and water logging in enclosed areas due to insufficient drainage possibilities. Mirroring historic overflow irrigation, some of the polders or low-lying areas called "beels" have been opened up and exposed to tidal influence again since the 1980s. This was initially forcefully done by the local population, by partly removing the flood-preventive embankments. Restored tidal dynamics scour the river beds and deposit sediments on polder lands, but also prevent agricultural production for a few years. This "illegal embankment cutting" came to be known conceptually as Tidal River Management. It remains a (hotly) debated policy topic within the context of sustainable management of the

by co-authors conducting research on controlled flooding in the deltas of the Netherlands, Bangladesh, Vietnam and the Sacramento-San Joaquin delta. 
delta's coastal zone (Gain, Benson, Rahman, Datta, \& Rouillard, 2017; Mutahara, Warner, Wals, Khan, \& Wester, 2017).

\section{Controlled seasonal flooding in the Vietnamese Mekong delta}

Successive long-term delta plans for the Mekong have all touched upon how to deal with the delta's flood dynamics, which are characterized by its seasonality. From the perspective of rice production and rice intensification, constructing flood-preventive embankment networks have increasingly halted flood dynamics in the delta. The downside of reduced flood spreading is that this exposes downstream urban areas to higher peak flows, and that the agricultural sector (which now faces reduced nutrient intake, soil quality and therefore needs substantial amounts of fertilizer) is affected. The positive dimensions of controlled seasonal flooding have received growing attention in long-term delta plans, up to the point the latest plan (the Mekong Delta Plan, endorsed by the Vietnamese government in 2013) explicitly suggests to restore controlled, seasonally flooding in the upper regions of the delta (Socialist Republic of Vietnam and the Kingdom of the Netherlands, 2013).

\begin{tabular}{|c|c|c|c|}
\hline & Case 1\# & Case \#3 & Case \#2 \\
\hline & $\begin{array}{l}\text { De-poldering the } \\
\text { Noordwaard polder in the } \\
\text { Dutch delta }\end{array}$ & $\begin{array}{l}\text { Controlled seasonal flooding } \\
\text { in the Vietnamese Mekong } \\
\text { delta }\end{array}$ & $\begin{array}{l}\text { Controlled flooding in } \\
\text { beels/polders with TRM in } \\
\text { the Bangladesh delta }\end{array}$ \\
\hline $\begin{array}{l}\text { Mini-map of } \\
\text { each case }\end{array}$ & $\begin{array}{l}\text { De-poldering the Noordwaard } \\
\text { in the Dutch Delta }\end{array}$ & $\begin{array}{l}\text { Controlled seasonal flooding } \\
\text { in the Vietnamese Mekong delta }\end{array}$ & $\begin{array}{l}\text { Controlled flooding in beels/polders } \\
\text { with Tidal River Management in the } \\
\text { Bangladesh delta }\end{array}$ \\
\hline $\begin{array}{l}\text { Short case } \\
\text { description }\end{array}$ & $\begin{array}{l}\text { Recently completed } \\
\text { controlled flooding project } \\
\text { entitled "Noordwaard de- } \\
\text { poldering project" (2007- } \\
\text { 2015) within the context of } \\
\text { the Room for the River } \\
\text { programme. }\end{array}$ & $\begin{array}{l}\text { Suggestions to restore } \\
\text { controlled seasonal flooding } \\
\text { in the upper regions of the } \\
\text { Vietnamese part of the } \\
\text { Mekong delta, as } \\
\text { incorporated in a recently } \\
\text { endorsed long-term policy } \\
\text { plan. }\end{array}$ & $\begin{array}{l}\text { Tidal flooding in polders or } \\
\text { "beels" in the coastal zone of } \\
\text { the southwest delta in } \\
\text { Bangladesh, by means of the } \\
\text { Tidal River Management } \\
\text { concept. }\end{array}$ \\
\hline
\end{tabular}




\begin{tabular}{|c|c|c|c|}
\hline $\begin{array}{l}\text { Environmental } \\
\text { delta } \\
\text { dynamics }^{8} \\
\text { Average } \\
\text { discharge } \\
\text { main river(s) } \\
\text { Flooding } \\
\text { Sedimentation } \\
\text { Coastal } \\
\text { vulnerability }\end{array}$ & $\begin{array}{l}2,300 \mathrm{~m}^{3} / \mathrm{s} \\
+/- \\
4 \text { million tonnes } / y \\
+/-\end{array}$ & $\begin{array}{l}16,000 \mathrm{~m}^{3} / \mathrm{s} \\
+ \\
100 \text { million tonnes } / \mathrm{y} \\
+\end{array}$ & $\begin{array}{l}30,000 \mathrm{~m}^{3} / \mathrm{s} \\
++ \\
1,000 \text { million tonnes } / \mathrm{y} \\
++\end{array}$ \\
\hline $\begin{array}{l}\text { Population } \\
\text { density }\end{array}$ & $500 \mathrm{pp} / \mathrm{km}^{2}$ & $425 \mathrm{pp} / \mathrm{km}^{2}$ & $1200 \mathrm{pp} / \mathrm{km}^{2}$ \\
\hline $\begin{array}{l}\text { Geographical } \\
\text { setting case }\end{array}$ & $\begin{array}{l}\text { Intertidal area: tidal/riverine } \\
\text { junction }\end{array}$ & $\begin{array}{l}\text { Inland riverine, with some } \\
\text { tidal influence }\end{array}$ & Active coastal tidal zone \\
\hline $\begin{array}{l}\text { Long-term } \\
\text { flood } \\
\text { management } \\
\text { policy } \\
\text { reconsidered? }\end{array}$ & $\begin{array}{l}\text { Earlier via the Room for the } \\
\text { River programme and } \\
\text { currently via the Dutch Delta } \\
\text { Plan and subsequent Delta } \\
\text { Program (being } \\
\text { implemented) }\end{array}$ & $\begin{array}{l}\text { Mekong Delta Plan } \\
\text { (moving } \\
\text { implementation) }\end{array}$ & $\begin{array}{l}\text { Bangladesh Delta Plan } 2100 \\
\text { (being finalized) }\end{array}$ \\
\hline
\end{tabular}

Table 1. Detailed information about case study deltas.

\subsubsection{Data collection: literature review, interviews and delta tours}

Data collection for this study consists of literature analysis, semi-structured interviews and (pre-)field trips to the case study projects. Literature analysis included project documentation, policy plans, academic analyses of water and flood management policies, as well as various historically oriented literature. In Table 2 a selection of different types of consulted literature sources has been presented.

\begin{tabular}{|l|l|l|}
\hline Literature type & $\begin{array}{l}\text { Specification by means of selected } \\
\text { examples }\end{array}$ & Reason \\
\hline $\begin{array}{l}\text { Environmental } \\
\text { delta histories }\end{array}$ & $\begin{array}{l}\text { (Biggs, 2010; Ghosh, 2004; Iqbal, 2010; } \\
\text { Nienhuis, 2008) }\end{array}$ & $\begin{array}{l}\text { Solid historical background, focus on water } \\
\text { and flood management, of the deltas } \\
\text { where case studies were conducted }\end{array}$ \\
\hline $\begin{array}{l}\text { International } \\
\text { examples } \\
\text { controlled } \\
\text { flooding projects }\end{array}$ & $\begin{array}{l}\text { (Bates \& Lund, 2013; Becker et al., 2015; } \\
\text { Cox et al., 2006; Eden \& Tunstall, 2006; } \\
\text { Hartmann, 2010; Maris et al., 2007; } \\
\text { Nowreen et al., 2013; Suddeth, 2011; } \\
\text { Warner, 2008a) }\end{array}$ & $\begin{array}{l}\text { Rele findings, information to base delta } \\
\text { case selection }\end{array}$ \\
\hline $\begin{array}{l}\text { Case-based } \\
\text { project } \\
\text { documentation }\end{array}$ & $\begin{array}{l}\text { Noordwaard de-poldering project } \\
\text { (Projectbureau Noordwaard, 2009), Tidal } \\
\text { River Management studies (Nowreen et } \\
\text { al., 2013; A. Rahman, 1995; Rashid \& }\end{array}$ & $\begin{array}{l}\text { Detailed understanding of (past) water and } \\
\text { flood management projects or initiatives }\end{array}$ \\
\hline
\end{tabular}

\footnotetext{
${ }^{8}$ Sources: (M. R. Islam, Begum, Yamaguchi, \& Ogawa, 1999; Jansen, 2015; Manh, Dung, Hung, Merz, \& Apel, 2014; Nienhuis, 2008; Van der Most et al., 2009).
} 


\begin{tabular}{|c|c|c|}
\hline & $\begin{array}{l}\text { Rahman, 2010), Mekong controlled floods } \\
\text { (Benedikter, 2013; Huu, 2011; Miller, 2003) }\end{array}$ & \\
\hline $\begin{array}{l}\text { Long-term policy } \\
\text { plans }\end{array}$ & $\begin{array}{l}\text { Dutch Delta Plans (Delta Committee, 2008; } \\
\text { Van Veen, 1962), Bangladesh Delta Plan } \\
\text { (Consultant Team BanDuDeltAS, 2014), } \\
\text { Mekong delta plans (NEDECO, 1993; } \\
\text { Netherlands Delta Development Team, } \\
\text { 1974; Socialist Republic of Vietnam and the } \\
\text { Kingdom of the Netherlands, 2013), see } \\
\text { also (Miller, 2003; Seijger et al., 2016) }\end{array}$ & $\begin{array}{l}\text { Background of long-term policy plan } \\
\text { formulation }\end{array}$ \\
\hline Policy studies & $\begin{array}{l}\text { (Benedikter, 2013; Dewan, 2012; Käkönen, } \\
\text { 2008; Rashid \& Rahman, 2010; Van der } \\
\text { Brugge, 2007) }\end{array}$ & $\begin{array}{l}\text { Analysis of policy change in water and } \\
\text { flood management in the respective deltas }\end{array}$ \\
\hline $\begin{array}{l}\text { Systems- } \\
\text { theoretical } \\
\text { literature }\end{array}$ & $\begin{array}{l}\text { (Berkes et al., 2008, 2000; Gerrits, 2008; } \\
\text { Haasnoot, 2013; Molle, 2003; Molle \& } \\
\text { Wester, 2009; Norgaard et al., 2009; A. } \\
\text { Smith \& Stirling, 2010; Van der Vleuten, } \\
\text { 2013) }\end{array}$ & Background on systemic delta interaction \\
\hline
\end{tabular}

Table 2. Selected examples of consulted literature.

Interviews were held with stakeholders involved with water, delta and flood management: policy advisors, water engineers, environmental experts, researchers and local residents. An interview list is included in Appendix B. Interviews were (partly) transcribed and statements or potential quotes from respondents checked with the interviewees for validity. Field work in the Netherlands was carried out in 2012 and 2013. Field work in Bangladesh consisted of 5 field visits, each lasting several weeks, between 2012 and 2014. Three trips were made to the Mekong delta, one in 2014 and two in 2016. Three MSc students have contributed with data collection: Jan van Minnen and Leendert de Die (2013) who developed their MSc theses on Tidal River Management in Bangladesh and Rik Heinen who engaged in an internship in Dhaka (2015) and via a student assistant position, conducted guided research in Vietnam (2016).

After preliminary delta selection and case study identification (see 1.5.2), orientation field visits "delta tours" were conducted in the startup period of the research project, to assess the suitability of each case. Delta tours were conducted from the perspective of case orientation, and included visiting the case study sites, getting familiar with local settings, conducted informal and informative discussions about the research topic, and initial network building. In each case the topic was confirmed to be fully active, be it in terms of policy debates or in terms of implementation. Selecting cases may come with doubts and it would be justifiable to change or drop cases at all along the way (Ragin 1997). It was not necessary to change or drop cases, but what has influenced the positioning of the cases and case analyses is that the research took place over an extended period of time. This means that some controlled flooding projects could be studied "in reality" during implementation, while in other cases 
controlled flooding initiatives remained plans on paper, potentially to be developed or implemented at a later stage.

\subsubsection{Dissemination of findings}

This thesis has an article-based structure, which means that individual chapters (2-5) have been submitted to and accepted for publication with peer reviewed academic journals. Based on to the analytical framework and findings presented in each chapter, it was decided which journal would be most appropriate to submit it for peer review. An important criterion was which audience could be reached via the respective journals, and whether journals had published on related topics before.

Chapter 2 was published with Ecology\&Society, a journal which publishes extensively on social-ecological systems analyses from a multidisciplinary perspective. The article was published at the end of 2015/early 2016 (http://dx.doi.org/10.5751/ES-08168-210108). It is an open access journal, and the article got around 3000 views and 1000 pdf downloads. The third chapter was submitted to Water International in 2014 with contributions from the entire supervision team (http://dx.doi.org/10.1080/02508060.2014.957510). The journal has a broad international audience of water management scholars and practitioners. Chapter four was published with Water Policy in 2017. Likewise with a broad international audience of scholars and policy-makers concerned with water policy processes, this journal was selected since the chapter specifically employs a tool for policy analysis: the policy pendulum swing concept (http://dx.doi.org/10.2166/wp.2016.029). The fifth chapter is published in the Journal of Environmental Policy and Planning. The journal's audience works in the domains of environmental governance and policy planning. The article was accepted for publication in June 2017 (http://dx.doi.org/10.1080/1523908X.2017.1348287).

Other kinds of dissemination of and discussions about research findings have been set up during (among others) a Delta Lessons Seminar in Bangladesh (2012), the Amsterdam International Water Week (2013), the Urbanizing Deltas of the World conference in Ho Chi Minh City in 2016, and a Delta Lessons Seminar in the Netherlands (2017).

Each article makes use of infographics as a way to visually introduce the investigated case study. This approach has been found very useful since infographics are attractive and easily accessible ways to disseminate often complex information. The infographics have been designed in a coherent layout. 


\subsection{Thesis outline}

The structure of this thesis is based on a number of published articles included as chapters. Chapters 2-5 have been peer reviewed and published with different academic journals between 2014 and 2017. Chapter 1 provides the general background information, problem definition, and objectives of the study. Chapter 6 ties together the findings of the individual case study chapters and presents the conclusions. In particular, Chapter 1 has highlighted how, in several deltas around the world, initiatives to restore controlled flooding in deltas have taken shape. Taking place against the background of decades of flood prevention, restoring flooding presents an interesting topic of analysis; it relates to questions about longterm delta sustainability and about the emergence of "greener" flood management approaches. The chapter explains how the selection of deltas and delta cases studies has taken place, and which research methods have been employed.

Chapter 2 provides the more theoretical background on systemic delta interaction which has been used in the subsequent case study analyses. It explores social-ecological systems theory, but also investigates how the field of socio-technical systems research can contribute conceptually to this field. It introduces the concept of "delta trajectories," which foregrounds that a systemic understanding of delta interaction is well-suited to explain how deltas evolve over time, but that the influence of technological systems (in this case, the system of hydraulic engineering works) should be explicitly acknowledged. In doing so, this chapter responds specifically to RQ1. Chapter 2 is published with Ecology\&Society.

Chapters 3-5 present detailed, empirical findings of three case studies, conducted in three different deltas, and provides answers to RQ2. Chapter 3 builds on Chapter 2 by underscoring the argument that hydraulic engineering has an important effect on the stability, and potential scope for change, of a delta development trajectory. This chapter shows how in the heavily engineered Dutch delta, technological lock-in and path dependency emerged. The Dutch delta development trajectory is not only relatively stable in terms of delivering flood protection, but therefore also distinctively rigid when it comes to aiming for change. The chapter investigates the de-poldering of the Noordwaard polder, and reflects on whether "bringing in" floods could contribute to long-term delta survival. It has been published with Water International.

Chapter 4 explores the Bangladesh delta. Compared to the Netherlands, the Bangladesh's delta purposefully presents different scales in many ways: environmental processes are much more dynamic, for example when looking at the enormous volumes of sediment-rich water 
that are carried through the delta annually, and this implies that hydraulic engineering faces a very challenging environment. Also, population density is double compared to that of the Dutch delta, which means that space is scarce. The introduction of this chapter starts with a social-ecological exploration of the delta's history, and describes how hydraulic engineering works have increasingly been constructed in an attempt to deal with the delta's water volumes. It analyzes the emergence of the Tidal River Management concept, which involves the temporary flooding of coastal polders by means of tidal flooding, against a policy background characterized by debates on whether open or closed flood management approaches should be pursued. This chapter has been published with Water Policy.

In Chapter 5, the Mekong delta is central. Also here, a social-ecological delta history intertwined with hydraulic interventions gave shape to the Mekong delta's development trajectory. In terms of environmental dynamics, this delta is positioned as "in-between" the Netherlands and Bangladesh. Its current development path has been questioned in several ways; climate change impacts, changes in how the Mekong river's water is being managed upstream, and the (un)sustainability of intensive rice production have been heavily debated by Vietnamese and international policy makers. This chapter has a stronger focus on past and contemporary policy formulation processes, zooming in on how controlled flooding has surfaced in a series of subsequent long-term delta plans for the Mekong delta. It has been accepted published with the Journal of Environmental Policy and Planning.

Chapter 6 synthesizes the findings and presents conclusions. It brings together the findings of the preceding case study chapters, thereby concisely answering RQ2 and RQ3. Furthermore, it reflects on the way controlled flooding has been incorporated in long-term delta plans for the three deltas, and how this could affect the delta development trajectory (answering RQ4). The second part of this chapter positions case study findings in relation to (the realignment of) delta trajectories, as an answer to the MRQ. The final part discusses in which ways the presented findings contribute to academic scholarship. It includes a reflection on the use of the conceptual framework (related to RQ1), and closes with a short future outlook on studying controlled flooding initiatives in deltas. 
$36 \mid$ 
Chapter 2. Hydraulic engineering in the socialecological delta: understanding the interplay between social, ecological, and technological systems in the Dutch delta by means of "delta trajectories"

\footnotetext{
This chapter has been published as: Martijn F. van Staveren and Jan P. M. van Tatenhove (2016) Hydraulic engineering in the social-ecological delta: understanding the interplay between social, ecological, and technological systems in the Dutch delta by means of "delta trajectories." Ecology and Society, 2016 www.ecologyandsociety.org/vol21/iss1/art8/
} 
Abstract

Several of the world's largest deltas have recently been conceptualized as social-ecological delta systems. Although such conceptualizations are valuable in emphasizing complex interaction between social actors and ecological processes in deltas, they do not go into specific dynamics that surround technological developments in the hydraulic domain. By drawing from concepts originating in socio-technical systems research, we stress the importance of technology, particularly the domain of hydraulic engineering, in shaping a delta's future. Based on two geographically distinct cases of flood management infrastructure in the Dutch delta, we demonstrate the influence of existing hydraulic works, in mutual interaction with social responses and environmental processes, on the development of the congregated delta system over time. The delta trajectory concept is introduced as a way to understand the interplay between social, ecological, and technological systems in deltas. We discuss options to realign unsustainable pathways with more desirable ones. Adaptive delta management presents a policy environment where these messages may be picked up.

\section{Keywords}

Adaptive delta management; delta trajectory; flood management; hydraulic engineering; path dependency; social-ecological systems; technological lock-in 


\subsection{Introduction}

Deltas are among the most resource rich and environmentally dynamic ecosystems on earth (MEA, 2005) They are said to provide delta services (Lund et al., 2008) ranging from fertile soil and various natural resources to a geography that allows for easy settlement, transportation, and navigation. Delta inhabitants have for centuries attempted to manage such services for human betterment: to draw from or enhance positive services on the one hand, while trying to control or reduce perceived negative services on the other. Dealing with a delta's water resources (and, strongly related, erosion and sedimentation processes) is an exemplary domain of both sides of the coin: Irrigation systems are built to further improve distribution of limited water resources for the benefit of agricultural production, and flood management infrastructure is constructed to deal with high water levels in rivers or coastal areas. Hydraulic works have thereby significantly impacted environmental processes in deltas (Syvitski et al., 2009). Considering general socioeconomic trends, growing pressure on space, and climate change consequences in deltaic environments, dealing with water and floods will be one of the most dominant issues for delta managers in the decades to come (Syvitski, 2008; Van der Most et al., 2009). In turn, hydraulic infrastructure will continue to play a central role in shaping future human-environment interactions in deltas.

Within the broader field of human-environment studies, social-ecological systems (SES) theory is frequently used to study interactions between human actors and environmental processes. From this perspective, several of the largest of the world's deltas have recently been conceptualized as social-ecological delta systems (delta-SES) (Renaud, Syvitski, et al., 2013). Similar ideas also have been used at the level of large river basins, most of which include deltas (Cumming, 2011). Although studies inspired by delta-SES argue that human-induced hydraulic interventions often negatively influence environmental processes in deltas, they do not go into details of how such technological dynamics in the hydraulic domain came about, and how they continue to steer delta futures.

Therefore, we were interested in further exploring how these dynamics, in particular the role of hydraulic engineering works, influencing and being influenced by social-ecological interactions in delta systems, affect the development pathway of the composite delta system. To do so we drew from socio-technical systems research. This simultaneously responds to earlier firm calls for intensified dialogue and exchange between SES research and sociotechnological systems studies (A. Smith \& Stirling, 2010). Insights from socio-technical systems 
research contributes to continued debate regarding the place of technology and technological processes in relation to SES conceptualizations (A. Smith \& Stirling, 2010).

The article introduces the concept of delta trajectories, with the objective to enrich SES-style analyses of deltas with ideas about technological development. Presented as an analytical tool, delta trajectories may be used to assess and understand the evolution of a delta-SES over time under the influence of mutually interacting social, ecological, and technological systems. We argue that the concept is useful in understanding how past hydraulic interventions are still profoundly shaping the present-day delta "state," as well as outline, in an extrapolative fashion, possible future delta-SES pathways. This is particularly relevant when it comes to discussing delta futures or long-term delta planning, which is sometimes done by means of SES perspectives but which does not take into account the in-depth conceptual lessons that socio-technical system research offers. We support our observations by discussing a number of contemporary flood management interventions materializing in several of the world's deltas; we also present options to realign identified unsustainable pathways with more sustainable ones, or to avoid unsustainable paths in the first place.

\subsection{Technology in human-environment conceptualizations}

Human-environment studies frequently adopt system views to understand the complex and intricately linked dynamics of actors, environmental processes, and physical networks, or respective systems (Gerrits \& Marks, 2008; Glaser, Krause, Ratter, \& Welp, 2008; Harden, 2012). Among these are systems theory (Berkes et al., 2008, 2000), complex adaptive systems perspectives (Dammers et al., 2013; Rammel et al., 2007), and coevolutionary ideas about systems development (Norgaard, 1994; Norgaard et al., 2009). Despite differences and variations in analytical emphasis, the approaches have in common that they stress dynamic interaction between social and ecological (sub)systems, and nonlinearity of system development over time.

Using an SES perspective primarily centers around notions of mutual interaction and coevolution of the social and ecological (Berkes et al., 2008, 2000; Gallopín, 2006; Norgaard et al., 2009). A coupled SES is conceptualized as moving over time through a trajectory of states, conditioned by various endogenous and exogenous processes including technologies (Smith and Stirling, 2010, based on Walker et al. 2006). Analytically, SES perspectives may be used as frameworks to assess how interactions between the social and the ecological take shape, and how the system under review evolves as a whole as an outcome of these 
interactions (Berkes et al., 2008, 2000; Enfors, 2013). Concepts such as resilience and adaptability express systemic states or capacities for change (Walker et al. 2006; Folke et al. 2010), whereas "rigidity traps" express persistent, inflexible system states (Gunderson, Garmestani, Rizzardi, Ruhl, \& Light, 2015).

The SES approach proved to be useful to study the impact of human interventions on ecosystems, resulting in recommendations to improve environmental policy and governance arrangements, and to formulate concrete management options (Anderies, Janssen, \& Ostrom, 2004; Domptail, Easdale, \& Yuerlita, 2013; Folke, Hahn, Olsson, \& Norberg, 2005; Lebel et al., 2006). At the same time, Halliday and Glaser (2011) argue that the approach will benefit from further conceptual exploration, refinement, and operationalizing frameworks.

\subsubsection{Delta-SES}

Recently, several of the world's largest deltas, such as the Mekong delta (Garschagen, 2010), the Sacramento-San Joaquin delta (Norgaard et al., 2009), the Dutch delta (Pel, Verkerk, Van Buuren, \& Edelenbos, 2014) and the Nile delta (Redeker \& Kantoush, 2014) have been conceptualized and studied as complex delta-SES. Using these frameworks is primarily driven by the different kinds of complexity encountered when dealing with water-related challenges in delta areas (Pel et al., 2014).

Both general and delta-specific SES studies have in common that they tend to criticize the aggravating human impacts on the delta ecosystem in the form of urbanization, reduction of natural area and ecosystem dynamics, and indirectly, climate change effects. Technology or infrastructure is thereby assessed in a dichotomous way. Flood protection infrastructures, such as high embankments, prevent flooding but also impact the ecosystem dynamics in which they are constructed. Scholars have argued that some deltas may be classified as Anthropocene-delta-SES, in which human hydraulic engineering has completely altered the initial Holocene delta-SES beyond recognition and resulted in irrevocable impacts (Renaud, Syvitski, et al., 2013). As formulated by Syvitski and Saito (2007, p.261) “...human engineering is now a major influence on the growth and evolution of many deltas, through control of the flow path of distributary channels, and mitigation of the seasonal flood wave with concomitant change in the delivery of sediment load." Although we concur with general observations that hydraulic engineering is profoundly impacting deltas, much more is to be said about how such interventions materialize and continue to affect delta futures, in other words, are persistent in delta systems over time. 


\subsubsection{Into technology: hydraulical engineering systems in deltas}

Insights from socio-technical systems research can contribute to continued debate regarding the place of technology and technological processes within SES theory (Kemp \& Rotmans, 2005; A. Smith \& Stirling, 2010; Young et al., 2006). Despite the different thematic interests, conceptual frameworks, and general objectives of socio-technical systems research, both fields of study find each other in addressing complex and dynamic interactions in systems, while proposing forms of governance for sustainability (Rijke, Farrelly, Brown, \& Zevenbergen, 2013; A. Smith \& Stirling, 2010) or managed transitions (Fischer-Kowalski \& Rotmans, 2009). From the broad domain of socio-technical systems research, we have a prime interest in the subfield of large technological systems (LTS) research and associated conceptual vocabulary, because those perspectives are applicable to the examples of large-scale hydraulic engineering that will be discussed later on.

The LTS field emphasizes the rigidity and long-term persistence of hard infrastructure over time by means of the mutually related concepts of path dependency and technological lockin. In the literature, path dependency and technological lock-in are often used interchangeably, but a distinction can be made between them. Path dependency emphasizes future development of a system, whereas technological lock-in emphasizes a certain system state. The central idea of both is that technology and technological systems follow development paths that are specific, persistent, and relatively difficult to step away from (Nelson \& Winter, 1982; Perkins, 2003). Following Wynne (in Feenberg, 2010, p.x), “Complex and usually distributed but highly coordinated modern technologies, once established, lay down both material and imaginative pathways and constraints that themselves effectively delimit what may be seen as possible future developments."

The explicit aim of LTS research is to study the development of LTS embedded in their wider social and environmental context (Hughes, 1983; Hughes, 1987), such as electricity networks or railways. In a narrative, case study-oriented research style (Van der Vleuten, 2013), a conceptual vocabulary has developed that explains the emergence, expansion, and general development of technological artifacts and their composite systems. From this perspective, technology researchers have shown an interest in studying the historic evolution and contemporary manifestation of hydraulic engineering systems using LTS or strongly related perspectives (Bijker, 2002; Kaijser, 2002; Van der Vleuten \& Disco, 2004), explaining contemporary unsustainable system states or technological pathways in deltas (Gerrits \& Marks, 2008; Syvitski et al., 2009; Sze et al., 2009; Wesselink, Bijker, de Vriend, \& Krol, 2007). 
From here on, when referring to a technological system, we specifically mean a hydraulic engineered system. A broadly defined hydraulic engineered system may comprise canals (irrigation, drainage, or navigation), sluices, locks, pumps, small-scale hydraulic works, dams, coastal or river embankments (also called dikes or levees in different parts of the world), or storm surge barriers. We focus empirically and analytically on the latter two.

\subsubsection{Pathways to the future: delta trajectories}

To better analyze how environmental, social, and technological systems interact in deltas, we introduce the delta trajectory concept. We define the concept as an analytical tool, intended to understand and assess the dynamic coevolution and interplay of environmental dynamics, social processes, and hydraulic infrastructure in delta-SES over time. It departs from socialecological conceptualizations of deltas, emphasizing complexity, coevolutionary change, and nonlinearity in systems development, while incorporating insights from the domain of sociotechnical systems research about the development of technological systems. Insights resulting from delta trajectory analyses are useful when discussing the future of the delta system under scrutiny, if centered around underlying challenges regarding water and flood management. With the delta trajectory concept, it is on the one hand possible to analyze the way past hydraulic engineering has affected and will affect delta futures, while on the other hand this concept provides scope to the development of sustainable pathways.

Complexity issues surface instantaneously when trying to get hold of the environmental delta system under scrutiny. Considering that water, floods, erosion, and sedimentation processes all originate in or are influenced by drivers outside the imaginary or formally delineated delta, and also materialize differently day by day, it is practically impossible to define geophysical or ecosystemic delta boundaries. Therefore, national borders or institutional jurisdiction do not correspond with the geophysical delta, invoking political-ecological tensions when it comes to delta governance. Advantages and disadvantages of attempting to define system boundaries are provided in studies done by others (Alessa et al., 2009; Halliday \& Glaser, 2011). Here we argue that a too narrow delineation ("delta blinkering") of a delta system comes with risks. When sea currents or upstream rivers supplying sediment are not considered to be within a delta's boundaries, these sedimentation processes may be left out and not assessed for their capacities in raising a delta's land surface. Narrow views may likewise disregard political realities when it comes to governance arrangements, policy processes, and social participation in hydraulic decision making or re-engineering in international delta regions (Bijker, 2007; Huitema and Meijerink, 2010). 
The delta trajectory concept underscores the materiality and persistence of engineered works in driving the collective delta-SES trajectory. These works may start relatively small, tending to expand spatially over time, or take form in relatively large engineered objects such as coastal dams. Assuming that these structures perform in terms of preventing floods, hydraulic choices are often maintained by building on prevalent and proven conceptual approaches (Garrelts \& Lange, 2011; Lach, Ingram, \& Rayner, 2005). In addition to this socio-institutional dimension, the sunken costs of expensive technology make it economically more efficient to continue in the line of the established pathway (for example, by heightening or reinforcing existing embankments in response to floods), compared with fundamentally different strategies, such as river widening or embankment relocation (Bubeck et al., 2013; Garrelts \& Lange, 2011; Ingram \& Fraser, 2006).

This is, however, not to say that a certain pathway is set in stone forever. A profound change of course in flood management strategy can materialize, but this would require great economic efforts and substantial change in policy, or as some argue from a somewhat fatalistic perspective, an occasional major flood event to initiate such drastic change (Geels \& Schot, 2007; Huitema \& Meijerink, 2010). We look here at the capacities of social actors, notably policy makers and river managers, but also at other professional domains and social groups that have increasingly involved themselves with hydraulic decision making to proactively either maintain an inherited technological path or to pursue an alternative trajectory. A case in point is the growing influence of social actors, ecologists, and hydraulic engineers favoring ecosystem-based approaches to water management during what has been labeled the ecological turn in Dutch water management (Disco, 2002; Saeijs, 2008). This has laid a basis for contemporary ecoengineering, or building with nature-inspired thinking (Van Slobbe et al., 2013; Waterman, 2008).

Managed change in flood management strategies commonly takes shape as a gradual transformation or incremental change to a prevalent approach instead of a radical shift (Huitema \& Meijerink, 2010). Policy change can be driven by policy entrepreneurs, individuals maneuvering between dominant policy approaches and personal objectives to bring in paradigmatic changed (Huitema \& Meijerink, 2010). Similarly, physical adjustments to infrastructure or changes in management operations of the engineered works may materialize in the form of technological add-ons, thereby offering some room to maneuver from relatively strong development paths (Geels \& Schot, 2007; Ingram \& Fraser, 2006). 
The delta trajectory concept is inspired by river basin trajectories (Molle, 2003; Molle \& Wester, 2009) and "dynamic adaptive policy pathways" (Haasnoot, 2013). River basin trajectories challenge linear thinking by arguing that there is no specific, preset direction or path for how river basins develop, both technologically and institutionally, over time (Molle, 2003). The dynamic adaptive policy pathways approach provides a framework to help assessing the "expiry date" of certain policy actions, providing indications as to whether path dependencies and lock-in situations may be encountered, and which management options are available to shift strategies (Haasnoot, 2013). On a different note, it has been argued that small-scale water system innovations have the capacity to open up new development trajectories (Enfors, 2013). Although these approaches mention the role of technology in shaping dynamics with and between social actors and environmental processes in deltas, they do not further explain how and why such dynamics are taking shape. This will be discussed in the second half of the article.

\subsection{Methodology}

To illustrate how delta trajectories develop over time as the result of the interplay of environmental dynamics, social drivers, and hydraulic system development, we selected two cases of hydraulic engineering in the Dutch delta: the Oosterschelde storm surge barrier as an example of path dependency and the delta's river embankment network as an exemplary case of lock-in in delta trajectories. These cases illustrate in a detailed, empirical way how complex interactions give shape to a particular development trajectory. The analyses of the cases is based on the theoretical-conceptual lessons outlined above to scrutinize complex delta developments. The analyses function as examples for similar investigations in other deltas or delta regions, where hydraulic infrastructure and social-ecological processes interact.

Characteristic for the Dutch delta ${ }^{9}$ (see Figure 5 below) is low-lying land formed by the rivers Rhine, Meuse and Scheldt, in tidal interaction with the North Sea. Centuries of water flows, erosion, sedimentation, vegetation growth, and human-induced modification by means of hydraulic engineering works are giving shape to a hybrid water-landscape. Drawing from insights from the Dutch delta is also legitimate because there is a growing interest in approaching the Dutch delta as a complex SES (Pel et al., 2014), because of the interest in hydraulic engineering from a socio-technical systems perspective (Bijker, 2002; Kaijser, 2002;

\footnotetext{
${ }^{9}$ In the light of the earlier discussion on delta boundaries, the "Dutchness" of the delta should be nuanced because the majority of water and sedimentation inflow in the delta comes from upstream countries, while Belgium (using the Westerschelde for the Port of Antwerp's shipping movements) is an important stakeholder when it comes to hydraulic engineering choices in the southwest delta region of the Netherlands.
} 
TeBrake, 2002; Van der Vleuten \& Disco, 2004), and because plans are being drawn up that address the challenges of dealing with long-term delta dynamics (Delta Program 2015, see also http://deltacommissaris.nl/english/, accessed April 2015). We depart from these examples because the hydraulic structures on which the accredited Dutch success in dealing with water-related challenges are based, display characteristics of technological lock-in and path dependency that only rarely are acknowledged or critically reflected on.

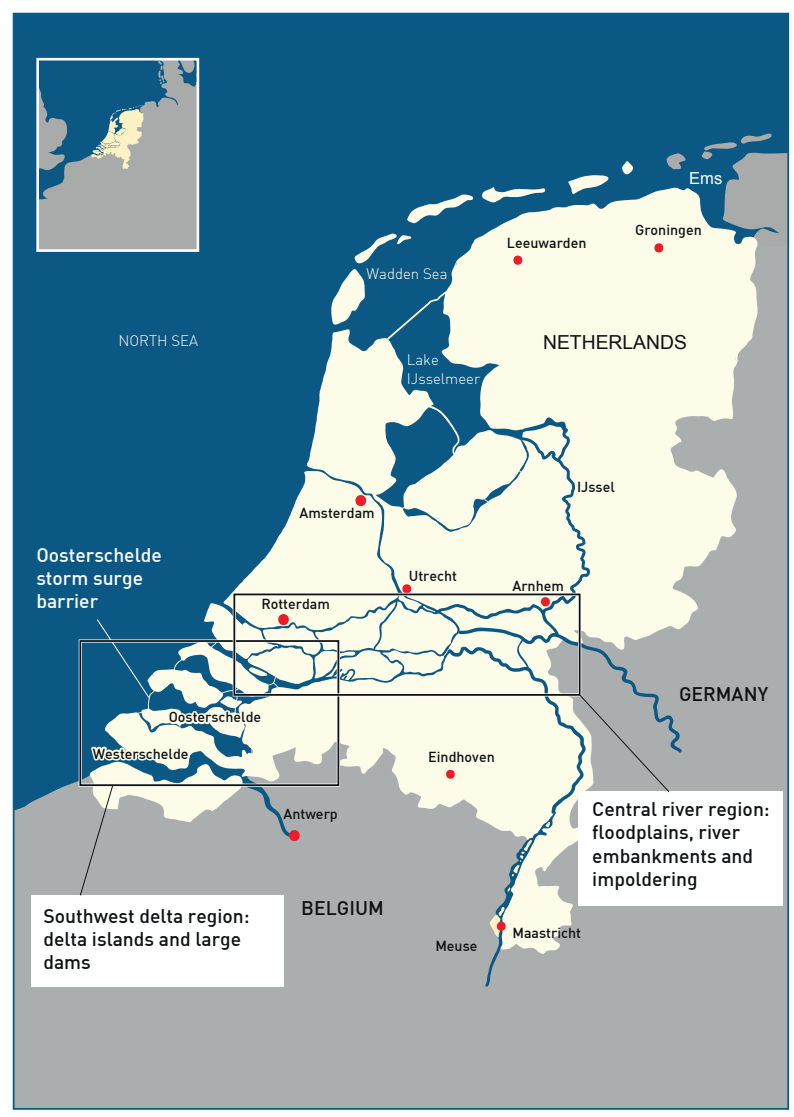

Figure 5. The Netherlands, located in northwest Europe. For images and additional background see www.martijnvanstaveren.blogspot.nl/2016/01/background-info-oosterschelde-storm.htm and www.martijnvanstaveren.blogspot.nl/2016/01/ background-info-embankments-in.html, respectively.

In this paper we place the empirical insights (primary data based on interviews, and secondary and referenced data based on literature) regarding historic developments in hydraulic engineering in the Netherlands in the light of contemporary debates about long-term, adaptive delta and flood management plans involving these structures. 


\subsection{Delta trajectories: examples from the Dutch delta}

\subsubsection{Oosterschelde storm surge barrier: pivotal in delta decisions and initiating path dependency}

After a devastating flood in the southwest delta of the Netherlands in 1953, plans for largescale hydraulic works closing off most of the delta estuaries resurfaced. The so-called Delta Plan was presented as the project of the century: an icon of Dutch flood management-to-be and exhibiting full control over the forces of nature. The plan dated back to the 1940s but needed an actual flood disaster before it was taken up by governmental policy makers. It foresaw closing off the estuaries in the southwest delta by means of dams, each several kilometers long. Illustrative of a political dimension in hydraulic delta engineering (see also Bijker, [2007[) was that only the Westerschelde, connecting the Port of Antwerp to the North Sea, was exempted from being closed off. Dams in the other estuaries would substantially shorten the coastline; therefore, investments to reinforce and heighten hundreds of kilometers of more inland estuarine embankments could be dropped. As a consequence, however, the closures would halt tidal movement in the delta estuaries, forming new delta lakes containing water of a mixed quality and foreseen to slowly shift from saline tidal water to fresh water entering the lakes from upstream rivers (Bijker, 2002; Van Veen, 1962).

The 9-km-wide Oosterschelde estuary presented the biggest engineering challenge. It was therefore planned to be the final closure, enabling the incorporation of lessons learned from preceding closures. When construction works of the Oosterschelde dam took off in the 1970s, the negative environmental impacts of those earlier closures boldly came to the fore: Instead of an expected transition from tidal saline estuaries to fresh water lakes, water quality in the new delta lakes quickly deteriorated. The Rhine river supplying water from upstream was at the time severely polluted, and marine ecosystems were quickly affected. Social pressure from concerned groups, but also growing professional doubts about environmental impacts of such large-scale engineering, were instrumental in the decision to step away from the plan to fully close off the Oosterschelde estuary. After years of social protests, compromising politics gave civil engineers leeway to pick up the idea and undertake the professional challenge of designing a storm surge barrier. In contrast with a fully closed dam, the designed storm surge barrier consisted of 62 sluice gates that are usually open to allow tidal movement and that can be closed individually in times of high water in the North Sea. The redesigned storm surge barrier would provide unprecedented flood protection to the region, while taking ecosystem dynamics into account (Bijker, 2002). 
The structure was presented as the masterpiece of Dutch hydraulic engineering, and at the time it promised to provide full flood protection for 200 years. This framing enabled acceptance of the project budget, which more than doubled to about 2.5 billion euros. The storm surge barrier fulfils its task when it comes to flood protection: Since its completion in 1986 the barrier has been closed more than 20 times to resist storm surges, most recently on October 21, 2014 (see http://en.wikipedia.org/wiki/Oosterscheldekering, accessed November 2014). However, it came with several environmental feedbacks. Although the barrier allows the majority of tidal inflow and outflow of water in the estuary, the reduction in volume is still substantial, which causes rapid erosion and disappearance of mud flats and tidal creeks in the Oosterschelde's interior. This causes the estuary bed to even out and at some locations undermines the foundations of embankments, making their underwater slope steeper. These second-order effects are met with additional engineering activities: Extensive sand supplementation is now done at strategic locations inside the estuary and broader delta, trying to compensate for the erosion losses of the mud flats. Within the context of the Building with Nature Programme, ecoengineering is brought forward as an approach to balance ecological dynamics and hydraulic engineering in the southwest delta, e.g. by using oyster reefs to stabilize eroding mud flats (De Vriend \& Van Koningsveld, 2012). These interventions are presented as hydraulic innovations (Rijkswaterstaat, 2008).

Cautious suggestions by the Delta Commission in 2008 to critically evaluate the barrier's functioning and future, hinting at potential removal, were heavily criticized. Other calls to deconstruct the barrier, notably on the part of environmental protection and conservation organizations, also rocked the boat, leading to responses stating that it is out of the question that the storm surge barrier would be removed prematurely. Long-term water and flood management strategies being drawn up for the southwest delta repeat the latter position, considering the option of dam removal unrealistic. In sum, such strategies pivotally revolve around the enduring presence of the barrier in the delta, which is foreseen for another 150 years, underscoring the robustness and long-term rigidity of this hydraulic structure (Deelprogramma Zuidwestelijke Delta, 2014; Delta Committee, 2008; Rijkswaterstaat, 2008).

\subsubsection{River embankments and impoldering: initiating a technological lock-in}

Hydraulic engineering used to provide protection from river floods and options to locally manage water includes river embankments, the practice of impoldering (reclaiming land by means of circular embankments, and small hydraulic works to manage water in their interior) in river floodplains or wetlands, and various types of small-scale engineered works, such as 
canals, dams, sluices, and gates. A large network of river dikes, established and expanding since the 13th century predominantly in the centrally located region of the Netherlands, significantly decreased both the frequency and magnitude of river floods. Agricultural production could intensify (also because of better water management in protected lands), spurring socioeconomic development behind the embankments. At the same time, however, water drainage, digging for peat to be dried and used as fuel, and soil compacting caused land subsidence in protected or newly reclaimed lands (Kaijser, 2002; TeBrake, 2002; Van de Ven, 2004; Van der Vleuten \& Disco, 2004).

The engineered constructions themselves impacted the hydromorphological regime within the rivers as well as the delta estuary. Embankments not only withheld flood waters, but also halted the seasonal deposition of sediments, clay, and silt on floodplains. Instead, sediment matter settled on, and silted up, the river beds, which increased water levels. In response to these issues, repetitive cycles of raising or strengthening embankments followed; in some areas of the Netherlands embankments are $8 \mathrm{~m}$ in height compared with the mean level of the land, holding back meters of water. This moved the Dutch delta toward a technological lock-in of ever-increasing embankment levels. Questions were raised about how long this can go on, both in technological and socioeconomic terms (Gerrits \& Marks, 2008; Wesselink, 2007).

Over the centuries discussions arose occasionally, especially after near flood events that showed the relative vulnerability of "living low" behind high embankments, about whether the traditional approach of river embankments for flood prevention was still the right path to follow, or whether a more spatially oriented approach to dealing with floods (based on diversions, temporary water storage, or embankment relocations) should be pursued (Van Heezik, 2008). This debate was most recently and vigorously held after near floods in the mid1990s, but it did not tip the balance to one strategy in particular. The Room for the River Programme (2005-2015) that was subsequently formulated strongly advocated for the spatial flood management paradigm, but it was also preceded by a fast-track, large-scale embankment reinforcement programme (Warner et al. 2013). Within the context of the program several river stretches have been widened or "depoldered" with the aim of combining water safety and nature restoration at the expense of agriculture. Such spatial solutions require huge investments, especially when compared with strengthening existing embankments. A recent program updating long-term flood management strategies in the Dutch delta stressed that investment in strengthening existing embankments was more cost- 
effective than, for example, spatial measures that would require buying out of farmers and acquiring land rights (Deelprogramma Rivierengebied, 2014). The program introduced new flood protection norms that require several hundred kilometers of embankments to be strengthened and/or raised before 2050 (Deelprogramma Rivierengebied, 2014). At the same time, proposals to slowly move away from the river embankment protection strategy and look for options that are deemed to address technological lock-in have received lots of criticism, both professionally and from broader society (Enserink 2004; Warner 2008). On an individual basis, projects in which removal or lowering of embankments is incorporated (see www.waterdunen.com and www.perkpolder.nl, in Dutch, accessed November 2015) also met fierce protests from social actors defending the dikes (Warner 2008; Van Staveren et al. 2014).

\subsubsection{Analysis and discussion: realigning unsustainable delta pathways}

The above accounts show that the interaction between social, ecological, and technological subsystems are complex and influence each other mutually. Regarding the coevolution of subsystems, we primarily observed that environmental processes and technological developments have become strongly intertwined in the form of the Building with Nature and Room for the River programs.

Moreover, they have shown how in the Dutch social-ecological delta, decisions made in the distant past have initiated technological trajectories based on large-scale flood prevention schemes. Issues associated with technological lock-in and path dependency materialized, which are regionally specific depending on particular environmental processes or social drivers. Environmental consequences of technological lock-in and path dependency usually are addressed by policy makers and hydraulic engineers as second-order problems and are counteracted by new sequences of hydraulic engineering: raising embankments to deal with higher flood risks as a consequence of higher water levels in the rivers and subsiding polders, and sand supplementation to compensate for tidal flat erosion following the construction of the Oosterschelde storm surge barrier. Nevertheless, considering long-term impacts of dams and dikes, scholars have argued that the Dutch delta finds itself in unsustainable conditions in the long run, with slowly subsiding polders on the one hand and rising sea levels on the other (Gerrits \& Marks, 2008), while environmental dynamics in the southwest delta are under increasing pressure.

Delta-SES that run the risk of moving toward an unsustainable or undesirable system state may benefit from conceptual ideas and practical interventions that can reorient an inherited technological pathway. We chose to further explore this primarily from the perspective of 
ecological engineering. Coastal realignment, as an example of ecoengineering, has been brought forward as an approach to bring social and technological dynamics in tune with the options, or limitations, of coastal environmental processes (French, 2006; Pethick, 2002). It steps away from a sole focus on rigid flood defense structures and aims for a balance between hard and ecosystem-based measures (French, 2006; Pethick, 2002). This often involves managed retreat at locations where hard coastal protection is no longer justifiable, given the socio-economic conditions in the area at hand. On similar terms, eco-engineering approaches take a different stance towards environmental processes, positioning itself as reconciling hydraulic engineering with different gradations in the incorporation of ecosystem dynamics in design and operation of hydraulic works (De Vriend \& Van Koningsveld, 2012), using terminology of ecotechnical system building (Van der Vleuten 2013, p.220), ecological engineering (Borsje et al., 2011) or building with nature (Korbee \& Van Tatenhove, 2013; Van Slobbe et al., 2013; Waterman, 2008).

When discussing realignment of a delta trajectory, timescales are important. Adopting longterm timescales may help to be reflexive about the unintended consequences (Tenner, 1997) of hydraulic engineering. On relatively short- and medium-term timescales, hydraulic engineering works provide protection from extensive floods, thereby facilitating socioeconomic development. When seen over much longer timescales, however, the negative impacts of such repetitive interventions also materialize: Flood prevention inhibits the accretion of land in polders because of prevention of sedimentation, and polders start to subside. In environmentally relatively stable deltas such as those in the Netherlands, these processes materialize only very slowly, especially in contrast to, e.g., the Bangladesh delta, which is home to much more dramatic water and sedimentation processes.

\subsubsection{Realignment in the Dutch delta}

In the Dutch delta, realigning flood protection with long-term coastal environmental processes is the central tenet of the Sand Engine project (www.dezandmotor.nl/en-GB, accessed April 2015). North Sea currents slowly erode an artificially constructed sand island, dispersing its particles along the coast. This compensates for erosion in sections along the coast just north of the project site, which would otherwise require large scale-sand supplementation (Janssen, Van Tatenhove, Otter, \& Mol, 2015). Similar plans have been proposed for the southwest delta region (Grontmij, 2012). Several ecosystem-based hydraulic measures, e.g., constructing oyster reefs to stabilize eroding mud flats, have been proposed 
to address second-order erosion problems following the construction of the Oosterschelde storm surge barrier (Rijkswaterstaat, 2008).

Realignment of unsustainable trajectories in the riverine region may likewise be addressed by ecosystem-based interventions, although this in practice results in different types of projects. River widening and depoldering take place at various locations in the Netherlands, which involve partial removal or lowering of river embankments. This restores flood dynamics in widened floodplains. Although depoldering, controlled flooding, and restored sedimentation processes in theory offer a way to break out of a technological lock-in (compensating for soil subsidence by increasing land height), it is not self-evident that this is pursued in practice. When sedimentation takes place in reconnected floodplains during floods, these new layers of soil are removed because the sedimentation would hamper the discharge capacity of the depoldered area (Van Staveren et al., 2014). In other large world deltas, however, despite differences in social-ecological drivers, temporarily restoring flood dynamics and capturing sediments in polders to increase land height are practiced: See Cox et al. (2006) and Maris et al. (2007) describing this for locations along the Zeeschelde in Belgium (the Flemish part of the Scheldt estuary), Bates and Lund (2013) for the Sacramento-San Joaquin delta in the United States, and Nowreen et al. (2013) for polders in the southwest delta of Bangladesh.

\subsubsection{Realigning trajectories with adaptive delta management}

Ideas about realigning trajectories are implicitly pursued by adaptive policies. Confronted by complex challenges taking place at the intersection of environmental dynamics, technological developments, and social processes, delta managers are turning to adaptive policies that can easily be adjusted over time when necessary (Walker et al. 2001; Clark 2002; Voß and Bornemann 2011; Becker et al. 2015). This rationale has been the foundation of adaptive delta management (Stratelligence, 2012) which has been developed within the context of the Dutch delta programme ${ }^{10}$ (Delta Programme, 2015, p.138). Central to adaptive delta management is thinking along potential socioeconomic development scenarios for which certain policy responses can be formulated, the use of adaptation pathways to deal with climate change, and tipping points assessing the effectiveness of policy actions (Haasnoot, 2013; Marchand \& Ludwig, 2014). As observed earlier, these approaches have set long-term timescales for which

\footnotetext{
${ }^{10}$ This national programme was launched in 2011 with the objective of developing adaptive policies in socioeconomic and climate related domains, resulting in practical challenges in the field of flood protection and fresh water supply in the Dutch delta (Delta Programme 2015. The final programme report has been made available in English. See also http://deltacommissaris.nl/english/, accessed April 2015).
} 
the delta trajectory concept might be of additional use, emphasizing historical aspects in delta planning and calling for realignment of unsustainable pathways.

\subsection{Conclusion}

Several of the world's deltas have recently been conceptualized and studied as complex socialecological delta systems, or delta-SES. This does justice to the dynamic nature of deltas, in terms of both environmental processes and social structures, which are capricious and difficult to delineate. Conceptualizations inspired by Delta-SES stress the importance of hydraulic engineering in shaping system states and system pathways, but apart from criticizing its environmental impacts, have been less explicit in explaining how specific dynamics surrounding technological developments in deltas take place.

Responding to calls for an intensified exchange of insights and ideas between the socialecological and socio-technical systems research domains (Smith and Stirling 2010), we have explored dynamics in the hydraulic domain via the concepts of path dependency and technological lock-in. This has laid the basis for the delta trajectory concept, which is put forward as an analytical tool to understand the historic evolution and congregated outcome of systemic interplay between the social, environmental, and hydraulic systems in deltas over time. By means of the delta trajectory concept, hydraulic interventions may be assessed in relation to the complex delta setting in which they are constructed. By doing so, the delta trajectory concept calls for specific attention to the influence of hydraulic choices in the past on the historic, present, and future delta states, which reinforces the notion that hydraulic history matters (Kaijser 2004). In reinforcing interaction with social and ecological processes, hydraulic engineering acts as a strong driver of a development pathway of the social-ecological delta.

We have used illustrative cases to describe two delta trajectories centered around large hydraulic works in the Dutch delta. The river embankment network and a large storm surge barrier provide high flood protection standards, facilitating socioeconomic development. They also came with unintended or unforeseen consequence such as soil subsidence, which has led some scholars to argue that the Dutch delta finds itself in unsustainable conditions in the long run (Gerrits \& Marks, 2008; Wesselink, 2007).

The delta trajectory concept shows that technological interventions done in the past profoundly shape the direction in which deltas develop. The challenge for delta managers is, therefore, not to pinpoint the present and start from there in designing future policies and 
delta interventions, but to depart in their work from the "hydraulic heritage," its enduring consequences, and options for improvement and adaptation over time. Within the context of adaptive delta management policies, delta managers are confronted by the general challenge to tune hydraulic interventions with long-term sustainable delta pathways.

Ecologically informed or ecosystem-based forms of hydraulic engineering can be used for gradual, region-specific reorientations based on eco-technological add-ons. This does justice to the physical rigidity of infrastructure, to past investments involved, and to interventions depending on environmental processes. A more thorough understanding of technological development in the hydraulic domain, in relation to social drivers and environmental delta dynamics, will contribute to formulating sustainable social-ecological delta futures. 


\section{Chapter 3. Let's bring in the floods: de-poldering in the Netherlands as a strategy for long-term delta survival?}

This chapter has been published as: Martijn F. van Staveren, Jeroen F. Warner, Jan P. M. van Tatenhove and Philippus Wester (2014) Let's bring in the floods. Controlled flooding as a strategy for long term delta survival? Water International, 2014 39:5, 686-700, http://dx.doi.org/10.1080/02508060.2014.957510 
Abstract

Controlled flooding, while heavily contested, is being experimented with in the Dutch delta as a new and ecologically oriented strategy to deal with floods, in contrast to the conventional flood prevention paradigm. The Noordwaard project (2012-15) represents an exemplary case. At the expense of agricultural practices, land is set aside occasionally to accommodate river floods, while restored flood and tidal dynamics aim to benefit nature development. It is argued that although controlled flooding aims to restore historical land and water dynamics in the area, the role of sedimentation processes has remained largely unaddressed in relation to shaping long-term delta futures.

\section{Keywords}

Deltas; flood management; technological lock-in; de-poldering; controlled flooding; the Netherlands 


\subsection{Introduction}

In deltas ${ }^{11}$, such as the Dutch delta encompassing the Rhine, Meuse and Scheldt rivers, dealing with water and floods is a never-ending challenge. The Netherlands has in large part been created and shaped by means of hydraulic engineering and, likewise, dealing with delta floods has generally been based on technocratic approaches, resulting in infrastructure aimed at "fighting the everlasting battle with water" and "preventing floods and protecting the land" (Van Stokkom, Smits, \& Leuven, 2005; Wesselink et al., 2007). However, following societal concerns about the environmental impact of a large-scale flood protection infrastructure programme during the 1950s and 1960s, full reliance on infrastructure and striving for water control according to human needs started to be challenged forcefully in the 1970s (Bijker, 2002; Disco, 2002). This boosted the 'ecological conceptualization' of water and flood management in the Netherlands, stimulating environmentally informed thinking about water management by involving different kinds of science (e.g. ecology), actors (e.g. spatial planners and ecologists) and measures (e.g. ecologically oriented and spatial solutions) in addressing floods (Saeijs, 2008; Van Hemert, 2008; Wiering \& Arts, 2006).

Following (near) floods in the Dutch rivers in the mid-1990s, the Room for the River programme that was subsequently formulated marked a turning point in dealing with river floods in the Netherlands. Objectives in the field of flood protection and improving environmental quality and nature restoration of the riverine landscape were accorded coequal importance (Min VenW, 2000b). The guiding principles of the programme included river widening, dike relocations and bypasses - horizontal instead of formerly dominant vertical measures (Roth \& Warner, 2007). Although still "engineering" in nature (Van Hemert, 1999), this sketches the context where some interventions, which may be almost un-Dutch when considering the earlier historical approach, are proposed: creating room for water by means of de-poldering ${ }^{12}$ agricultural areas to accommodate peak river discharges, while at the same time restoring 'delta dynamics' and riverine nature.

This paper analyses the Noordwaard project as one of the projects of the Room for the River programme. The Noordwaard is an agricultural polder located in the south-west of the Dutch delta. It will be reconnected to the Merwede River, at the expense of current agricultural practices. This provides space to convey peak river discharges through the middle zone of the

\footnotetext{
${ }^{11} \mathrm{~A}$ delta can be defined as "the area where two different systems - river and sea - both with important influences on the morphology of the land, meet and influence each other" (Meyer, 2009, p.432).

${ }^{12}$ Reconnecting embanked polders to a river or sea in order to (re)introduce water and flood dynamics (Schut et al., 2010).
} 
polder, while at the same time restores daily tidal dynamics and seasonal flooding (Projectbureau Noordwaard, 2011). Besides addressing primary objectives in the field of flood management, the measure is aimed at nature development ${ }^{13}$ by improving and physically reconnecting currently separated segments of the adjacent Biesbosch wetlands. Central to the project is the restoration of historic land and water dynamics in the area (Bosch Slabbers, Van de Goor, Lagendijk, \& Rijsdorp, 2005; Projectbureau Noordwaard, 2011), which in itself has been shaped for centuries by land and water dynamics and the growth of vegetation (De Schipper, 2010).

The main argument of the paper is that although the de-poldering project aims to restore historic land and water interactions in the area (contributing to nature development and flood management objectives), the associated and recurring sedimentation processes following polder floods has remained largely unaddressed. We place this finding within the context of societal, technological and policy debates about flood management in delta settings. The societal debate, largely concerned with environmental and ecological aspects of flood management interventions (including ecologically oriented measures), is emphasized in the third section.

The technological debate focuses on the physical sustainability of the Dutch delta in relation to flood management and concerns about systemic, technological "lock-in" - which according to some authors is the current "state" of the delta (Wesselink et al., 2007). Central to the idea of lock-in is that systems, impacted by technological measures of which the drawbacks are only learnt in a later stage, follow specific and difficult-to escape paths (Perkins, 2003). In the case of flood management in the Dutch delta, this is reflected in the construction of an extended network of river dikes since the 14th century (Van der Ham, 2009). River dikes pinned down the rivers' physical trajectory and in combination with expanding cultivation of floodplains the peak-carrying capacity of the rivers was greatly reduced (Kundzewicz, 2002; Van Heezik, 2008). Embankments (also called dikes) were built to protect the drained and cultivated floodplains, and formed polders in which water levels could be controlled. Subsequently, sediment was no longer deposited on wetlands or floodplains, but concentrated in the riverbeds. Sedimentation in riverbeds (sometimes temporary removed by means of dredging), on the one hand, and drainage, peat extraction and soil subsidence in the adjacent polders, on the other, led to self-reinforcing and repetitive cycles of building ever

\footnotetext{
${ }^{13} \mathrm{~A}$ "Dutch" collective term for active (guided and regulated) and passive (encouragement) restoration and management of nature in the Netherlands (Van den Berg \& Koole, 2006).
} 
higher dikes (Wesselink et al., 2007). This infrastructural approach has its natural and physical limits (Saeijs, 2008), and with climate change predictions (sea level rise, and more frequent and higher peak river discharges) and a gradually subsiding geological base, it appears that the Dutch are in dire straits (Wesselink, 2006). ${ }^{14}$

While past practices have a profound long-term influence on shaping delta developments, policy debates have a more forward-looking direction. Incorporating longer timescales in the discussion is important because today's measures may have (unexpected) impacts in the future, but also because delta dynamics seen over longer timescales may in themselves contribute to designing more sustainable approaches (Kundzewicz, 2002; Norgaard, 1994; Norgaard et al., 2009). In the Netherlands, two national programmes deal with water and flood management objectives over longer timescales. The already mentioned Room for the River programme is based on a "hydraulic future" in 2100, of expected peak river discharges up to $18,000 \mathrm{~m}^{3} / \mathrm{s}$ (Min VenW, 2006b). On the delta scale, the Dutch Delta Programme ${ }^{15}$ is likewise working with a 100 year planning horizon. Besides "hydraulic futures" involving future scenarios on climate change (sea level rise, extreme peaks and lows in river discharges), also socio-economic developments are included based on four potential development scenarios (Deltaprogramma, 2012b). Both programmes propose a combination of infrastructural and ecologically oriented measures. Considering the 100-year planning horizon, it may be expected that the proposed measures are formulated within a context of delta developments on longer timescales.

The paper is structured as follows. The second section discusses in more detail the theoretical background in relation to the argument, including the two themes of technological lock-in and dynamic delta management seen over longer timescales, already shortly introduced above. The third section describes how, against a history of impoldering and flood prevention, an ecological conceptualization took shape that provided a context for de-poldering projects. Although its origins date back several decades, this conceptualization continues to take different forms; the contemporary de-poldering case as the latest appearance. The Noordwaard case is then explained in more detail by zooming in on historical flood and sedimentation specifics of project. The paper closes with a discussion/conclusion on de-

\footnotetext{
${ }^{14}$ For a contrasting opinion see Stijnen et al. (2014) who argue that the Dutch polder approach may be technically and economically sustainable until 2100.

${ }^{15}$ A national programme with the objective to develop adaptive delta management strategies in response to expected (climate change related) challenges in the field of flood protection and safeguarding supply of fresh water in the Dutch delta (Deltaprogramma, 2012b).
} 
poldering practices in the Noordwaard in relation to technological lock-in and long-term delta developments, with relevance for other world deltas.

\subsection{Theoretical background}

With concerns about technological lock-in (leaving out discussions of institutional and social lock-ins) as its point of departure, the paper builds on theory concerning change and interaction in socio-technical systems. Three interrelated elements will be discussed here: theoretical background on (1) technical regimes and trajectories as a theoretical "starting point," (2) the growing awareness of the contribution of societal actors to technological developments, and (3) change in socio-technical systems seen over longer timescales. The Dutch delta is conceptualized for this purpose as a socio-technical system, comprising social actors, on the one hand, and the range of physical and technical measures employed to address flood management issues, on the other.

Nelson and Winter (1982) have described and argued for "technical regimes" as a conceptual approach to understand how certain technologies prevail and are dominant, often supported by "...shared cognitive routines in an engineering community, that give shape to patterned development along certain technological trajectories" (in Geels \& Schot, 2007, p.399). In the case of Dutch flood management, this is reflected in a prolonged dominant engineering approach to dealing with floods. In addition, in technical systems positive feedback loops reinforce a certain technological "trajectory" (Perkins, 2003). This is highlighted by the selfreinforcing approach of building (higher) dikes in the Dutch river landscape, which causes continued deposition of sediments in the riverbed (and no longer in extended floodplains), leading to the need of increasing the height of the dikes again. It demonstrates the "entrenchment" of technologies (Wesselink et al., 2007). Due to physical "fixation" of large parts of the delta system and costly flood defense network in the Netherlands, large-scale and fundamental changes to flood management infrastructure are therefore highly problematic. Infrastructural measures may therefore be persistent in nature. Therefore, it is likely that managed change with respect to flood management strategies takes the shape of gradual transformation (instead of radical transition) or to some authors' preference, add-ons (Geels \& Schot, 2007) to existing flood management infrastructure. This may account for both physical infrastructure, as well as flood management strategies on a more conceptual level.

In the 1980s researchers have called for more emphasis on the role of societal actors in (re)shaping "preferred" engineers' technologies (Perkins, 2003). Notably sociologists of 
technology have demonstrated how scientists, policy makers, users and special-interest groups contribute to patterning of technological development (Bijker, Hughes, \& Pinch, 1987; Geels \& Schot, 2007), broadening Nelson and Winter's approach, to "socio-technical regimes." As will be demonstrated later, the way how the design of the Oosterschelde closure dam was changed into a storm surge barrier, is exemplary for how this process took shape in the Dutch flood management domain. Professionally, the Oosterschelde example also initiated a professional collaboration between flood management engineers, environmentally oriented experts and social interest groups in developing flood management strategies. There are numerous perspectives on how to approach dynamics and change in sociotechnical systems (e.g. Geels [2005] on system innovation processes, and Rotmans et al. [2001] and Van der Brugge [2007] on transition management). Recently, calls for co-evolutionary perspectives have been issued (Norgaard, 1994; Norgaard et al., 2009), the latter authors discussing the past and present co-evolution of the Sacramento-San Joaquin delta in the US. Central to this approach is the understanding how mutual interaction between the social system and the delta ecosystem takes shape and outline delta development trajectories over time. As a consequence, such an approach calls for thinking in longer timescales. This concerns both historical timescales (how past practices influence and have led to present-day conditions), as well as future timescales (how measures of today may have long-term effects, and how longterm dynamics may in itself be incorporated in developing measures). As will be shown below, discussions on technological lock-in in the Dutch river system and potential break-out fit well in a context where co-evolutionary and long-term delta perspectives are upheld.

\subsection{From impoldering to de-poldering in the Dutch delta}

The Dutch delta is to a large extent built up of consecutive impoldering projects (Van der Ham, 2009), both in geographical (laterally embanking mudflats along the coast) and temporal (reclaiming land, sometimes multiple times lost to floods) settings. In 1968, part of Lake IJssel in the center of the country was impoldered to form the largest agricultural production polder (measuring about 100,000 ha) in the Netherlands (Van der Ham, 2009). Due to typical delta land and water dynamics, some of the impoldered areas have been lost to sea or rivers. Most of the de-poldered or reflooded areas in recent history in Northwest Europe (including 14 in the Netherlands) occurred due to storms breaching dikes, which were for technical or financial reasons difficult to restore (Wolters et al., 2005). Those de-poldered areas became quickly liable again to tides, flood regimes, sedimentation processes and pioneering vegetation. Yet, during the last two decades deliberate de-poldering is taking shape on a conceptual (both in 
research as well as in policy arenas) as well as on a practical level in different regions of the Dutch delta. Discussions on de-poldering are characterized by the combined objectives in the field of flood management and nature restoration. Therefore, first some space is dedicated to show how this "ecological conceptualization of water and flood management" took shape in the Netherlands in the 1970s, adding to dominant engineering methods, and evolved further, providing a conceptual background for "greener thinking in relation to flood management and de-poldering (Disco, 2002; Saeijs, 2008; Wiering \& Arts, 2006). The paper looks first at the estuarine region of the Southwest Delta, and then considers the Dutch river landscape.

\subsubsection{Ecological turn in the Southwest Delta}

The ecological conceptualization of water and flood management most notably took root in the southwest region of the Dutch delta. After the most devastating flood in the Netherlands in recent history (in 1953, claiming over 1,800 human lives in the Netherlands while also Belgium, France and the UK noted casualties), a committee was instated which advised to close off four of the five estuaries of the southwest delta with dams to prevent floods in the region "forever" (Disco, 2002). Planning and project implementation took off in the late 1950s, but in the early 1970s, when preparatory construction works for the final closure dam in the Oosterschelde estuary were already started, strong societal protests against the dam and its expected devastating impact on the estuary's ecosystem dynamics, brought the project to a standstill (De Schipper, 2008). The original plans for a dam were abandoned and instead a technologically challenging storm surge barrier was designed. The 62 open sluice gates maintain to a large extent tidal flows and ecological functioning in the delta estuary, and may only be closed in times of storm surges.

This "ecological turn" at the time of the Oosterschelde storm surge barrier (Disco, 2002), constituted two main aspects. The first aspect, mainly as a consequence of the case, is a "professional" ecological turn in the domain of water and flood management (Bijker, 2002; Disco, 2002). The appointment of biologists at Rijkswaterstaat (the organization responsible for the design, construction, management and maintenance of the main infrastructure facilities in the Netherlands) in the early 1970s turned out to be an essential factor in the professional ecological turn within the organization later on (Disco, 2002). "In the Environment Unit of Rijkswaterstaat's Delta Department, the organization obtained in-house environmental knowledge which was required to respond to the established societal demand of environmentally sound (water) infrastructure. The eventual construction of the permeable Oosterschelde barrier demonstrated that ecologically informed design did not necessarily 
preclude old-fashioned hydraulic engineering glamour - it was an invitation to civil engineers to embrace ecologically informed design." (Disco, 2002, p.221).

Moreover, it initiated a professional convergence between the water, environmental and spatial planning domains. This convergence became prevalent in a series of key national water management policy documents in the following decades, notably in "Dealing with Water" (Min VenW, 1985). Proponents of ecologically oriented measures challenged the concept of impoldering and measures that heavily impacted delta ecosystem dynamics (Saeijs, 2008). Early ideas on de-poldering in the 1970s integrated (on paper) the potential relevance of (former) floodplains for long-term delta development with temporary flood water storage, and contributing to improve environmental quality.

The second aspect, functioning mainly as prerequisite of the case, concerns a broader movement of environmental awareness in society, initiated by a range of environmental problems (for example, the deteriorated quality of water in the Rhine and Meuse rivers which led to societal protests) (Bijker, 2002; Disco, 2002). The 1972 Club of Rome report "Limits to Growth" had a particularly significant impact in the Netherlands, in the sense that its messages were effectively picked up by a range of societal actors concerned with environmental problems, notably the pollution of water resources (Bijker, 2002). Re-naturalization as an movement against engineering practices has been anticipated in earlier studies (see Kundzewicz, 2002).

\subsubsection{Room for the River programme}

Conceptually, the ecological turn extended to the river landscape via Plan Stork. Plan Stork (De Bruijn, Hamhuis, Van Nieuwenhuijze, \& Overmars, 1986) sketched a vision of the Dutch riverine landscape by departing from "core" river functions consisting of transporting water, ice and sediments. The authors proposed to allow rivers more space by widening riverbeds. This would restore dynamics in the reconnected floodplains in terms of sedimentation processes, flood regimes and pioneering vegetation based on fluctuating river levels. The role of agriculture in floodplains was reduced in favor of nature development. Plan Stork won a prestigious award in a national contest on future visions on the river landscape. The plan was generally well received among environmentalists and ecologists, but there were critical voices too, regarding the ecological soundness of the plan (Van Hemert, 2008). A few months after an agro-chemical disaster in Basel, Switzerland (which had devastating effects on the ecosystem of the Rhine), in November 1986, the ministers of the Rhine riparians adopted the Rhine Action Plan, which aimed at the restoration of the Rhine ecosystem (De Jonge \& Van 
der Windt, 2007). In the Netherlands, the Plan Stork approach became integrated into the national Rhine restoration efforts in the late 1980s. The early 1990s saw the rapid spread of the development of "new" nature in the floodplains of the Rhine branches (Van Hemert, 2008).

After flood events in 1993 (Meuse) and 1995 (Meuse, and near-floods on the rivers Waal and Rhine), the Dutch government prepared for a new river management programme along the conceptual lines of Plan Stork (Min VenW, 2000a). In the meantime, the Delta Act on the Major Rivers was passed that allowed for immediate dike reinforcements in 1996-97. The Room for the River programme that took shape in the early 2000s aimed at creating more physical room to accommodate peak river water discharge horizontally, but in conjunction with objectives in the field of nature development, landscape values and spatial quality (Min VenW, 2006a; Roth, Warner, \& Winnubst, 2006; Wiering \& Driessen, 2001). The role of dikes as flood protective infrastructure was changed and put in the light of spatial requirements: dike relocations were proposed to create physical room for flood water. Two regional Steering Committees were instated (for the lower and upper river region respectively) which were assigned with developing a package of potential measures that would enable the Dutch rivers to carry peak river discharges of $16,000 \mathrm{~m}^{3} / \mathrm{s}$ in 2015, and $18,000 \mathrm{~m}^{3} / \mathrm{s}$ in 2100 (Bureau Benedenrivieren, 2004). In the first outline of the Room for the River programme, three socalled emergency retention areas were appointed in the upper river region, and also river widening measures in the lower river region were explicitly mentioned (Min VenW, 2000a). Emergency retention areas had to function as temporary storage of the peak volume of river water discharge, while river widening was intended to reduce water levels by spreading out water volumes, and discharge this towards the delta estuary (Min VenW, 2000a). Although "controlled inundations" were already included in the $4^{\text {th }}$ Policy Document on the Water System some years before (Min VenW, 1998), broad attention in national media in 2000 sparked waves of protests against 'cutting the dikes' (Roth et al., 2006). The government instated the Committee Luteijn, assigned with the task of investigating the need for emergency retention areas (Commissie Luteijn, 2000). Although they recommended that the emergency retention areas were necessary, inhabitants formed local action groups and successfully challenged the plans for upstream retention (Roth \& Warner, 2007; Roth et al., 2006). While plans for retention areas in the upstream river area did not pull through, the Noordwaard de-poldering case presents a different outcome. 


\subsection{De-poldering in the Noordwaard region}

The larger Noordwaard region ${ }^{16}$ is located at the heart of the Dutch delta (Figure 6 below). The Noordwaard agricultural polder measures 4500 ha and is wedged between the Sliedrechtse and Brabantse Biesbosch wetlands (Schut, Leeuwis, \& Van Paassen, 2010). It is one of the Room for the River projects and appointed as a "de-poldering area," meaning that the dikes of the area will be lowered or removed in such a way that daily tidal movements and seasonal flooding will occur (Min VenW, 2006b; Projectbureau Noordwaard, 2011). Restoring tidal and flood dynamics in the area is expected to contribute positively to the environmental quality of the surrounding Biesbosch wetlands (e.g. creating different types of vegetation and improving water quality). Before de-poldering works the area housed about 75 (farmer) families, who had the option to stay in the Noordwaard (often in newly constructed farms on mounds), or to be financially compensated to move elsewhere (De Gast, 2005; Van der Meulen, 2007). The project contributes to a reduction of upstream river water levels by 30 $\mathrm{cm}$, by carrying up to one-third of Merwede's flood waters in extreme conditions (Projectbureau Noordwaard, 2010), which makes it possible for the Room for the River programme to achieve its hydraulic objective of conveying 16,000 m³/s by 2015 .

\subsubsection{The fifth life of the Noordwaard}

The Noordwaard is now up for its 'fifth life' (Rijkswaterstaat, 2005). Tidal dynamics, sedimentation, flooding, land reclamation and de-poldering have interactively shaped the area during the last centuries. Around $900 \mathrm{AD}$ the larger marshlands started to be structurally reclaimed, embanked and cultivated. The polder Groote Waard, covering the whole of the Noordwaard region, was completely flooded during the St Elisabeth flood in 1421. This created a large inner sea. In the centuries following the flood, tides and rivers transported considerable amounts of sediment which deposited on the area (Kleinhans et al., 2010). Subsequently it developed into a marshland with low vegetation, willow forests and reed lands: the Biesbosch wetlands. The slowly increasing land height allowed for small-scale land reclamation. At the end of the 19th century, the Nieuwe Merwede canal/river was constructed in the western part of the area. This canal/river conducted upstream water volumes through one channel, instead of via the numerous and sometimes congested creeks. This hydraulic measure enabled the creation of several small, embanked polders (1-2 km in width) in the area, separated by creeks and small lakes. From 1935 onwards, agricultural

\footnotetext{
${ }^{16}$ A distinction is made between the Noordwaard region, when the larger area is concerned. When 'the Noordwaard' alone is mentioned, it refers to the de-poldering project of the Noordwaard polder (4500 ha) located in the centre of the region, wedged between separated Biesbosch wetlands.
} 
development stimulated the improvement and merging of smaller polders and continued land reclamation. For more efficient water management purposes, during the 1970s several polders were integrated into the larger Noordwaard polder. It became fully embanked and although referred to as one polder, the former smaller polders are still demarcated by the old dikes and carry their old names. The closure of the Haringvliet ${ }^{17}$ in 1970 reduced the tidal amplitude in the area, which dropped from $2 \mathrm{~m}$ to $30 \mathrm{~cm}$ (De Schipper, 2010; Pleijte, During, Gerritsen, \& Stuyt, 2005; Projectbureau Noordwaard, 2010).

\subsubsection{Introducing de-poldering in the Biesbosch}

The Noordwaard project is not the first effort aiming at de-poldering and restoring land and water dynamics in the region. The flooding of polder de Dood can be considered to be the first de-poldering in the region in the last decades. This small polder (60 ha) was flooded following a storm breaching the polder dikes in December 1962. Instead of repairing the dike, the new director of Staatsbosbeheer ${ }^{18}$ in the Biesbosch, biologist W. Thijsen, refrained from action and sustained tidal interactions in the area, which developed as part of the Biesbosch wetland. Although the area was property of Thijsen's organization, he got in trouble professionally since his actions were against prevalent flood management policy (De Schipper, 2010).

A second de-poldering initiative came up in the early 1990s. Nature development, and the restoration of and connection between smaller and separated nature areas became a priority for national governments in the 1970s, which was embedded in a nation-wide Nature Policy Plan, developed by the Ministry of Agriculture, Nature and Fisheries (LNV) (Min LNV, 1990). It introduced the so-called Ecological Main Structure which stipulated prevention of ecological deterioration of the river landscape and promotion of nature restoration, by (re)connecting floodplains to rivers and linking up separated nature areas as green corridors to allow species mobility (Min VenW \& Min LNV, 2001). In the plan, the Ministry of LNV expresses its ambition for nature restoration in and around the Biesbosch wetland which was graphically included as part of the Ecological Main Structure and intended for nature development at the expense of agriculture (Min LNV, 1990). Whereas the Nature Policy Plan represented a guiding policy framework, by formulating the NOP ${ }^{19}$, the Ministry introduced a de-poldering paradigm in the region.

\footnotetext{
${ }^{17}$ One of the proposed dams of the Delta Works, closing off the Haringvliet estuary, constructed in the years before the "ecological turn" took place.

${ }^{18}$ Staatsbosbeheer, founded in 1899 with a focus on forest restoration, is the biggest organization managing nature reserves in the Netherlands (www.staatsbosbeheer.nl/, accessed November 2013).

${ }^{19}$ Natuur Ontwikkelings Project (Nature Development Project).
} 


\section{De-poldering the Noordwaard in the Dutch Delta}

The Noordwaard agricultural polder will be reconnected to the adjacent river, by means of lowering or removing dikes. Controlled flooding will occur in the flow-through area in times of high river water levels. Together with restoring tidal dynamics in the broader estuary, this restores dynamic land and water interactions around and in the Biesbosch wetlands. Hybrid-engineered dike

Near the Steurgat Fortress, a willow forest will be laid out in front of a section of the dike. This reduces flood waves and compensates for required dike reinforcements.

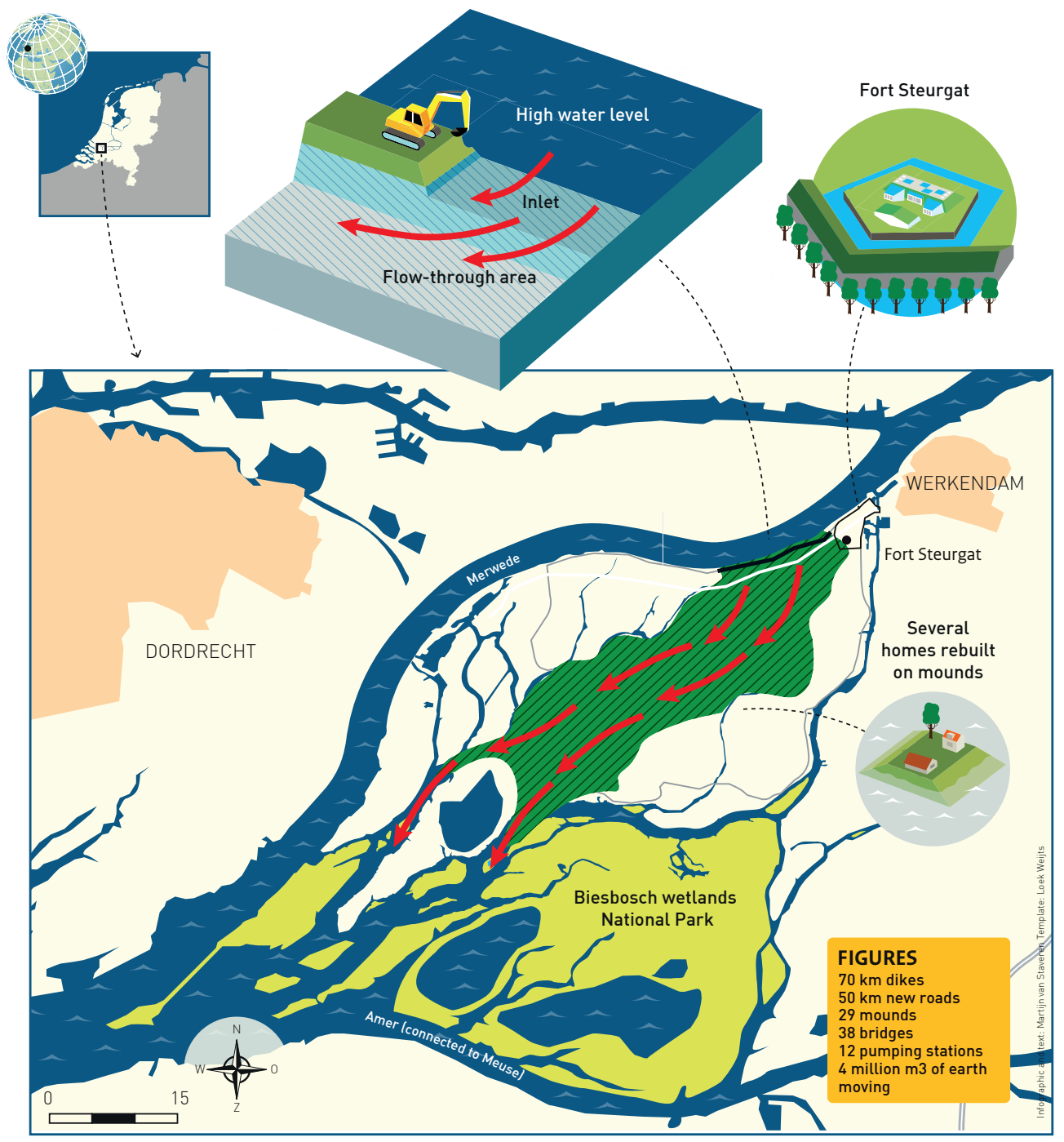

Figure 6. De-poldering in the Dutch delta 
The project was formulated in the early 1990s and planned for de-poldering 600 ha agricultural land in the western part of the Noordwaard, with the aim to physically connect the separated Brabantse and Sliedrechtse wetlands (Min LNV, 1990). After the floods in 1993, its water and nature objectives became co-equal when the NOP was brought under a river development programme jointly funded by the Ministry of LNV and the Ministry of VenW (Feddes, 2012; Grontmij, 2002). In the early 2000s the NOP became one of the seven so-called "autonomous projects" that were included in the Governmental Position Document on Room for the River (Min VenW, 2000b). After two years of de-poldering works, the then Dutch Crown Prince Willem Alexander, known for his interest in water management, completed the project in 2008 by operating the excavator that cut the polder embankment. De-poldering the Noordwaard polder followed shortly after.

\subsubsection{Non-listing, short-listing and top-listing the Noordwaard}

The Noordwaard polder itself has long been out of the picture for de-poldering works. Although several exploratory studies in preparation of the Room for the River programme in the early 2000s discussed the potential of (parts of the) Biesbosch area for flood retention, de-poldering the Noordwaard is not explicitly mentioned. ${ }^{20}$ Instead, often a green river ${ }^{21}$ through the Land van Heusden en Altena (just east of the Noordwaard) is referred to multiple times as a highly effective, but also costly and socially contested solution (Bureau Benedenrivieren, 2004). During so-called "design sessions," a round of interactive stakeholder consultations, a short list of 42 proposed potential room for the river measures was composed for the lower river region (Bureau Benedenrivieren, 2004).

During the design session de-poldering the Noordwaard was formally not part of the 42 measures (Schut et al., 2010). The situation changed over the course of a month, when decision makers in the Steering Committee had to classify 22 each of the 42 potential measures as a go/no-go option (Schut et al., 2010). The "green river" through the Land van Heusden en Altena was classified as a no-go due its limited public support and huge costs. De-poldering the Noordwaard was discussed during the meeting as a potential alternative. This also was a sensitive issue, due to the province's earlier promise in the 1990s, that the Noordwaard (where some of farmers relocated to, from the NOP area) would not be touched in the near future. During the meeting the green river and the Noordwaard were both classified as

\footnotetext{
${ }^{20}$ See for the most relevant studies: Bureau Benedenrivieren (2004) and (RIZA, 2001).

${ }^{21}$ A green river merely consists of two dikes through a landscape, which could become operational to discharge water from another river (Schut et al., 2010).

${ }^{22}$ Classification of alternatives: unacceptable, controversial, or non-controversial.
} 
"controversial". From a non-option, de-poldering the Noordwaard was on the table at the same level, and as a realistic alternative, to a green river (Schut et al., 2010). After the meeting, a representative from the farmers' organization ZLTO supported the Noordwaard "suggestion," which was quickly picked up by the Steering Committee who coordinated the second phase of the consultation sessions.

Roughly in the period 2001-03, there was no unequivocal or organized protest against the depoldering plans. Although it was clear that polder inhabitants were unhappy with what might happen to the area and to their agricultural practices, they also felt that going against the Room for the River programme, would have only a small chance of success. Especially considering that only a few dozen people lived in the area, while the Room for the River programme was of national relevance, both in terms of its setup and its thematic focus. ${ }^{23}$ In addition, protest would lead to years of procedures and uncertainty (Van den Brink, 2009). The farmers organization ZLTO also had a special position, since its members did not only live in the Noordwaard polder, but also in the Land van Heusden en Altena. According to them, it would be better to choose for the lesser evil and thereby secure an agricultural future in the Land van Heusden en Altena. ${ }^{24}$ It was also remarked that the adjacent NOP has already "opened the door" for continued de-poldering in the Noordwaard (Brabants Dagblad, 2002). The planning and design process in the initial years was open and inclusive, which built up trust and reliance to co-decide on the new layout plan of the area, or to choose for financial compensation when farmers preferred to relocate (Van den Brink, 2009). By the end of 2003, the Steering Committee decided that de-poldering the Noordwaard was the preferred measure to reduce peaks in river discharge (Schut et al., 2010). Because the setup of the planning, stakeholder participation and design process changed (for example, a range of new actors became involved in the project ${ }^{25}$ ), de-poldering antagonists formally organized themselves in the $\mathrm{PBN}^{26}$ in 2004 . A series of contra-expertise studies were carried out by the PBN and alternatives to de-poldering were proposed (Pleijte et al., 2005; TU-Delft, 2004). In terms of process steps, the organized resistance and contra-expertise studies came late. The Ministry of VenW was not receptive to alternative design options as proposed by the PBN and remarked that the PBN represented only a fraction of the polder inhabitants, while the farmer

\footnotetext{
${ }^{23}$ Interview former chairperson Association of Residents, 14 November 2013, Wageningen.

${ }^{24}$ See footnote 23.

${ }^{25}$ See footnote 23.

${ }^{26}$ Platform Behoud Noordwaard (Platform for the Preservation of the Noordwaard) was formed in 2004 by farmers who did not agree with layout and design plans for the Noordwaard, and who felt not well represented.
} 
representative organization spoke on behalf of the majority (Min VenW, 2006a). The Ministry gave the Noordwaard the status of "frontrunner project" in June 2005, which means that, while anticipating the formal decision, implementation of the de-poldering works had already been formally decided upon - only the layout specifications were still open to discussion (Pleijte \& During, 2006).

\subsubsection{Adjusting the dikes and bringing in the floods}

The role of dikes, as icons of Dutch flood management meant for flood prevention, has in the Noordwaard changed to enabling a certain flood regime. The dikes are adjusted (lowered or removed) to allow daily tidal dynamics, yearly inflow of water and submersion of extensively used lands in the so-called "central flow-through area," and occasional river flooding when river discharge peaks. Three flood regimes will manifest in the Noordwaard: (1) daily freshwater tides in the intertidal areas, mainly in the Southwest section of the polder, (2) floods in low embanked "wet" polders in the flow-through area during winter season, and (3) floods in low embanked "dry" polders in the flow-through area. Daily fresh water tides of up to $80 \mathrm{~cm}$ amplitude will flood areas physically (re-)connected to the river (Projectbureau Noordwaard, 2010, Appendix 3). In terms of flood water coming from the river, it is expected that the lowembanked polders (in use for extensive livestock production) will be submerged for about 100 days per year in winter season, which will affect 1350 ha. When the water level in the Merwede river reaches a level of $2 \mathrm{~m}$ as compared with average river discharges, water flows over the lowered primary embankment, and enters the polder via four entry points (culverts) in the secondary embankment (Projectbureau Noordwaard, 2009). This will flood the low embanked 'dry' polders, but only with a frequency of $1 / 100$ in three polders and $1 / 1000$ in seven polders. In those cases, an additional maximum of 700 ha becomes submerged. In extreme situations, which would also affect the upstream river region and substantial parts of the Dutch delta, also the high embanked polders (in fact the entire polder) of the Noordwaard will become submerged.

\subsubsection{Bring in the floods - bringing in the sediment?}

Together with tidal and river floods, sedimentation will build up in the area. In the planning phase, sedimentation processes have been used as an argument to look for alternative solutions (Pleijte et al., 2005). Based on hydro-morphological studies it is expected that this will amount to approximately $1 \mathrm{~cm}$ per year (50 cm by 2060) (Projectbureau Noordwaard, 2009). Although the historic situation of 1905 which is aimed for was characterized by sedimentation rates that increased the height of the land of flood-prone areas (De Schipper, 
2010; Kleinhans et al., 2010), sedimentation in notably creeks and channels is considered as a threat to their hydraulic profiles (Projectbureau Noordwaard, 2010). Although considered as a natural process well in line with historic land and water dynamics, sedimentation in the case of the Noordwaard "...needs to be kept within an acceptable range in order not to affect the hydraulic discharge capacity of the area." 27 In terms of the Noordwaard's contribution to reducing river water levels by diverting part of the flow, there is a rather small margin and sedimentation in the area will immediately compromise this. ${ }^{28} \mathrm{~A}$ similar attitude is noticeable in terms of the growth of vegetation in the flow-through area, which likewise has to be kept within certain boundaries, in order not to compromise the discharge capacity (Projectbureau Noordwaard, 2011). Currently, discussions about detailed maintenance plans and how to keep the Noordwaard's flow-through area and edges free from vegetation and sedimentation, are currently on-going (Rijkswaterstaat, 2013).

\subsubsection{Continued de-poldering in the Noordwaard region?}

It can be argued that the region can be characterized as not only a historical and contemporary, but also future "hotspot" for de-poldering when reviewing long-term plans for the area. While the current project is on-going, new de-poldering projects are mentioned in future scenarios and long-term visions for this part of the delta. The so-called Delta Rim scenario (2100) anticipates a physically connected delta landscape, from the Biesbosch wetlands, along one of the estuaries all the way to the delta mouth. Inward dike relocation is considered one of the options, and the scenario sketches subsequent de-poldering works in the west and the south of the Biesbosch (Deltaprogramma, 2012a, p.61). Moreover, in the report it is stated that "...just like the Noordwaard, a flow-through area will be constructed in the Oostwaard [an area east of the Noordwaard], with agricultural polders which will flood occasionally." (Deltaprogramma, 2012b, p.39). The Biesbosch Management Plan formulates future objectives in the field of conservation or expansion of the Biesbosch surroundings by increasing the extent of creeks and canals facilitating fresh water tides (Biesbosch National Park Authority, 2004). This may well be in the direction of the city of Dordrecht, which develops plans to construct "delta dikes," which combine a ramped embankment with vegetation cover, and partly de-poldering an area west the Biesbosch, to safeguard the city from high water levels and urban floods (Kelder, Gersonius, \& Hulsebosch, 2013).

\footnotetext{
${ }^{27}$ Interview Water Board Rivierenland, 15 November 2013, Tiel; Interview Rijkswaterstaat, 6 December 2013, Werkendam.

${ }^{28}$ Interview Rijkswaterstaat, 6 December 2013, Werkendam.
} 


\subsection{Conclusion}

This paper shows how de-poldering, within a general context of "greener thinking," is taking shape in the Netherlands as an approach to deal with (river) flooding in conjunction with objectives in the field of nature development. It sketches how Dutch flood management has slowly been informed by ecologically oriented thinking, and how this culminated into efforts of de-poldering and the restoration of flood dynamics. The Room for the River programme was instrumental in providing the institutional ground and storylines in which water management and nature development converged. Culminating in practice, de-poldering and controlled flooding have added a different perspective to the functioning of flood infrastructure: the role of dikes, icons of Dutch water management, changed from being intended for flood prevention, to facilitating, up to a certain level, a (tidal) flood regime in the area. In the case of the Noordwaard de-poldering project, recurring sedimentation following restored flood regimes has not been assessed on its potential contribution to heightening the delta physically over longer timescales. Instead, sedimentation is seen as a threat in the sense that it may impact the hydraulic discharge capacity of the area. In that sense the clearly set hydraulic objective of the Room for the River programme (carrying expected peak river discharges up to $18,000 \mathrm{~m}^{3} / \mathrm{s}$ in 2100) that the project aims to contribute to, in a way "narrows down" the width and potential of the de-poldering concept. It can therefore be argued that de-poldering within the context of the Room for the River programme, where reconnecting floodplains and creating space for peak flows stands central, did not enable the conceptual opening that would connect the de-poldering concept to debates about technological lock-in (and potential break-out) or the opportunities of sedimentation seen over longer timescales. It is, however, relevant to note that the opportunities for de-poldering and sedimentation start with the availability of space and sediment (Stroeken \& Van Winden, 2009), which are very different along, for example, the Dutch coast and the Wadden Sea. At the same time, societal actors, notably inhabitants of the areas appointed for controlled flooding, have resisted de-poldering plans. In the Noordwaard project, a governmental decision made an end to attempts of societal actors resisting the measure, thereby concluding a complex negotiation and decision making process. Taking new de-poldering sketches into account, it can be expected that de-poldering and controlled flooding will remain at the forefront of policy and societal discussions about flood management in the Netherlands. 


\section{Chapter 4. Bringing in the tides. From closing down to opening up delta polders via Tidal River Management in the southwest delta of Bangladesh}

This chapter has been published as: Martijn F. van Staveren, Jeroen F. Warner and M. Shah Alam Khan (2017) Bringing in the tides. From closing down to opening up delta polders via Tidal River Management in the southwest delta of Bangladesh. Water Policy, 2017 19:1, 147-164 http://wp.iwaponline.com/content/19/1/147 


\section{Abstract}

The southwest coastal delta of Bangladesh is not only geographically home to a dynamic interplay between land and water, and between fresh surface water and saline tides, but also to contentious debates on flood management policy. It has been argued that dealing with delta floods in this region boils down to adopting either open or closed approaches. This paper longitudinally structures the open-or-closed debate based on a number of emblematic water management projects in the region. Departing from a typical open wetland history, river and polder embankments increasingly started to constrain flood dynamics. Upheaval among rural populations in response to the negative impacts of hydraulic engineering plans and works coalesced in efforts to restore open approaches, synthesized in the Tidal River Management concept. Its resemblance to historic overflow irrigation is often used politically as a yardstick to challenge the dominant hydraulic engineering paradigm. This paper argues that dealing with floods in Bangladesh requires plans, policies and projects formulated against the historic background of complex interactions among social processes, environmental dynamics and technological interventions: a lesson to be incorporated in on-going policy-making processes and long-term delta management plans.

\section{Keywords}

Bangladesh; controlled flooding; delta management; hydraulic engineering; policy pendulum swing; Tidal River Management (TRM); water policy 


\subsection{Introduction}

It has been argued that dealing with flood dynamics in Bangladesh boils down to adopting either an open or closed approach (R. Hughes, Adnan, \& Dalal-Clayton, 1994; N. Islam, 2001; R. Rahman \& Salehin, 2013). Both approaches rely on hydraulic engineering, but in a somewhat dichotomized way, closed approaches can be characterized by high river or polder embankments and large water control structures, while open approaches include floodplain management, temporary water retention and lower embankments (N. Islam, 2001; Warner et al., 2013). Different policy perspectives on how water and floods should be dealt with prescribe different kinds of interventions. Over the last decades contentious water policy debates took shape, during which both perspectives have been supported as well as criticized (N. Islam, 2001; Klaassen, 2009).

Although nuance to these "extremes" is justified, for now we will follow this line of thinking and approach water policy debates in Bangladesh accordingly. We will structure the policy debate longitudinally by means of selected hydraulic engineering initiatives, plans and projects materializing against the background of various epochs in Bangladesh's flood management, with a geographical focus on the southwest delta. ${ }^{29}$ In the southwest delta of Bangladesh, dealing with the delta's rivers and tidal flood dynamics takes center stage. The region is home to several million inhabitants who depend on its agri- and aquaculture producing capacities as well as ecosystem resources provided by the Sundarbans coastal mangrove. Prolonged water logging, sinking lands, river siltation tidal intrusion and climate related sea level rise have been identified as urgent environmental challenges that need to be addressed in the region (Brammer, 2014; Pethick \& Orford, 2013; Syvitski et al., 2009). Historic interventions are overridden by contemporary water and flood management projects ${ }^{30}$ that try again and again to address old and newly emerging socio-environmental challenges. Understanding the evolution of water policy in Bangladesh, under the influence of on-going environmental, technological and social dynamics, is important given contemporary challenges, in particular in the country's southwest delta (Chowdhury, 2010). In doing so we place contemporary policy debates ${ }^{31}$ on water, flood and polder management in the

\footnotetext{
${ }^{29}$ The southwest delta of Bangladesh comprises the districts of Khulna, Jessore and Satkhira, which are bordered by the Sundarbans coastal mangrove to the south. See also Figure 7.

${ }^{30}$ See the Blue Gold program (www.bluegoldbd.org), the World Bank's Coastal Embankment Improvement Project (www.worldbank.org/projects/P128276/coastal-embankment-improvement-project-phase-1ceip1 ?lang=en), the Char Development and Settlement Programme IV (www.cdsp.org.bd), and the Bangladesh Delta Plan 2100 (www.bandudeltas.org), all accessed January 2016).

${ }^{31}$ For an impression of recent debates, see www.worldbank.org/projects/P128276/coastal-embankmentimprovement-project-phase-1ceip-1?lang=en and for discussions www.scidev.net/south-asia/environment/ne-
} 
southwest delta in an historical perspective and flesh out relevant insights that are not axiomatically incorporated into current policy making processes.

We will analyze the debates by means of the policy pendulum concept. Its main tenet is that policy approaches tend to oscillate between contrasting policy directions over time under the influence of social, environmental or technological drivers. The pendulum's position, located somewhere on an imaginary line between the two poles, characterizes the policy orientation dominant at the time. A pendulum swing was implicitly described in a UNDP mission report that reviewed a major flood management plan for Bangladesh (Faaland, 1995) and was later used by water policy researchers to analyze policy dynamics (Huitema \& Meijerink, 2009; Warner, 2008b), see also Wallace (2000).

Hydraulic engineering often attempts to control water dynamics prevalent in world deltas by means of "separation": land from water, or fresh water from saline water. During British colonial rule a large infrastructural network was put in place which physically prevent seasonal overland water flow from spreading out over the floodplains in Bengal. This kind of 'dividing' infrastructure was not only implemented from the perspective of flood prevention; hundreds of miles of slightly raised earthen walls were constructed in muddy floodplains to support a vast railway network, intended to ease inter-delta communication and transportation (Iqbal, 2010).

The process of compartmentalizing the delta, initiated at the end of the 19th century, soon started to display its side effects (Bhattacharyya, 2011). The earthen walls were often constructed perpendicularly to the direction of flows, thereby crisscrossing and damming various waterways. Insufficient drainage capacity in the form of culverts underneath the embankments resulted in stagnant water in enclosed areas. Failed crops and reduced agricultural production, extensive and abnormal floods elsewhere, and water-related diseases including severe outbreaks of malaria started to plague the delta's population (Iqbal, 2010).

ws/bangladeshi-experts-defend-coastal-dikes.html and www.newscientist.com/article/-mg22229752.700-bangladeshs-sea-walls-may-make-floods-worse.html, all accessed January 2016). 


\section{Controlled flooding in beels/polders with Tidal River Management in the Bangladesh delta}

Several beels/polders in the southwest delta of Bangladesh face water logging as well as silted rivers 1 . This hampers effective drainage of water as well as agricultural production. Tidal River Management (TRM) involves the temporary (usually several years) removal of an embankment section adjacent to a beel or polder. During the years of tidal in- and outflow, the area is not suitable for agriculture but may be used for aquaculture. With twice-daily high tide, water and sediments scoured from the river bed flow into the beel concerned 2. Twice-daily water flows out again, thereby leaving part of the scoured out sediment inside the beel 3. Over the years, river profiles improve as well as the height of the land, which is then taken into cultivation again 4

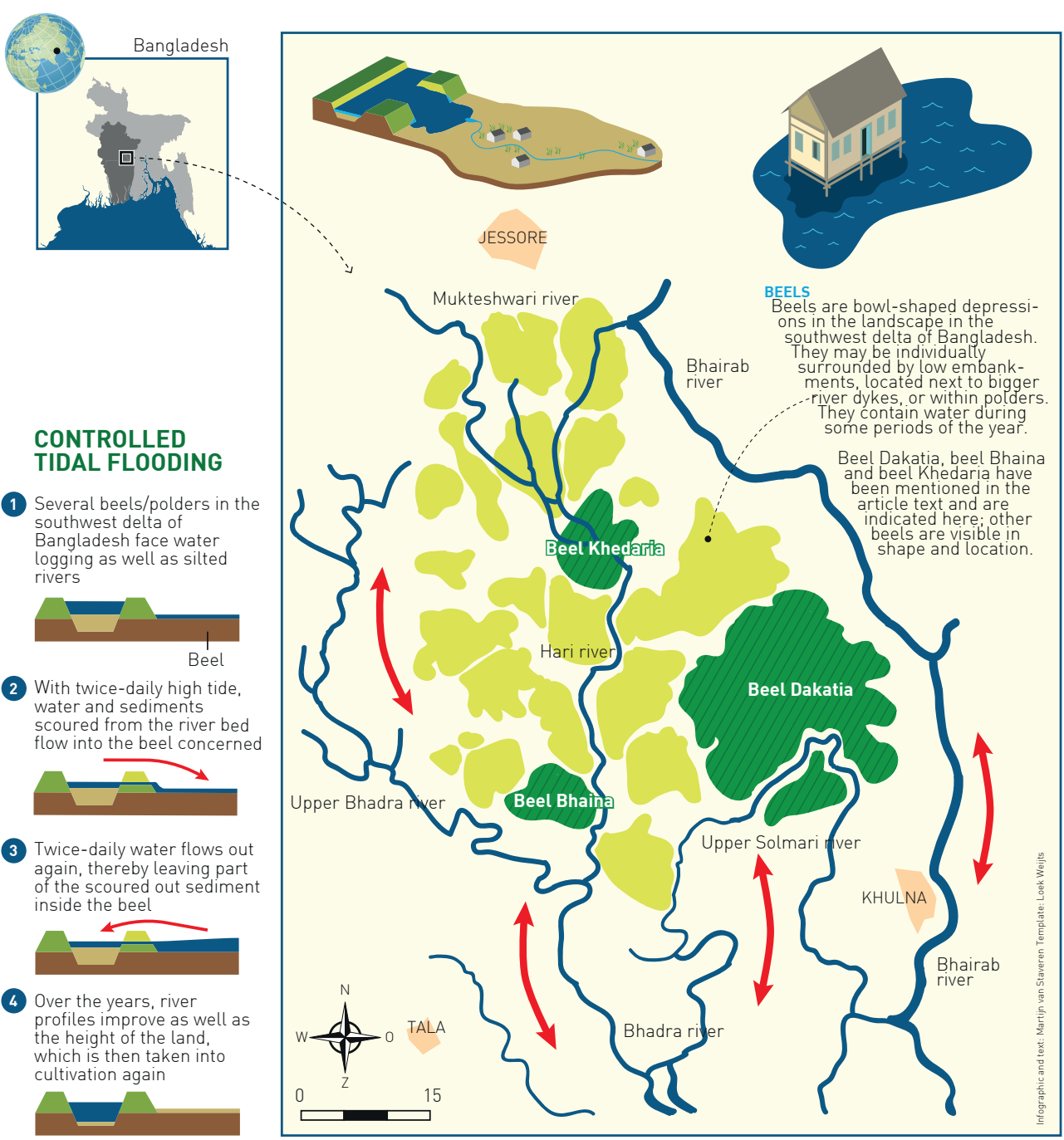

Figure 7. Tidal River Management in the Bangladesh delta 
While general concerns regarding the socio-environmental impacts of the construction of the railway-supporting and floodplain-constraining embankment network were expressed as early as 1846 (Sage, Simms, and M'Clelland 1846 cited in Bhattacharyya 2011, see also Harrison 1875; Majumdar 1938), explicit critiques of the closing-off infrastructure came from British health researchers. Charles Bentley convincingly showed that the breeding grounds for mosquito larvae (along water edges) dramatically increased following the construction of embanked water pools and the resulting stagnant water (Bentley, 1925). Sir William Willcocks, the renowned British civil engineer who designed the first Aswan dam in Egypt and who was stationed in Calcutta in the late 1920s at the end of his career, heavily criticized the interventions that affected water flows in the region (Ozden, 2014). He questioned British colonial interventions in Bengal head-on by publicly and vigorously advocating for traditional forms of overflow irrigation covering Bengal's wide floodplains and fields: "Overflow irrigation, with the muddy waters of the river floods, is the only kind of irrigation on which engineers, agriculturists, and public health authorities can be in absolute accord, for it enriches the soil, combats malaria and relieves the congestion of the river in flood" (Willcocks 1930:104). This statement should be seen as "...yet another call for colonial engineers to be more attuned to the physical and historical conditions of their territory" (Ozden 2014, p.203 referring to Klingensmith, 2007). The Bengal Irrigation Department interpreted his message as a call for large scale removal of embankments and responded by stating that "...it is easy to pile up embankments, [but] it is a most complex matter to remove them" (Addams-Williams, 1919 cited in Klingensmith, 2008, p.9).

The short historic debate outlined above shapes the contours of a by-now centuries-long, and most likely "delternal" policy struggle over dealing with water, and its associated flood and sedimentation processes, in Bangladesh. The hydro-morphological characteristics of the Bengal delta pose seemingly insurmountable challenges for policy makers (Chowdhury, 2010; Sadoff et al., 2013). Similar policy discussions have been ongoing in other large deltaic areas, resulting in evolving insights and policy re-orientations, which sometimes include the rediscovery or restoration of "old" practices. In the case of the Mississippi delta, a long period of reliance on river-constraining levees, or "levees only" policy, was complemented by ideas including proposing floodways and flood diversion after a major flood in 1927; this was more in line with the historic dynamics of that river system (Barry, 1998; Priscoli \& Stakhiv, 2015). In the Dutch delta, a Room for the River Programme was launched in the early 2000s, which proposed embankment setbacks and re-opening up floodplains for controlled flood dynamics 
(Warner et al., 2013). This style of river management had previously been replaced by straightjacketing and dredging of rivers (Van Heezik, 2008), an approach currently strongly supported in Bangladesh (Cook, 2010).

The article continues by sketching a brief social-ecological history of the southwest delta (Iqbal, 2010). A third section highlights selected key initiatives ${ }^{32}$ that have profoundly impacted the debate in recent decades: the Coastal Embankment Project (CEP), the Flood Action Plan (FAP) and the Khulna-Jessore Drainage and Rehabilitation Project (KJDRP). We characterize the FAP as a policy formulation project, with the objective of crafting a national policy and action plan in response to Bangladesh's floods. The KJDRP engaged with the socioenvironmental consequences of the CEP and was an implementation project in the southwest delta. Within the context of the KJDRP, the contested Tidal River Management concept materialized. This concept is further explored in more detail in the fourth section. A final section presents concluding points.

\subsection{A brief social-ecological history of the southwest delta of Bangladesh}

For millennia the Bengal delta has been home to a dynamic interplay of water and land, for which catchwords such as "fluid geographies" and "hybrid landscapes" have been coined to indicate the difficulty of demarcating where land ends and water starts (Lahiri-Dutt and Samanta 2013; see also Biggs 2010). Peak discharges in the rivers Ganges, Brahmaputra and Meghna, tidal movements, and an occasional earthquake drive erosion and land formation processes in the delta (R. Hughes et al., 1994; Sarker, Akter, \& Rahman, 2013). This has created the basis of a typical flat delta landscape, characterized by braided rivers, moving islands and fertile soil, but which is profoundly atypical when considering the enormous volumes of water and suspended sediment passing through the delta. The delta's hydro-morphology changes on a daily basis and ranks the delta amongst the most dynamic in the world.

Rivers in Bangladesh frequently change their courses. Maps depict rivers as floodplains stretching for miles in width, comprising various strands of channels and sandbars. The delta is scattered with baors, or oxbow-shaped lakes. These are remnants of meandering rivers that have changed course over time and left physical marks of their past trajectories in the

\footnotetext{
${ }^{32}$ Selection of the projects is based on existing overviews of water and flood management projects (Ahmed, 2013; Chadwick \& Datta, 2001; Dewan, 2012) and discussions with experts, in order to identify a manageable number of projects which have significantly influenced water and flood management in Bangladesh and are relevant to the open versus closed debate. The focus on these events is justified because water management policy in Bangladesh is heavily based on flood events and their aftermath (Sultana, Johnson, \& Thompson, 2008).
} 
landscape. The Ganges, one of the most prominent rivers in the delta, used to flow southward, through the Hooghly river and Calcutta in India and straight into the Bay of Bengal. It was only a few centuries ago that the river started to discharge part of its water towards the southeast, entering contemporary Bangladesh via its western border. This new trajectory started to form the southwest delta of the Bengal delta, and it expanded the Gorai river. Presently, the Ganges itself is facing substantially reduced incoming flows of water and suspended sediment for various reasons; it is reorienting its course due to geological tilt (Sadoff et al., 2013).

During medieval times, consecutive rulers built series of embankments to protect their capitals from seasonal flooding. Especially under Nasiruddin Mahmud Shah (1442-59), portions of the southern region of Bengal were equipped with irrigation and drainage works. These local forms of hydraulic infrastructure were far from systematic hydraulic schemes. During the rule of the Mughals, which started in the early 17th century, emphasis was placed on flood and irrigation management and on the distribution of water via canals. These rulers also introduced new water governance arrangements. Zamindars ${ }^{33}$, local landlords who held large amounts of land and employed peasants or raiyats to work in their fields, assumed the task of pulbandi works, or public (water) works constructed by communities. A governmental budget was allocated for these tasks, and Zamindars were entitled to charge taxes to people using or benefiting from hydraulic infrastructure (Kamal, 2006; Van Schendel, 2010).

In the haor ${ }^{34}$ and beel ${ }^{35}$ regions of Bangladesh, particular forms of hydraulic engineering materialized. In both regions contour bunds, or relatively low embankments, were constructed for water management purposes since the 14th century (Quassem \& van Urk, 2006). Also referred to as submersible embankments, these low dykes protect Boro, or winter rice, which is cultivated during the dry season, during its final growth stage against high water in the flood season. By the time harvesting was completed, embankments started to overflow and thereby inundated the haors for several months. After flood season, the embankments needed repair, which was conducted by community labor (CEGIS, 2012; Duyne, 1998; R. Hughes et al., 1994).

\footnotetext{
${ }^{33}$ The social structure, in which Zamindars held important positions, was in place when the British took control over the region. With the establishment of East Pakistan as a provincial state of Pakistan, followed by the Tenancy Abolition Act, the Zamindar position was formally abolished in 1950 (Van Schendel, 2010).

${ }^{34}$ Haors are bowl or saucer shaped shallow depressions that contain water during the whole year. They form a regional wetland found in northeast Bangladesh (CEGIS, 2012).

${ }^{35} \mathrm{~A}$ beel is a bowl shaped natural depression in the southwest delta landscape, which contains water during parts of the year. There may be several beels in one polder.
} 
Very similar to hydraulic practices in the northeast, in the southwest delta Zamindars oversaw the construction of low, temporary embankments and wooden sluice gates in the tidal coastal region during the 17 th and 18th centuries. These temporary embankments were called ostomasi badh (BWDB, 2003; Institute for Right View, 2010), meaning "embankments for eight months". They were operational roughly between October and May (Begum, 2011). The embankments prevented inflow of tidal water in the rice fields during the last months of the dry season, when the Aus spring rice was ready for harvesting. After harvest, farmers would partially dismantle the temporary embankments to allow flood waters to enter into the previously enclosed areas, which enabled the deposition of sediments, nutrients and also allowed for seasonal fishing. This flood period, roughly between June and September, could be labeled jowar bhata khelano, meaning free play of tidal flow, on agricultural lands (Institute for Right View, 2010). It was important not only for fertilizing the soil and for widely distributing sediments but also for spreading out flood waters during flood season. For this form of overland irrigation and soil nourishment, embankments are “...an abomination, unless they are freely pierced by openings" (Willcocks, 1930, p.101).

Under British colonial rule a number of developments took place that tipped the balance towards structural closing-off efforts. In addition to an extended railway network, embankments were systematically constructed alongside rivers, for example along the Damodar river (Bhattacharyya, 2011; Lahiri-Dutt \& Samanta, 2013). According to Bhattacharyya (2011), the first major hydraulic works were laid out by the British beginning in the 1830s in an attempt to protect the city of Barddhaman (Burdwan) in lower Bengal. The plans to strengthen the left bank of the Damodar were accompanied by plans to remove 25 miles of embankments across the river, allowing that side to overflow first in case the river water levels reached a critical height. The Bengal delta was regarded as a region with misbehaving rivers and delta wastelands that should be trained and reclaimed respectively for revenue generating purposes (Iqbal, 2010, pp.26-28). The 1793 Permanent Settlement Act built on the existing Zamindar socio-institutional system and created a governance structure that stimulated land reclamation, private ownership (and hence, protection) of land, and discouraged the Zamindars taking social responsibility for coordinating maintenance of canals and other hydraulic works (Iqbal, 2010; Kamal, 2006). This quickly led to river siltation. Rivers started to overflow their banks and sometimes breached at various locations, against which the British formulated stronger protective strategies. It did not occur to them that many of these breaches or kanwas were secretly made by communities in an attempt to have water 
flow through "dead" or silted up rivers again. This represented the last remnants of a disappearing form of overflow irrigation (Kamal, 2006; Willcocks, 1930). Silted up canals were referred to as dead rivers or drainage lines at best, and they lost their meaning as flood irrigation canals in combination with temporary embankments (Kamal, 2006).

This short social-ecological history has sketched how a combination of technological interventions, environmentally dynamic processes and social drivers and responses started to close off parts of the open delta landscape. Interventions were still relatively isolated as well as temporary in nature, but during the British colonial period, more priority was given to schematic embankment construction and land reclamation using flood protective infrastructure. This went hand in hand with sharp debates on whether systematic river embankments were appropriate interventions in this fluvial environment or were, instead, an approach that should be avoided. By the 19th and into the first decades of the 20th century, the Bengal delta was socio-environmentally in decline; emblematic of this decline was the need to start importing rice from neighboring Burma (Iqbal, 2010).

From the middle of the 20th century "modern" water management policy, along with its particular ontology, technologies and concepts were introduced to Bangladesh in general and to the southwest delta in particular. As shown by David Biggs in his analysis of the Mekong delta, the advent of foreign hydraulic experts as well as implementation of new hydraulic projects does not occur on a clean slate. History and a gradual process of new forms of water management merge or overlap with pre-existing prevalent approaches (Biggs, 2010). This "introduction," in the case of Bangladesh, was distinctively dominant because institutional organization was weak and technical assistance from international donors was channeled solely through a new national executing agency (EPWAPDA, later BWDB or Bangladesh Water Development Board). BWDB quickly evolved into a massive and technocratic institution to pursue primarily flood protection and food production, based on a technical-engineering view on water management. This happened in close connection to international institutions and individuals, who saw Bangladesh as a region of unequalled professional challenges regarding delta management (UNESCO, 1966). The next section will discuss a number of plans and projects resulting from these developments. They distinctly represented, as well as contributed to, the evolution of the open versus closed policy debate. 


\subsection{Hydraulic projects: closure and slowly opening up}

Foreign involvement in water management has arguably flooded Bangladesh, leading to an overwhelming number of plans and physical interventions in the hydraulic domain since the 1950s. Consecutive floods in 1954, 1955 and 1956 caused large-scale damage to human lives and food crops in East Pakistan (now Bangladesh). The Government of Pakistan requested technical assistance from the United Nations to formulate engineered flood prevention measures. The international advisory mission, known as the Krug mission ${ }^{36}$, expressed serious doubts about the need for a policy consisting of large flood protection schemes alone ( $R$. Hughes et al., 1994). While stressing the possible benefits of embankments, such as improved protection against floods, the mission stated that "...another objection to the use of embankments is that they exclude flood water at times when it may be beneficial in irrigating the crops and in bringing silt which increases the fertility of the soil". Additionally, "...the erection of embankments across natural drainage outlets has led to water logging and malarious conditions. Drainage of areas behind the embankments should always receive careful consideration" (United Nations 1957, p.251). In contrast to common belief, the Krug mission clearly exhibited hesitation regarding how to best approach flood issues; it encouraged smaller water control and drainage projects, including in the southwest region (United Nations, 1957). With the Great Bengal Famine of 1943-44 in the back of its mind, the government's Irrigation Department had already initiated a relatively small programme of embankment construction in the 1950s. In an effort to initiate a (pre)green revolution intended to re-establish the "granary of Khulna" (Haque, Chowdhury, \& Khatun, 2014; Iqbal, 2010) saline tidal floods were to be kept out of the lands to facilitate increased rice production (Quassem \& van Urk, 2006).

The Krug mission recommended establishing the East Pakistan Water and Power Development Authority (EPWAPDA), which represented a run-up to hydraulic initiatives of a different magnitude. Right after its founding in 1959, EPWAPDA ordered research to be conducted by its technical consultant on a larger, intensified flood prevention programme in the southwest delta. The International Engineering Company (IECO), based in San Francisco, California, subsequently coordinated this study and proposed to scale up the on-going embankment

\footnotetext{
${ }^{36}$ The mission was headed by J.A. Krug, former United States Secretary of the Interior. Another member was Dutch professor W.J. van Blommenstein, who has been active in developing large flood control, drainage and irrigation systems in East Asia. A third member was C.W. Okey, formerly working with the Tennessee Valley Authority (United Nations, 1957), a large scale water control project intended for regional economic development.
} 
construction efforts in a concerted programme. It lost the nuance conveyed in the Krug mission report but straightforwardly called for an extensive embankment project to fully prevent floods, positioned within the context of modernized water management introduced in the southwest delta in the 1960s (Leedshill-De Leuw Engineers, 1968). The proposed project was called the Coastal Embankment Project (CEP) and ran at a time when "hydraulic closure" was prominent not only in the southwest delta but also in other regions. ${ }^{37}$

\subsubsection{CEP: rise of the flood embankments}

Within the context of the CEP (1961 - late 1970s) over one hundred polders were constructed in southwest delta region, comprising a network of hundreds of miles of embankments. The CEP was funded by USAID and relied heavily on the Dutch polder concept: constructing peripheral embankments intended for full flood prevention, with sluice gates, canals and other hydraulic infrastructure to manage water inside the low-lying polder (Leedshill-De Leuw Engineers, 1968). Recommended in an updated Master Plan (1964), three types of polders were proposed: polders with gravity drainage, polders with tidal sluice drainage and polders with pump drainage (www.icid.org/cp country.php?CID=8, accessed January 2016).

A special advisory group on deltaic areas, formed after an international delta management conference, assessed and applauded the achievements CEP had made by 1965 (UNESCO, 1966; United Nations, 1966). ${ }^{38}$ It minimized reservations about the potential environmental, hydrological or social impacts of the hundreds of miles of embankment and reduced floodplains in the southwest. It was argued that there would be only minor impacts on the changed tidal and sedimentation processes after the completion of the project. The CEP “... is to be considered as a first step on the long road ultimately leading to an optimum utilization of the agricultural and industrial resources of the coastal belt and to an adequate degree of protection of the population and their properties against flooding from both the rivers and the sea." (United Nations, 1966, p.12). During phase One, which lasted until 1971 when Bangladesh gained independence, nearly 100 polders were constructed. Phase Two started in 1972 and lasted until the late 1970s, during which an additional 40 polders were embanked (Ali, 2002; Chadwick \& Datta, 2001).

\footnotetext{
37 The Brahmaputra Right Bank Embankment project involved constructing a 150 mile unilateral river embankment on the river's right (west) bank in the 1960s. In the Chittagong Hill Tracts, the Kaptai hydropower dam was constructed between 1957 and 1961. It was celebrated as a triumph of modernity, but after closing the gates, rising water levels behind the dam covered $650 \mathrm{~km} 2$ and displaced 100,000 people (Van Schendel, 2010). ${ }^{38}$ Four of the six team members were Dutch civil engineers: J.B. Schijf (team leader), C.P. Lambregts, C.H. de Jong and J.C. Pape (United Nations 1966:5).
} 


\subsubsection{FAP: river engineering plans and compartmentalized controlled flooding pilots}

Major flood events in Bangladesh in 1987-88 triggered another surge of Western donors intended to, in collaboration with the Government of Bangladesh (GoB), start developing a national flood management strategy with the objective of preventing flood disasters in Bangladesh once and for all. The ensuing birth of the FAP in 1989 targeted to "...provide protection from flooding by the construction of significant engineering projects including major embankments, compartments and other related structures" (Wood 1999, p.733). Eight proposals were generated for tackling flooding based on control activities supported by studies and pilots. The French proposal in particular sought to train the rivers to discharge the water as fast as possible into the Bay of Bengal. The US proposal (Rogers, Lydon, \& Seckler, 1989) was far more integrated but impossible to implement by assuming cooperation between upstream and downstream riparians (Brammer, 2010; Parker, 1992). The doubts raised by the Krug mission about constructing a large flood prevention scheme, especially in the sensitive hydro-morphological dynamics of the central southwest, were largely ignored.

In the first years of the FAP, large scale hydraulic planning proceeded relatively unchecked by societal groups. Sparked by international indignation with the top-down engineering approach and lack of societal participation in yet another hydraulic megaproject (Dreze, Samson, \& Singh, 1997), the attitude changed in the early 1990s, forcefully opening up the debate and allowing various social groups to join in discussions about flood management concepts (Adnan, 1992; Kvaløy, 1994). While the spontaneity of anti-FAP demonstrations can be questioned (Kvaløy, 1994), public protests did attract media attention: they were broadcast around the world, causing uneasiness amongst the donor community. Rising tensions about the FAP policy were also felt at the level of FAP's individual projects, including the Compartmentalization Pilot Project, or FAP-20. This plan's centerpiece project was implemented between October 1991 and July 2000 by BWDB and two foreign consultancy firms in a pre-existing flood control and drainage scheme in Tangail. Funded by the Dutch and German governments together with GoB, the project presented a new flood control and water management concept for "living with floods": compartmentalized flooding. The plan envisaged controlled flooding and drainage in compartmentalized sections of an existing polder, with the objective of experimenting whether the practice would lead to improved food production based on this form of water management. Although heavily "controlling" in terms of managing flood flows, FAP-20 contrasts with flood prevention in the sense that it pursued opening up embankments and facilitating floods in compartmentalized polders. Similar plans 
existed before 1989 amongst international institutions (UNDP 1989, as mentioned in IOV (Operations Review Unit) 1993), but because there were no earlier opportunities, a pilot or "socio-environmental experiment" was purposefully included in the FAP.

FAP-20's development model, however, also encouraged the partial enclosure of beels located within polders, thus squeezing the area available to fishermen dependent on free flows of water, and instigated a regulated water system inside the embankments coordinated by water user groups. The implementation of piloted controlled flooding in the area meant that less-valuable land was sacrificed for the benefit of more valuable land, and that lands occupied by homeless would be needed for flooding and newly constructed embankments (Parker, 1992). The promised "secure environment" for Tangail in practice only benefited landowners at the expense of sharecroppers and the landless fishers facing inadequate mitigation measures - instead, the plan was a prelude to widened socio-economic disparities. In a very practical sense, the sluicegate (meaning flooding or no flooding) operators were not paid and neither were participatory subcommittees. Thus, despite the intended participatory mechanisms, those with money to pay the operator, or alternatively to pay mastans, or musclemen, to enforce a decision, were effectively in control. Interviews about CPP's project design suggest that while the Dutch wanted the controlled flooding and drainage option, the Germans wanted to "pour concrete," which was also much favored by BWDB. A participatory exercise was organized with five options, from drainage-only to an increasing numbers of control structures. When the Dutch sociologist leading the consultation was on holiday, the most concrete-intensive option was pushed through. As a consequence, far more embankments were built than necessary to test the concept (Warner, 2008b, 2010).

By the early 1990s FAP-20 was being framed as an environmental disaster in the making. International and Bangladeshi NGOs, who bussed thousands of demonstrators from Tangail to the World Bank office in Dhaka, criticized the effects on livelihoods, especially for the fishermen and char land dwellers outside the embankments. While the environmental catastrophe besetting beel Dakatia (see next section) was held up to the donors defending compartmentalization and controlled flooding in FAP-20, the project cannot meaningfully be called a "development disaster" (A. Rahman, 1995), yet it could ride the wave of successful opposition to hydraulic development projects, such as the Narmada dam in nearby India (Dreze et al., 1997). This made donors circumspect about supporting unpopular development projects, and protests against the FAP did indeed stir up these feelings. It led to Ministerial visits from sponsors the Netherlands and Germany, to debates in Dutch, German and 
European Parliaments, and to an intermediate change of consultant (Warner, 2010). FAP was discontinued in the mid-1990s. While FAP-20 continued for a few more years until 2000, the compartment idea was not fully dropped but was mirrored in the KJDRP.

\subsubsection{KJDRP: contestation over restored tidal flooding}

The mid-1980s and early 1990s revealed a number of socio-environmental consequences resulting from the CEP embankments. While in the first years after polder construction the absence of tidal floods allowed two rice harvests to be produced, the siltation in the adjacent rivers and waterlogging within the polders soon became a structural phenomenon in the region (Awal, 2014; Shampa \& Pramanik, 2012). The polder embankments not only prevented floods from overflowing the land but also halted the deposition of silt and clay on the former floodplains. Vast amounts of suspended sediment in the tidal water settled progressively in the rivers. The Hari-Mukteshwari, Bhadra and Kobodak rivers, three of the major rivers in the region, severely silted up during this period, creating problems with draining water from the polders. These environmental consequences resulted in 10-12,000 hectares of land in beels and polders being structurally water logged, as the water could not be drained away overland, nor could it be discharged (Institute for Right View, 2010).

In an attempt to address water logging issues and to improve drainage, the Khulna-Jessore Drainage Rehabilitation Project (KJDRP) was formed in the early 1990s and thereby paralleled the policy formulation process of the FAP. KJDRP was funded by ADB and GoB and executed by BWDB (ADB, 2004). It covered approximately 100,000 ha; a quarter of the CEP area. The KJDRP had to address the physical hydraulic heritage of the CEP polders, including the socioenvironmental consequences of the project. It offered a spot-on arena where debates about physically building on top of existing engineering works - versus more open ways to approach water and land management issues in the delta - would materialize in practice. As will be demonstrated, this amounts to technological as well as social forms of opening up, thus building on a movement that had been set in motion during the FAP. Importantly, during this period awareness of environmental flow requirements for rivers grew (Rogers et al., 1989).

The centerpiece of the debate on open versus closed approaches during KJDRP is an iconic public embankment cutting in beel Dakatia. This largest beel in Bangladesh's southwest region is located within the peripheral embankment of polder 25, constructed in the late $1960 \mathrm{~s}$ during CEP and located within KJDRP's project boundaries. By 1982 the beel started to experience severe waterlogging problems. Calls on the authorities, and even a march involving thousands of people demanding that water logging be addressed did not have any effect. The 
land remained completely infertile and was presented as an environmental development disaster (A. Rahman, 1995). In September 1990, during a mass community mobilization (mahashamabesh), four "public cuts" or non-authorized breaches were made in the embankment with the intention of draining away water from the beel and restoring tidal dynamics (and land heightening) inside it (Adnan, 2006; A. Rahman, 1995). The restored open connection with the Hamkura river immediately initiated tidal dynamics and sedimentation processes within the beel. A substantial increase in the land level was observed after the public cuts were forcefully closed by BWDB in 1994 (Adnan, 2006). The temporary restoration of controlled tidal flooding in polders came to be known conceptually as Tidal River Management (TRM).

Accounts vary in attributing relevance or prime importance to the factors driving public embankment cutting. The southwest delta already had a century-old history of local social movements, especially in relation to water and environmental governance (Haque et al., 2014). Amongst these are historic examples of illegal cutting of embankments, under the cover of darkness, in response to the disregard of indigenous flood management practices (Adnan, 2006; Willcocks, 1930) and the formation of the badhbondi andolon (embankment movement) in response to negligence of hydraulic maintenance during the last decades of the Zamindar era (Haque et al., 2014). Such local movements were strongly associated with leftist political activism and later on attracted the support of NGOs who had close ties to community leadership. Haque et al. (2014) argue that it was not so much a leftist political agenda that was being pursued but that it was the established social network in itself that facilitated the formation of newer movements, with strong support from local leadership. In the 1980s, NGOs aiming to improve socio-economic conditions for communities living in the impacted southwest delta increasingly started to take an interest in this form of controlled tidal flooding (Adnan, 2006; Haque et al., 2014). This was especially the case for the NGO Uttaran, working exclusively in the southwest region since 1985 (www.uttaran.net, accessed January 2016, [Uttaran, 2011]). The NGOs critiqued the construction of polder embankments and the neglect of social participation in hydraulic decision-making head-on, stirring up general discontent with the governmental agencies unwilling to incorporate people's solutions into hydraulic projects preceding KJDRP (A. Rahman, 1995). Past engineering works, embankment strengthening projects and their executive institutions were all targeted (Coastal Development Partnership, 2008; Institute for Right View, 2010; Uttaran, 2011). The KJDRP was impugned publicly as a "project of mass destruction," and one of its components, the 
Bhobodah sluice gate, referred to as a "death trap" (S. Islam and Kibria 2006, cover page, p.14).

For BWDB, the public cutting of embankments was unacceptable because it went against BWDB's authoritative monopoly in managing hydraulic engineering works. Although international consultants had incorporated plans for controlled tidal flooding in coastal basins in project documents in the early 1990s (Haskoning, 1993), BWDB did not include the practice in the KJDRP, arguing that it misrepresented the real problem and that it was not scientifically grounded. The lack of hydro-morphological insights regarding the suitability or effects of TRM remained a contested issue in TRM projects to come (Nowreen et al., 2013). A socioenvironmental impact study carried out by EGIS in early 1998 was an important step in terms of combining open and closed approaches in a single policy recommendation: it advised the construction of a number of engineering works, but it also argued for the inclusion of a TRM project based on scientific study (EGIS, 1998). Only towards the end of the KJDRP in 2002 did BWDB incorporate TRM in beel Kedaria (ADB, 2004).

\subsection{Analysis and discussion: hybridizing flood management with TRM?}

The previous sections have highlighted a number of water-related policy approaches, plans and practical interventions materializing in the southwest delta of Bangladesh. They show that over time, a dominant paradigm prescribing closing-off infrastructure was complemented by incidental occasions where room for opening up in the form of restoring controlled flooding within polders was created. During the KJDRP era, initiatives emerged that became conceptually formulated as Tidal River Management: restoring tidal flooding by means of a temporary and partial removal of (polder) embankments, scouring the adjacent river bed and depositing sediments within the beels (see Figure 7). We will now look more closely at TRM and analyze how the practice may be positioned in relation to the open versus closed water policy debates.

TRM takes place in a national context where reliance on closing-off engineering and infrastructural approaches to water management is profoundly dominant (Cook 2010; see also footnote 31). Therefore, TRM does not genuinely represent an all-encompassing move towards open or hybrid approaches but might be better seen as a "partial" pendulum swing, or, in innovation literature terms, as niche development in a broader policy landscape (Geels and Schot 2007). In regard to the "place" of TRM on the scale of the open versus closed debate, it may be seen as a hybrid form: based on existing flood-preventive embankments but 
temporarily open to tidal flood dynamics. The way TRM operates resembles pre-polder overflow irrigation, seasonally submersible embankments, and periods of jowar-bhata khelano in floodplains (Haque et al., 2014; Institute for Right View, 2010; Willcocks, 1930). Its feasibility is limited to particular geographical areas (beels or other low-lying areas in the tidal zone of the southwest delta) and the scale of the practice is so far is only marginal compared to the seize of the southwest delta. Furthermore, TRM depends on a specific duration of tidal dynamics (usually a number of years) in order to be effective. The temporal nature of the practice means that political and policy decisions will have to made be regarding when to open and when to close a selected beel.

TRM has socio-politically and conceptually been framed in a number of ways. As remarked by Haque et al., quoting one of their interviewees: “...It's a long time when polders and waterlogging were main targets of [our] TRM movement; we are now more of an environmental movement for rescuing the southwest from ongoing ecological disaster and climate change" (Haque, Chowdhury, and Khatun 2014, p.205). The earlier shift in emphasis on TRM as a form of indigenous hydraulic engineering, a solution for water logging problems, and a means over which to challenge vested institutional power relations has by now been complemented by representations of TRM as a climate change adaptation measure and ecoengineering innovation (Uttaran, 2011, 2013), an innovation (R. Rahman \& Salehin, 2013), and regarded as the object of study within the context of ecosystem services valuation. We are not certain whether the interest of "new" actors - including political actors and socioenvironmental NGOs - in TRM preceded this conceptual broadening, or vice versa. Relatedly, the representation of TRM as a community-driven intervention based on unequivocal consensus is contrasted by findings referring to communities being interested in embankment construction and flood prevention, and to communities that opposing and even closing the embankment cuts (Cook, 2010; EGIS, 1998; Paul, 1995).

The political nature of TRM is also represented by BWDB's initial reluctance to accept a "nonscientific concept" in KJDRP's project design and calls for TRM to become scientifically grounded. Following the seminal EGIS study (1998), several scientific studies now go into the technical and social dimensions of TRM. ${ }^{39}$ These investigations may provide further insights in

\footnotetext{
${ }^{39}$ Besides project-based studies undertaken by research institutes CEGIS and IWM, studies include (Awal, 2014; Coastal Development Partnership, 2008; Haque et al., 2014; Ibne Amir, Khan, Kamal Khan, Golam Rasul, \& Akram, 2013; Shampa \& Pramanik, 2012; Uttaran, 2011). Few policy analysis studies have been conducted on the concept (Nowreen et al., 2013; R. Rahman \& Salehin, 2013). A Dutch research programme
} 
its potential. In the meantime, after the public discontent over TRM operations and crop compensation, BDWB is now moving away from the "problematic" region to other more receptive areas such as Pakhimara with renewed TRM projects. TRM plans have been incorporated in long-term policy plans for the region and envisage an upscaling in the future. ${ }^{40}$

Restoring controlled tidal flooding in basins is not unique to Bangladesh. In the Dutch delta, for example, a series of projects is currently underway that involves the lowering or full removal of embankment sections, subsequently restoring (tidal) flood dynamics. ${ }^{41} \mathrm{~A}$ major difference is that sedimentation is not always strategically pursued as a way to increase land height (Van Staveren et al., 2014). In the Vietnamese Mekong delta, similar practices are proposed (Socialist Republic of Vietnam and the Kingdom of the Netherlands, 2013). Along the Potomac river, located in the northeastern USA, in front of the Pentagon a tidal basin flushes the Washington Channel. ${ }^{42}$

\subsection{Conclusion}

In the near and longer term future the southwest delta of Bangladesh will experience a number of intensifying environmental and human challenges including river siltation, flooding in coastal zones, population growth, and impacts of climate change (Brammer, 2014; Pethick \& Orford, 2013; Syvitski et al., 2009). Contemporary policy makers are therefore confronted with the question of how to address the southwest delta's water, flood and sedimentation dynamics.

The outcomes of earlier debates among policy makers, engineers, and international advisors embedded in a broader socio-political-environmental reality subsequently materialized in a "layered" series of policy plans and hydraulic projects. We explored these policy debates in a longitudinal and purposefully dichotomized "closed" (high river or polder embankments and large water control structures) versus "open" (floodplain management, temporary water retention and lower embankments) way, to analyze how the debate has evolved over time.

(www.nwo.nl/en/research-and-results/programmes/Urbanising+Deltas+of+the+World, accesses June 2016) includes projects that will conduct research on TRM.

${ }^{40}$ The Bangladesh Delta Plan proposed to further investigate TRM on its potential (senior policy consultant at Bangladesh Delta Plan, personal communication). A TRM Master Plan indicates three series of beels to be inundated in sequence, in three different river catchments between 2015 and 2049. (non-disclosed document, senior policy consultant at Bangladesh Delta Plan, personal communication). See also Uttaran (2013).

${ }^{41}$ For impressions see www.waterdunen.com and www.perkpolder. $n$ l (in Dutch, accessed January 2016).

${ }^{42}$ http://dc.about.com/od/touristattractions/a/TidalBasin.htm, accessed January 2016. 
Using a pendulum swing metaphor (Huitema \& Meijerink, 2009; Wallace, 2000) the article shows how the water policy debates, plans and initiatives in dealing with floods have oscillated between these extremes over time. Neither one of the policy orientation extremes is met in full: even during historic times of unrestrained flows of water, there has always been some form of local city-protecting bundh raising. During the Flood Action Plan's full-fledged engineering plans, counter voices argued for more open (physically as well as socially) approaches, and these sometimes materialized in bottom-up embankment cutting. We argue, therefore, that we might better speak of a bundle of pendula that oscillates between the two poles. At a certain point in time, a majority of pendula may be located near or swing towards a pole, but others are located somewhere in between. Representing alternative interventions or approaches vis-à-vis the dominant policy approach, it may not be known whether they will follow the bundle or remain pending. On the this scale, TRM can be seen as a hybrid form: it departs from existing engineered embankments, but is distinctly open in regard to the temporary restoration of tidal flood dynamics in the beels of Bangladesh. At the same time, the socio-political use of the TRM concept complicates effective debates about its potential.

Drawing from insights in TRM we argue that both embankments as well as tidal flood dynamics should be conceptualized differently. In addition to embankments' capacity to prevent floods, they should also be regarded as having flood facilitating capacities in both time and spaced: preventing some floods but allowing beneficial floods in regard to raising land and scouring silted rivers. In the same vein, dealing with tidal flood dynamics is not about closing down rivers in the face of twice daily rising water levels; it is also about occasionally opening up a river for its suspended sediments. Understanding tides (and sediment flow) for their dynamics is key to understanding their value: the tides that cause fluctuating water levels and the inand outflow of water; water that, in turn, facilitates the movement of suspended sediment. As argued by Uttaran, “...The history of water management [...] is mainly a history of silt management" (Uttaran 2013, p.18). These lessons were implicitly adopted in historic approaches, but may need to be highlighted again if they are to be included in contemporary debates on long-term delta planning and water management policy.

While we started this analysis from the physical point of view, a social form of opening up was also identified at the level of social participation processes in hydraulic policy making. Although taking shape hesitantly, and sometimes only effectuated after donors' interventions or vigorous social protests, it can be argued that discussions about water management and TRM in the southwest delta are no longer the exclusive domain of hydraulic planners and 
engineers but also of various social actors and representative organizations. Changes in policy orientation have therefore also been effectuated by social actors, represented by broader actor networks and new advocacy coalitions pushing for different types of approaches, which reconfigured existing institutional structures by challenging the dominant policy perspective for its failures. Especially during recent decades, attention to environmental issues and an emphasis on social participation in local water management projects have (forcefully) created some room for 'opening up' in the social domain of hydraulic engineering.

This article underscores the complexity of interactions between societal processes along with political discourses, environmental dynamics and technological developments to such an extent that it is difficult to trace the prime drivers of specific outcomes, or in this case, the way the pendulum swings. From our analysis we conclude, however, that the physical rigidity of infrastructure is a relatively strong driver in shaping future development pathways that tend to build on existing flood prevention networks as well as prevalent policy directions (Van Staveren and van Tatenhove, 2016). We argue, therefore, that addressing the dynamics of the Bangladesh delta should be informed by an historic understanding of its layered "hydraulic heritage," long-term environmental processes as well as social network analyses in the water policy domain. Especially in relation to the latter, it has been demonstrated that social action can profoundly modify hydraulic design and operations (Bijker, 2002). A perspective acknowledging this complexity and the complex interaction between a range of processes, therefore, in turn, seems a suitable analytical point of departure to formulate water policy and interventions in the fluid delta environment of Bangladesh. 
94 | 


\section{Chapter 5. The tenth dragon: controlled seasonal flooding in long-term policy plans for the Vietnamese Mekong delta}




\section{Abstract}

Recently the Vietnamese government has endorsed a long-term policy plan in which it is proposed to restore controlled seasonal flooding in the upper regions of the Vietnamese part of the Mekong delta. Restoring controlled flooding would contrast a period of several decades characterized by a dominant flood prevention approach to enable intensive rice production in the delta. This article investigates a series of long-term policy plans, which have been developed for the Mekong delta since the 1960s, on their take on flood control sensu flood prevention, or the opposite, controlled seasonal flooding. By doing so it is demonstrated how perspectives on flood management have gradually evolved and, in the specific case of suggesting controlled flooding, have been framed in various ways by various actors. Contemporary proposals for controlled seasonal flooding are supported by actors ranging from governmental institutes to environmental NGOs, and connect to on-going debates about environmental challenges and sustainable development of the Mekong delta. We adopt a systems approach to analyze social, environmental and technological dynamics in the Mekong delta, and discuss whether the different interpretations of controlled flooding may contribute to the long-term sustainability of the delta.

\section{Keywords}

Controlled flooding; delta trajectory; long-term delta planning; Mekong delta; Vietnam 


\subsection{Introduction}

Conceptualizing the Mekong delta as a hydro-agricultural machine (Biggs, Miller, Chu Thai, \& Molle, 2009, p.216) has instigated the question to which extent flooding could be harmful, or contributive, when it comes to "keeping the engine running." This issue has long been the object of debate, since the delta's rice production system needs substantial inflow of water and sediments, but also a form of flood protection against unexpected high water. While over the past decades this debate resulted in a dominant flood prevention approach (Benedikter, 2013), challenging calls to preserve or even restore seasonal controlled flooding in the densely populated and urbanizing Mekong delta have recently been brought forward (Käkönen, 2008; Marchand et al., 2014; K. V. Nguyen et al., 2015). In order to better understand these topical discussions, this article analyzes a number of long-term policy plans drafted on the scale of the Mekong delta on their take on flooding - prevention, preservation, restoration, or a combination thereof. In doing so we shed light on why certain flood management ideas have been suggested, how these institutionalized and continue to affect the development trajectory of the Mekong delta, and lastly why new conceptual flood management proposals emerged.

In the analyzed policy plans we note general interest in "greener" forms of flood management, which is not unique to the Mekong delta. Also in other deltas including the U.S. SacramentoSan Joaquin delta and the Dutch delta, an interest in restoring flood dynamics on lands which have long been cut off from rivers or estuaries is observed (Bates \& Lund, 2013; Van Staveren et al., 2014). From a gradual recognition that the absence of flooding also comes with considerable environmental drawbacks (Gerrits \& Marks, 2008; K. V. Nguyen \& James, 2013), restoring relatively "manageable" flooding could meet flood management objectives and environmental concerns at the same time. Regarding environmental concerns, it is argued that flooding supports the conservation of wetland ecosystems and biodiversity, that it brings in fresh sediments and nutrients, and that it is more compatible with sustainable flood-based agricultural production schemes in the Mekong (Ehlert, 2012; Nikula, 2008; Tong, 2017). Regarding flood management objectives, spreading out flood peak discharge over a larger area, for example by means of flood diversion, floodplain reconnection or temporary retention, contributes to regional flood safety by lowering peak water levels (Van Staveren et al., 2014). Portraying floods as environmentally valuable challenges the often dominant flood prevention paradigm, based on a one-dimensional understanding of flooding as damaging and therefore undesirable. It is therefore not surprising that these considerations have sparked 
contentious policy debates about which flood management strategy would benefit the Mekong delta's development path (Käkönen, 2008).

As a major contribution to this debate, a recently endorsed long-term policy plan (the Mekong Delta Plan ${ }^{43}$ [MDP]) explicitly recommends to capitalize on extensive seasonal flooding in the upper agricultural regions of the Vietnamese part of the delta (Socialist Republic of Vietnam and the Kingdom of the Netherlands, 2013, pp.86-88). The MDP follows on earlier delta-scale policy plans, composed in the 1960s, 1970s and 1990s likewise formulated by the Vietnamese government and their international advisors (the Mekong Delta Development Program [1968], the Netherlands Delta Development Team plan [1974] and the NEDECO plan [1993] respectively). It will be demonstrated that these sequential plans present evolving frames on flood control (in the sense of prevention) and controlled flooding (the facilitated overflow of [seasonal] flood water over or through river embankments). Controlled flooding can be understood as having: (1) a primary hydrologic objective, designating areas for flood retention or diversion routes, as a protective measure safeguarding downstream areas (so from that perspective, still a form of flood control) but more often as having (2) a specific agroenvironmental objective which involves the facilitated intake of seasonal flood water (including suspended sediment and nutrients) for the benefit of agricultural production or the natural environment (Van Staveren et al. 2014). These objectives are not mutually exclusive.

A better understanding of how and why interests in restoring controlled flooding developed is relevant in order to anticipate social tensions that might arise when controlled flooding initiatives are to be implemented. In An Giang province, located in the upper regions of the delta where controlled flooding is proposed, from 1975 onwards the construction and heightening of embankments has been pursued to support increased rice production. This resulted in a strong dependency on flood-preventive embankments, but in parallel also a social development trajectory created, comprising certain farming-based livelihoods, socioinstitutional networks, and vested interests (Hieu, 2010; Howie, 2011). New flood management measures can influence this trajectory, ranging from modifications to the hydraulically engineered delta landscape, to enforced changes in agricultural production.

Section 2 will present our analytical approach. We make use of a systemic perspective on delta development, which analyzes how social, environmental and technological factors mutually

43 See www.wur.nl/upload_mm/2/c/3/b5f2e669-cb48-4ed7-afb6-682f5216fe7d_mekong.pdf, accessed February 2016. 
interact and shape how deltas develop over time. Section 3 will provide the necessary background on water dynamics and flood management in the Mekong delta, and describes how a certain delta development trajectory was "kicked-off" in the past. Section 4 presents the main empirical findings, consisting of a detailed analysis of four long-term policy plans, along the lines of the systemic delta perspective, and with a particular interest in how those plans approach flooding. Section 5 brings up a number of points for further discussion, relating these points with the Mekong's development trajectory. In the final section, we draw the main conclusions.

\subsubsection{Methodology}

The conceptual approach to understand delta development provides the framework to analyze the selected long-term policy plans, where their take on water management in the Mekong delta in general, and on controlled flooding in particular, are the central topics. We analyze how these frames relate to environmental dynamics, social processes and technological development in the hydraulic domain, and investigate how the interventions suggested in the plans have impacted, or could impact, the Mekong delta's trajectory.

Data collection consisted of analyzing existing gray literature, primarily a number of long-term policy planning documents, and additional expert interviews, which were conducted in English or mediated by a translator. The selection of earlier long-term planning documents was based on the overview provided by Miller (2003, Appendix F), complemented with the most recently formulated long-term delta plan in 2013. Since many sectoral and regional policy plans are available, an important criterion has been whether the selected plans adopted a delta scale. Due to practical reasons, the analysis concerning the Mekong Delta Plan has been done in more detail (document review and interviews) as compared to the older gray plans (document review). Interviews were conducted in 2016 with representatives from Vietnamese research institutes, NGOs and provincial government officials who have been involved in water policy planning.

\subsection{Delta trajectories and frames on flood management}

We conceptualize deltas as interacting social-ecological-technological systems, where a "delta trajectory" expresses how a delta develops over time (Van Staveren \& van Tatenhove, 2016, see also Benedikter, 2013, p.95; Molle, 2003). This approach stresses the mutual interaction between social and governmental actors (embedded in a political-institutional setting) shaping policy choices, the (historic) construction of hydraulic engineering works resulting from these choices, and the delta environments in which these actions take shape. 
The conceptualization of deltas as social-ecological-technological systems is inspired by socialecological systems views (Berkes et al., 2008; Folke et al., 2005). It has been argued that such views are highly relevant for delta-oriented analyses (Edelenbos, Van Meerkerk, \& Van Leeuwen, 2015; Käkönen, 2008; Renaud, Syvitski, et al., 2013). At the same time it has been noted that more attention should be paid to how technological systems, such as hydraulic infrastructure, influence social-ecological systems trajectories (A. Smith \& Stirling, 2010). This is supported by historical analyses of the Mekong delta, which highlight how hydraulic engineering works have mutually interacted with the delta's environment and influenced its social structures (Biggs, 2010; Brocheux, 1995; Miller, 2006).

The intricate relations between social, environmental and technological systems in shaping a composite delta trajectory show from the effect of embankment construction (be it in "simple" or technically more advanced ways) on the social and the environmental systems. Embankments create relatively flood-free land, enabling socio-economic development in areas formerly exposed to frequent flooding. But suspended sediments do longer deposit on floodplains but instead start making river beds more shallow. Especially in deltas, flood-free land starts to subside due to soil compaction or groundwater extraction. In order to keep safeguarding these lands, there will be calls for increased protection against high water. This typically takes place via heightening or reinforcement of existing embankments. Intertwined with the parallel formation of associated hydraulic institutions, hydraulic engineering works therefore start to display characteristics of technological and institutional lock-in (Lach, Rayner, \& Ingram, 2005). This may lead deltas towards long-term unsustainable system states, as in the above example the difference between land and water is ever increasing (Gerrits, 2008). The enduring connection between past hydraulic interventions and contemporary debates shows from the notion that the canals that opened up the Mekong delta in the past (see next section), are now contributing to salinity intrusion far inland, affecting agricultural production (Tuan et al., 2007).

The delta development trajectory that results from interaction between social, environmental and technological systems may be defined as sustainable or unsustainable, in which the adopted time scale is critical. Yardsticks such as technical possibilities can be used to assess whether flood management innovations are capable of dealing with the future impacts of climate change. Also, social acceptance of costs related to constructing and maintaining hydraulic works, and acceptance of environmental impacts of such works, is important to assess whether a certain water management frame yields sufficient support or becomes 
challenged. We argue therefore that stability or change in delta trajectories is determined by the interactions between social, ecological and technological factors, and that drivers for change can originate in either of those systems. Despite their interrelatedness, each system can be further specified, emphasizing how stability or change may be triggered.

To start with, delta environments are highly dynamic, involving a continuous interaction between land and water, including seasonal flooding, erosion, sedimentation and land formation processes. We define the technological system (the hydraulic network of canals, flood embankments, sluice gates and pumping stations) as the material outcomes of societal choices about how to deal with a delta's watery environment. Hydraulic infrastructure can result from formal policy planning processes and the subsequent implementation of recommended works, but also from local initiatives that are disconnected from such processes. The social system comprises actors and networks that are connected to dealing with water and flood management in the Mekong. This understanding is purposefully broad, since a variety of actors is involved in the topic, including international policy and planning advisors (Biggs, 2010; Ekbladh, 2002). Vietnamese governmental bodies have exerted a strong influence in deciding on policy choices, based on technical advice provided by their associated research institutes (Benedikter, 2013), while NGOs working on environmental issues and with farmers, increasingly engage themselves with local water management. Social actors may have the capacity to oppose or enforce redesigning of flood management projects resulting from distant policy plans (Wesselink \& Warner, 2010).

In order to analyze evolving perspectives of policy plans, as well as social actors' position towards water and flood management in the Mekong, a framing approach is used (Rein \& Schön, 1996). In policy and planning studies, frame analysis is employed to distinguish between different groups of ideas or perspectives, typically supported by a number of allied social actors, regarding a certain policy issue (Dewulf, 2013; Hajer \& Versteeg, 2005). Actors or actor coalitions may adhere to existing or develop alternative frames which typically results in competition between existing, reframed, and new frames (Dewulf, 2013; Wesselink \& Warner, 2010). Subsequently, these dynamics may challenge dominant institutional arrangements, creating legitimacy or interest-driven opportunities for other actors to join in policy debates. Dynamics regarding frames and (re-)framing in flood management are therefore often socio-politically driven (Wesselink \& Warner, 2010). Frames represent a situation in a particular light, legitimize particular courses of actions, and are particularly important in development cooperation. They naturalize (or resist) interventions to tackle a 
particular socioeconomic problem. For example, Mitchell (1991) shows how the World Bank successfully framed Egypt as an overpopulated country in need of development, legitimizing large-scale American and multilateral support.

\subsection{The Mekong's watery development trajectory: mastering the dragons}

The Mekong delta is the low-lying region of the Mekong river basin, where numerous rivers and canals release sediment-laden water into the sea. The delta is to a large extent located within Vietnamese territory. Just below Phnom Penh in Cambodia, the Mekong splits into two distributaries; the Mekong (or Tien) river and the Bassac (or Hau) river. Depending on the season, $80-85 \%$ of the water flows via the Mekong, while $15-20 \%$ flows via the Bassac. Downstream of the Vam Nao river, which connects both rivers again roughly at the latitude in between the Long Xuyen Quadrangle and the Plain of Reeds (see Figure 8 below), the distribution of water through both channels is balanced out again. There is a substantial difference between low flow $\left(2.340 \mathrm{~m}^{3} / \mathrm{s}\right)$ and peak flow $\left(25.500 \mathrm{~m}^{3} / \mathrm{s}\right.$, with an extreme discharge of over $29.000 \mathrm{~m}^{3} / \mathrm{s}$ in 2000) during the year. Flood water drains into the Gulf of Thailand (or West Sea) via a number of large canals, and into the South China Sea (or East Sea) via a number of distributaries. Especially during flood season large quantities of suspended sediment flow into the delta which either get deposited on floodplains, settle in river beds, or are carried further downstream to the delta's coastal zone (Hung et al., 2012; Renaud \& Kuenzer, 2012; Tri, 2012).

The Mekong's Sino-Vietnamese name, Cuu Long, popularly translates as "nine dragons," referring to the Mekong's nine historical branches conveying water towards the sea ${ }^{44}$ (Renaud \& Kuenzer, 2012). But in addition to these river flows, which find their ways through rivers, canals and a network of sluice gates, we identify a "tenth dragon." During flood season from July to December, large volumes of water flow overland across the Cambodia-Vietnamese border towards the South (see upper left arrows in Figure 8). Overland flooding is entirely different from water conveyance via river branches. Overland flooding is a relevant water related dynamic in the Mekong delta, but get easily overlooked when only focusing on water conveyance via river branches.

\footnotetext{
${ }^{44}$ One of the distributaries is closed due to sedimentation (Jansen, 2015).
} 


\section{Controlled seasonal flooding in the Vietnamese Mekong delta}

The Mekong delta is the low-lying region of the Mekong river basin, where numerous rivers and canals release water into the sea. The delta is to a large extent located within Vietnamese territory. Flood water drains into the Gulf of Thailand (or West Sea) via a number of large canals, and into the South China Sea (or East Sea) via a number of distributaries. The Mekong's Sino-Vietnamese name, Cuu Long, popularly translates as 'nine dragons', referring to the Mekong's nine historical branches conveying water towards the sea. A 'tenth dragon', however, could consist of sediment-laden flood water overflowing embankments during flood season. While in large parts of the delta this dynamic is prevented or reduced due to embankment construction, policy plans now propose to restore this form of controlled flooding in the upper regions.

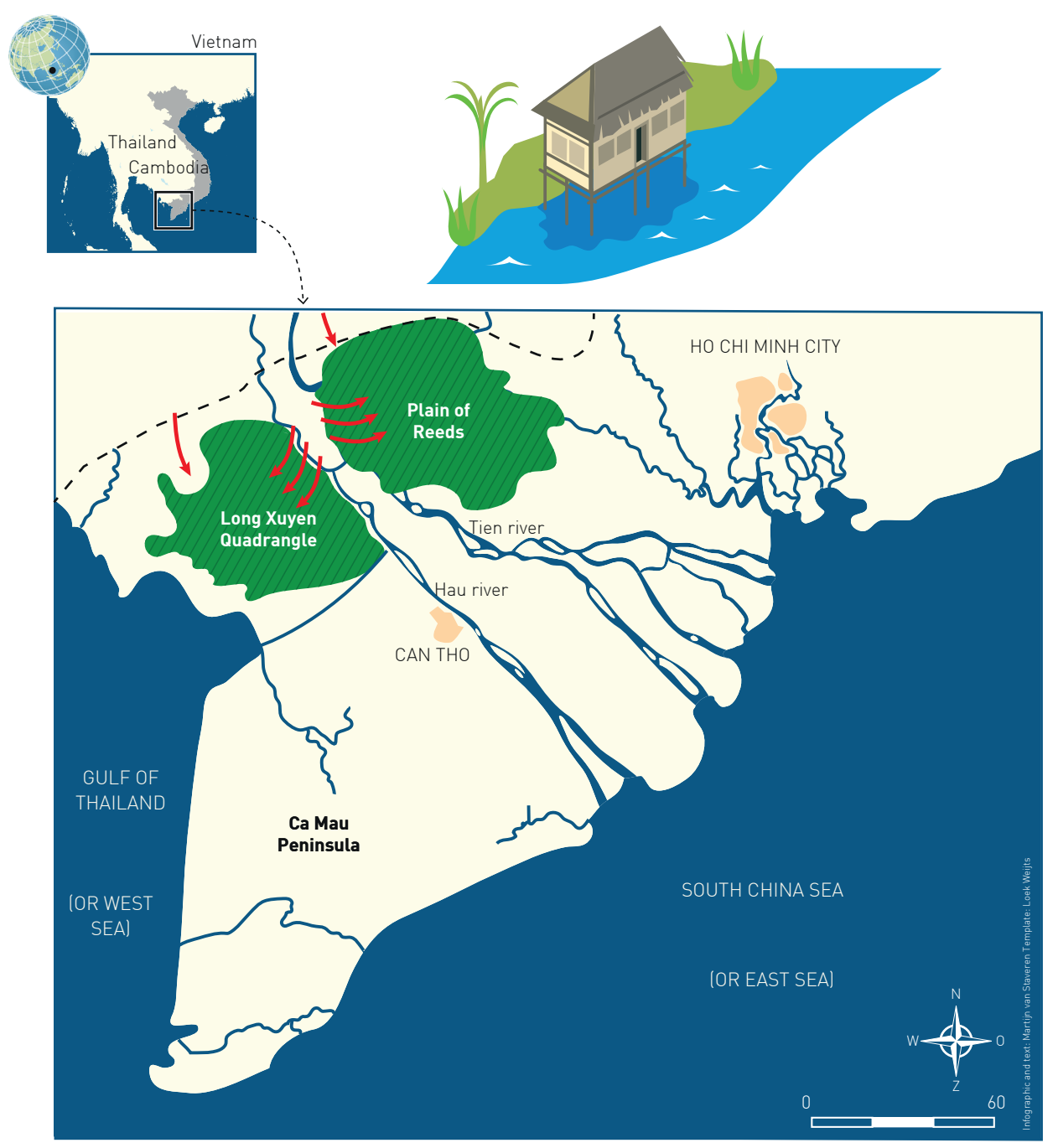

Figure 8. Controlled seasonal flooding in the Mekong delta 
Overland flood water steadily fills up canals and starts overflowing embankments, notably in An Giang/Kien Giang (Long Xuyen Quadrangle) and Dong Thap (Plain of Reeds) provinces. ${ }^{45}$ Whether seasonal flooding will be moderate or extensive is difficult to predict since the delta's hydrology is highly complex: water volumes build up slowly to "overflow level," upstream water storage or release with hydropower dams and in Tonle Sap lake, and the influence of the twice-daily tides reaching far inland all play a role in this (Hung et al., 2012; Tri, 2012). Although large parts of the region are embanked with high or medium-high embankments, about $45 \%$ of the region can still become submerged during flood season - not uniformly, but depending on whether or not individual plots or zones are embanked (Hung et al., 2012; Tri, 2012). Sometimes controlled flooding is practiced on a rotational basis: over a period of three years, eight rice crops are produced while during one period of seasonal flooding, the fields are submerged with water.

Seasonal flooding has environmental benefits: from flushing out acidic soils, to depositing sediment, bringing in nutrient-laden moisture to prepare fields for the next cropping, and to killing pests such as rats (Ehlert, 2012; K. V. Nguyen \& James, 2013; V. X. Nguyen \& Wyatt, 2006; Nikula, 2008). It constrains opportunities for rice production, for example when three rice crops per year are pursued, or when extreme seasonal water levels cause damage to urban areas such as Can Tho, located centrally in the delta. The most recent extreme flood events took place in 2000, 2001 and 2011, causing large-scale damage (Renaud \& Kuenzer, 2012).

\subsubsection{Initiating the Mekong's delta development trajectory}

Unsurprisingly, resulting from these watery dynamics, the Mekong delta's history is characterized by hydraulic interventions aiming to master the delta's water flows. Generations of actors, whether distant policy makers or local farmers, have molded an environmental and social development trajectory in the Mekong. Biggs (2010) and earlier Brocheux (1995) have demonstrated how hydraulic engineering, notably dredging, canal construction and the introduction of water pumps during the time of French colonial rule (1887-1954) has shaped the Mekong delta's development path. French dredgers physically opened up the Mekong delta wetlands by digging hundreds of kilometers of canals during the first decades of the $20^{\text {th }}$

\footnotetext{
45 The Vietnamese language uses different wordings for floods, ranging from storm floods (bao lu) in the mountainous regions, to the relatively slow inundation following the overland flow (lu lut), also referred to as mua nuoc noi; water rising season (Tuan et al., 2007, p.27) or water moving season (Benedikter, 2013, p.82) in the Mekong delta. There is also a distinction between "supplying" floods: nuoc son (reddish water) referring to the water color of heavily silt-laden water from upstream, or "draining" floods: nuoc bac (silver water) referring to greenish and transparent water that drains fields with acid surface soils (Tuan et al., 2007, p.26).
} 
century. These canals provided access into the Mekong's still sparsely inhabited wetlands, and made it possible to reclaim, settle, and develop those lands into agriculturally productive areas. Once these areas were accessible, tens of thousands of farmers from Vietnam's northern regions were relocated to settle in these areas (Jansen, 2015). The soil that became available by excavating the canals was used to raise the canals' embankments, effectively starting to divide the delta plains into an agglomeration of individually enclosed lands with a unitary hydrology (Hashimoto, 2001, p.25). These 'polders' were later purposefully constructed in the central regions of the Mekong delta to be able to better grasp local land and water management within areas surrounded by embankments (Biggs, 2010). These early day interventions outlined the contours of a development trajectory where "natural" wetland was converted into lands intended for agricultural production, and which necessitated a form of water management but above all, flood control.

While adapting to seasonally rising water levels has been the way of life in Mekong delta societies for centuries (Ehlert, 2012; Miller, 2003), the construction of so-called August dykes from the 1970s onwards signified an important step in shifting from flood avoidance and adaptation to strategies geared towards flood control (Benedikter, 2013; Truong, 2000). In addition to the expanding canal network and fragmented flood protection works, August dykes (bao lung, [Benedikter, 2013, p.110]), also referred to as medium-high, temporary or semi-dykes (de bao thang tam, [Trung, Tuan, Trieu, Bastakoti, \& Lebel, 2013, p.119]), prevented flooding of fields until August. After August seasonal floods would overflow the banks and inundate rice fields for a number of months (Howie, 2011). But following policy reforms in 1986, targeting increased rice production under relatively flood-free conditions, the Vietnamese government set about heightening this embankment network (Benedikter, 2013; Howie, 2011). By now, most August dykes turned into high flood-preventive embankments, comprising an extensive network consisting of flood-preventive embankments. These developments have provided the backdrop for subsequent policy plans that proposed further hydraulic interventions, to which we turn in the next section.

\subsection{Mekong delta long-term policy plans: changing frames on water and flood management}

\subsubsection{Frames on flooding in policy plans}

The Mekong delta has been the object of future-making for a long time, with water and flood management challenges as central topics (Biggs et al., 2009; Miller, 2006). Various policy studies have been conducted on individual sectors or geographic areas, but occasionally plans 
aimed for integrated and delta-scale analyses (Miller, 2003). These delta-scale policy plans display, as will be demonstrated in more detail below, evolving attitudes or frames on how the Mekong's (seasonal) flooding should be dealt with.

\subsubsection{The MDDP}

The first long-term master plan on the scale of the Mekong delta was developed in the late 1960s (Miller, 2006). The Mekong Delta Development Program (MDDP) was drafted by David Lilienthal, a US engineer and chief architect of the Tennessee Valley Authority (TVA) in the U.S. The TVA was set up as an integrated regional development model, proposing hydraulic interventions to control flooding and improve navigation in the Tennessee river. But it also designed agricultural and social programmes with the ambition to spur socio-economic development on a regional scale along the lines of technological modernization (Ekbladh, 2002; Lilienthal, 1944). Potential negative environmental impacts of large hydraulic works did not receive much attention. The TVA model came to serve as the US' overseas development model; proposing technological interventions accompanied by societal development models for agrarian societies in an attempt to turn back the tide of communism (Ekbladh, 2002).

After two years of investigation, compromised by the Vietnam war (1960-1975), the MDDP was issued in 1968 and clearly mirrored TVA ideas. It framed the development challenge in the Mekong as to be addressed by investment in technological means, improving agricultural production by means of extensive water control and drainage works. It proposed a "closingoff” approach (Miller, 2006), recommending “...A 20-year development programme covering the largest part of the delta in Vietnam, comprising of a complete diking and water control system and aiming at tripling of rice production by 1990" (Netherlands Delta Development Team, 1974, p.20). Representative of its take on controlled flooding, the plan included massive flood bypasses to the Gulf of Thailand (or West Sea) and via the Plain of Reeds to the South China Sea (or East Sea) to route the controlled diversion of seasonal peak flows (Miller, 2003, p.187). While the implementation of the MDDP was obstructed because of the Vietnamese war, its recommendations were quite in line with later proposals (Miller, 2003).

\subsubsection{The NDDT plan}

In collaboration with the Mekong Committee (the current Mekong River Commission), the Dutch government made a number of experts (hydraulic engineers, agricultural experts and a sociologist) available in the early 1970s to draft the Netherlands Delta Development Team's (NDDT) plan for the Mekong delta (Netherlands Delta Development Team, 1974, p.15). The work of the team was similarly heavily influenced by the intensifying war in the Mekong delta, 
which impeded field work and new local research being conducted. Most of the report was therefore based on existing studies and composed in the Mekong Committee's office in Bangkok.

Reflecting the MDDP's framing, the report strongly focused on agricultural development by means of water control. It saw good opportunities for this in the central regions of the delta, since flood dynamics were only moderately deep there and soil conditions supportive for rice production. It discouraged investing in the upper region of the delta, since the magnitude of the yearly floods was impressively large (with flood depths up to four meters) and expected returns on investment were low. The report instead advised to "let the northern regions flood" and in doing so framed controlled flooding as a means of flood diversion, enabling socio-economic development primarily in the central regions. Another reason to accept controlled flooding shows from considering it unnecessary to construct embankments in the upper regions, since dams were planned upstream: “...Because high dikes might become superfluous in the future when upstream development [hydropower dams] would cause a considerable reduction in flood levels, flood protection of the area with deep flooding should be avoided as long as there are other development opportunities [in other regions] (Netherlands Delta Development Team, 1974, p.7)."

Environmental impact assessments of proposed works, or considerations of positive aspects of seasonal flooding were absent in this plan. Nevertheless, a socio-institutional chapter acknowledged the importance of a proper understanding of societal needs and limitations, up to farm level. It argued that the individual use of pumps for irrigation and drainage, to which farmers have become fully acquainted with, should not be substituted suddenly by extensive water control projects, because of social-psychological reasons (Netherlands Delta Development Team, 1974, p.136).

After the end of the Vietnam War in 1975, a number of isolated irrigation and flood management projects were implemented but these were not very effective. Due to economic downturn in the 1980s no larger investments were possible. This changed in the early 1990s, when the Doi Moi, or economic liberalization policy formulated by the Vietnamese government in 1986, started to take effect (Benedikter, 2013). 


\subsubsection{The NEDECO plan}

Almost 20 years after the NDDT plan, a consortium of Dutch experts under the name of NEDECO (NEtherlands DEvelopment COrporation) formulated the "Master plan for the Mekong delta in Vietnam" or in short the NEDECO plan (NEDECO, 1993). The drafting of this plan was influenced by several socio-environmental developments concerning the Mekong in the 1990s. Importantly, the economic liberalization policy stimulated market development and major investments in water infrastructure by international financing institutions - hence many of the works recommended by the NEDECO plan were implemented, be it with lag time (Benedikter, 2013, p.103). Also, the Dutch government and in particular its Ministry of Transport, Public Works and Water Management developed an interest in collaborating with a relatively new development partner for political-economic reasons (Kleinen, Van der Zwan, Moors, \& Van Zeeland, 2007).

Compared to the MDDP and the NDDT plan, its various water control measures were not exclusively geared towards improving agricultural production. Instead, the plan adopts a slightly broader frame: water and flood dynamics are placed in relation to its relevance for the delta environment, in particular nature reserves and wetlands, in addition to its agricultural dimension (NEDECO, 1993, pp.21-22). Explicit reference is made to the Brundtland report (WCED, 1987), the seminal work advocating sustainable development in response to environmental problems issued a few years earlier (NEDECO, 1993, p.3), and to the work of environmental NGOs such as WWF and IUCN (p.136). The plan address Brundtland's message by reiterating the need for Environmental Impact Assessments to be conducted for individual measures and suggests to set up an Environmental Protection Center. In this way the NEDECO plan recommendations started to connect with discussions about the (un)sustainability of potential interventions. In particular the NEDECO plan advocated for controlled flooding on various locations: in the deep-flooded areas in the upper regions (p.50) and linked to certain scenarios also in the shallow flooded areas more central in the delta (p.73, see also the next paragraph). It argued that full flood protection would be out of the question due to the backwater effects affecting Cambodia, and for environmental reasons. It kept the door open for flood bypasses in the form of "green rivers": areas in use for agriculture that could be flooded in order to drain high water. This mirrored earlies bypass ideas, as included in the MDDP. Controlled flooding is thereby framed as an element of sustainable flood management, and relevant in relation to the development of the Mekong delta's trajectory. To date, the plan and the underlying studies conducted to support its recommendations are still important reference material. 
The plan has a future outlook comprising a few decades (until 2050) and distills three development scenarios: (1) an extreme scenario with no limits to water abstraction even during low flow, pursuing triple rice cropping and flood control, (2) an intermediate scenario with no limits to water abstraction but some restrictions on rice production and flood control and (3) the "moderate" scenario, following a prudent development path with no additional water abstractions during the critical low-flow period from early March to early May, and no additional triple rice cropping; full flood protection is allowed in the shallow-flood areas; in the deep-flood areas only controlled flooding is an option to safeguard the harvesting of the Summer-Autumn rice crop (NEDECO, 1993, p.71). The moderate scenario was felt to be the most suitable. Although socio-economic development is the main objective, the master plan limits itself to recommending an institutional framework to implement recommended projects in a rather top-down way: the plan clearly frames farmer organizations as recipients that should be made receptive for Vietnamese institutions 'selling the message' and the NEDECO plan's individual projects.

\subsubsection{The Mekong Delta Plan}

Another 20 years later, the Mekong Delta Plan ${ }^{46}$ was composed within the context of a by now active bilateral cooperation between Vietnam and the Netherlands on water and delta management (Government of the Netherlands, 2009; Socialist Republic of Vietnam and the Kingdom of the Netherlands, 2013). The initiative to start formulating yet another delta plan has to a large extent been driven by the establishment of the Dutch Delta Committee in the Netherlands in 2008 (Seijger et al., 2016). This state advisory committee developed the latest interpretation of long-term delta planning, which also characterized the MDP process: it consisted of a scenario-based approach; foregrounded adaptive policy as a way to deal with uncertainties; used extended time horizons up to 2100 , and specifically aimed to address climate change impacts. The Dutch government felt that this approach should be followed in other world deltas as well, notably the delta countries where international development relations existed (Government of the Netherlands, 2009) and made the chair of the Dutch Delta Committee available as a special advisor to the MDP process. Although it was not entirely clear among Vietnamese partners what was being meant by long-term delta planning,

\footnotetext{
${ }^{46}$ See footnote 43 . It has recently been endorsed broadly by international development partners as well as the Vietnamese government. It acts as the World Bank guiding framework for a major investment plan in the region (www.worldbank.org/en/news/press-release/2016/06/10/vietnam-building-climate-resilience-and-ensuringsustainable-livelihoods-of-farmers-in-the-mekong-delta, accessed August 2016).
} 
a gradual exploration of how this approach could benefit Vietnamese policy planning, typified the planning process (Government of the Netherlands, 2009, Interview ${ }^{47}$ ).

With the bilateral cooperation between Vietnam and the Netherlands increasingly focusing on business development between the two countries, the MDP found opportunities in this direction by proposing an agribusiness development scenario ${ }^{48}$ and by referring to concentrated flood protection and innovative forms of flood management. A frame of innovative water management is presented by suggesting to look at the Room for the River programme (Socialist Republic of Vietnam and the Kingdom of the Netherlands, 2013, pp.8889) which proposes multi-purpose river restoration in the Netherlands. The Room for the River programme consists of dozens of river widening, flood diversion channels and controlled flooding projects (Van Staveren et al., 2014). With concentrated protection urban centers such as Can Tho would be protected against high water, while controlled flooding contributes to lowering peak water levels and contribute to a sustainable agribusiness scenario simultaneously.

The MDP makes a clear plea to preserve and at some places restore seasonal flood dynamics in the upper region of the Mekong delta by means of facilitated embankment overflow. It resonated the NEDECO plan in that it frames controlled flooding as beneficial to agricultural production schemes and the natural environment. The plan discourages triple rice croppings in the upper regions, which is a major shift in agricultural policy. Presenting more detailed analyses on the economics of agricultural production, Tong (2017) and K.V. Nguyen, et al. (2015) show that the net benefit of intensive triple rice farming with high embankments is lower than forms of agriculture which include the seasonal flooding of fields. Especially soil quality is deteriorating in flood-deprived lands: since there is little to no soil leaching by flood water, soil acidity builds up, and more fertilizers are needed to keep up with rice production targets. Controlled flooding contributes to sediment and nutrient load on the land submerged during flood season, but comes with the downside of losing the opportunity to grow three rice crops per year. Hence it is suggested to re-think the sustainability of intensive agricultural farming in the delta, and call for combined or diversified land uses for cost-effective, sustainable production (K. V. Nguyen et al., 2015; Tong, 2017).

\footnotetext{
${ }^{47}$ Interview Senior Advisor World Bank, 7 April 2016, Ho Chi Minh City.

48 Three other development scenarios were developed as well. The agribusiness scenario surfaced as the preferred development scenario by most of the stakeholders (Seijger et al., 2016).
} 
Vietnamese farmers tend to see controlled seasonal flooding as beneficial for agricultural production as well as for enabling access to pre- and post-harvest resources such as fish and snails (Ehlert, 2012; Huu, 2011). At the same time, other farmers have called for increased flood protection (Interview $\mathrm{II}^{49}$ ). When the MDP's flood restoration measures materialize at places where flood dynamics have purposefully been ruled out, discussions can be expected about how to shape new agricultural farming systems as past agricultural and infrastructural investments will be annulled. Some pilot projects using new agricultural farming systems based on seasonal flooding, for example floating rice, have been positively evaluated by farmers (Interview III ${ }^{50}$ ). A stakeholder participation and feedback process has been undertaken (Seijger et al., 2016), but will need to be updated when concrete measures are proposed. While it has been noted that Vietnamese farmer households may adapt to changes in flood dynamics and farming systems, it will need a transformative process in order not to create social disparities among farmer communities (Tran \& James, 2017).

Regarding the natural environment, the MDP makes a clear connection with the delta's central wetlands reserves such as the Tra Su forest in the Long Xuyen Quadrangle, and Tram Chim National Park in the Plain of Reeds, underscoring they require a substantial inflow of seasonal water (V. X. Nguyen \& Wyatt, 2006; Socialist Republic of Vietnam and the Kingdom of the Netherlands, 2013, p.26, Interview III $^{51}$ ). The status of Tram Chim National Park as a Ramsar ${ }^{52}$ wetland site increases the need to address high risks of forest fires and to maintain biodiversity including numerous special bird species, by means of safeguarding seasonal flooding. Especially for NGOs, MDP's ideas about controlled flooding framed as supporting wetland reserves and the broader delta environment supports their agenda (Interview III ${ }^{53}$ ).

The framing that (controlled) flooding can also have agricultural and environmental benefits is contrasted by Vietnamese provincial policy planners who have understood controlled flooding primarily as a form of flood control. Resonating the MDDP and the NDDT recommendations, the MDP proposes a flood diversion channel in Long Xuyen Quadrangle, discharging a majority of the flood water towards the west via the indicated routing (see

\footnotetext{
${ }^{49}$ Interview Department of Agriculture and Rural Development, An Giang province, 27 April 2016, Long Xuyen.

50 Interview IUCN, 4 April 2016, Ho Chi Minh City.

${ }^{51}$ See footnote 51.

52 www.ramsar.org, accessed August 2016.

53 See footnote 51.
} 
Figure 8). It is therefore regarded as a flood protection measure for downstream areas such as Can Tho, where the high water otherwise would have drained to (Interview II ${ }^{54}$ ).

\subsection{Discussion}

Our analysis shows that the reviewed long-term policy plans present different frames on flooding. Earlier plans recommended technical-engineering approaches to prevent flooding, while the later plans adopted more integrated planning ideas, emphasizing that socioinstitutional as well as environmental aspects of water management should receive more attention.

We primarily associate these evolving frames in the policy plans with the respective international advisors' recommendations about how water and in particular flood peaks should be managed: US and predominantly Dutch experts recommended approaches that were in line with their professional training and working expertise, acting as "terms of reference" in formulating their recommendations. ${ }^{55}$ A steady inflow of evolving flood management discourse from the Netherlands to Vietnam, for example, has been enabled by the initiation of bilateral cooperation between both countries since the 1970s (Kleinen et al., 2007). The transfer of contemporary discourse is clearly visible in the latest joint policy plan: recent policy developments in the Netherlands, ranging from using "integrated delta planning" as a policy approach in itself (Delta Committee, 2008) to proposing "greener" flood management innovations (Janssen et al., 2015), all figure prominently in the MDP (Socialist Republic of Vietnam and the Kingdom of the Netherlands, 2013, pp.10, 86-89).

This instigates the question to which extent Vietnamese policy makers have readily accepted such discourse. It has been argued that Vietnamese policy makers are critical towards international policy recommendations, preferring their own perspectives and allowing foreign influence only on paper (Benedikter, 2013; Biggs, 2010). Parallel to the MDP process, for example, Vietnamese policy makers have been formulating their own policy plans that are

\footnotetext{
${ }^{54}$ See footnote 50 .

${ }^{55}$ The influence of Dutch water (and later, also other sectoral professional domains) experts in developing longterm delta plans for the Mekong stands out. The origin of long-term delta planning, acting as the guiding framework to draft the Mekong Delta Plan, can be traced back to the first Delta Plan formulated in the Netherlands in the late 1950s. This plan (Van Veen, 1962) became an institutionalized approach to look at complex delta challenges in an integrated manner. In the 1970 s long-term delta planning adopted methodological, analytical and decision-supporting policy tools originating in the US (Disco, 2002; Goeller et al., 1977) to formulate policy recommendations. In the 2000s the most recent branch of Dutch delta planning emerged which was largely driven by potential climate change effects (Delta Committee, 2008) and presented as a promising vehicle to market Dutch water management abroad, including Vietnam (Government of the Netherlands, 2009).
} 
heavily based on flood control (SIWRP, 2016). It therefore remains unclear whether observed changes in the policy plans are representative of evolving thinking about flooding among Vietnamese policy makers.

We note that the NEDECO and MDP plans started to emphasize the environmental dimension of flood management, a development which has been referred to as an "ecological turn" in water management (Disco, 2002). The NEDECO plan, for example, recommends to conduct environmental impacts assessments to scrutinize proposed flood management interventions on their environmental consequences. With acknowledging the dependency of the delta's last remaining wetland reserves on seasonal flooding, stronger calls were issued to develop more environmental-inclusive flood management approaches (V. X. Nguyen \& Wyatt, 2006). In part this trend can be explained by the increasing number and diversity of actors involved in flood management, against the background of an emergence of environmental concerns in water management in general (Disco, 2002; Gleick, 2003; Marchand et al., 2014). This surfaces prominently in the MDP, where environmentally concerned actors such as IUCN, WWF and institutes such as An Giang University's Research Center for Rural Development, advocate controlled flooding for its positive effects on the delta's environment. By contrast, provincial policy makers and their associated technical research institutes primarily see controlled flooding in the upper regions as a hydraulic measure, intended to reduce high water impacts on the Mekong delta's urban locations further downstream.

It might be attractive to equate an increased interest in the environmental aspects of (controlled) flooding with the existence of a "living with floods" policy, often referred to as the official flood management approach in the Mekong since the 2000s, as it implies a policy environment conducive for controlled seasonal flooding. But a number of government policy decrees that advocate living with floods ideas, discuss the term only vaguely (see Danh \& Mushtaq, 2011; Trung et al., 2013). Even more, contradictory interventions, ranging from community resettlement to river widening or even large-scale embankment construction, are presented as "suitable" under a living with floods header. Käkönen therefore considers the concept "misleading" (2008, p.201). An understanding of living with floods which could provide such an enabling environment, has been formulated by Miller (2003, p.295) as "...an expression which refers to the local, adaptive approach to floods in the delta, whereby efforts to minimize the negative effects of floods seek to not undermine their positive values." 
Relating these findings with the development trajectory of the Mekong delta, we make the following observations. Explicitly adopting long-term planning horizons (ranging from a few decades to a hundred years), as the analyzed plans do, has contributed to initiating debates about the sustainability of certain flood management approaches. Intensive rice production impacting soil quality, coupled with the absence of floods flushing fields, has been flagged as unsustainable in the long run. The NEDECO and MDP plans, which have the longest planning horizons, propose interventions that move away from or re-orient the existing trajectory. It can be questioned to which extent this is only a paper reality, for reasons argued above. But restoring controlled flooding at most only partly address sustainability issues. First, diverting nutrient and sediment rich flood water to designated areas means that other areas still remain unexposed to its environmental benefits. Secondly, pursuing controlled flooding assumes a seasonal volume of water that actually enables such flooding. But against the background of already complex upstream water and flood dynamics as stressed in Section 3, in 2016 it became clear that seasonal flooding may unexpectedly be entirely absent due to natural variations in rainfall, river discharges or water storage upstream. ${ }^{56}$ Lastly, it would be unfeasible to expect that these changes to flood embankments materialize overnight, considering the rigidity of existing embankments, and farmers who might be unsupportive of controlled flooding ideas. Controlled seasonal flooding therefore has both advantages and weaknesses, and in its current form might only partly contribute to reorienting the Mekong's development trajectory.

\subsection{Conclusion}

This article has adopted a social-ecological-technological systems perspective on the Mekong delta (Van Staveren \& Van Tatenhove, 2016) to describe how after initial land reclamation in the early $20^{\text {th }}$ century, a delta trajectory was "kicked-off" that aimed for intensive agricultural production enabled by large-scale flood control infrastructure. This trajectory has been intensified by gradual national investments in expanding embankment networks and agricultural intensification efforts from the 1970 s onwards. Since then, several internationally supported, long-term policy plans were formulated on the scale of the Mekong delta, in which new water related interventions were proposed. This article has investigated how and why flooding and flood management (ranging from flood protection to preservation or restoration

\footnotetext{
56 http://english.vietnamnet.vn/fms/society/165261/with-no-floods--mekong-delta-farmers-suffer-losses.html, accessed October 2016.
} 
of seasonal flooding) were framed in those plans, and reflects on how these (proposed) interventions (would) impact the Mekong's delta development trajectory.

We conclude that technical-engineering approaches to prevent flooding have been complemented by more recent suggestions to incorporate socio-institutional as well as environmental aspects of flood management in long-term policy planning in the Mekong. The earlier MDDP (1968) and NDDT (1974) plans pursued agricultural intensification, supported by flood protective infrastructure. Strengthening the existing development trajectory, these plans suggested large scale flood prevention to safeguard productive agricultural areas, and controlled flood diversion via economically less important locations. From the more recent plans, the NEDECO plan (1993) suggested improving water control in general, but starts making explicit reference to environmental considerations of flood management. Most recently, the MDP (2013) inquired long-term sustainable development for the Mekong, partly instigated by potential climate change impacts, and suggested an agribusiness development path supported by urban flood protection and controlled seasonal flooding in the upper regions of the delta.

When zooming in on the various frames on controlled flooding as recommended in the MDP, we have encountered a number of diversified but related understandings of the concept. It has been framed as primarily a form of flood control (safeguarding urban areas downstream in the delta), as an innovative form of flood management supportive of sustainable agriculture, and as beneficial to the delta's environment. While there has been some tension between these understandings, controlled flooding has acted as a conceptual 'attractor', enabling different actors to develop their own interpretation and rationale of support. But since these framings may represent different views of reality, this may result in practical barriers when conceptual policy choices need to be translated into the functional design of flood management infrastructure.

We attribute the existence of various frames primarily to the increasing number of actors that has become involved in flood management in the Mekong. Environmentally concerned actors, including international donors, have flagged the negative long-term impacts of large scale engineering on the delta's environment, and raised concerns about the sustainability of the delta's subsequent development trajectory. They have been critical in stressing the need for water management concepts that are environmentally inclusive. 
Especially the MDP, sketching a 100-year future development horizon for the Mekong delta, argues that the current development trajectory characterized by full flood prevention is an unsustainable one. Instead, it proposes a different perspective on flood management which supports not only flood protection for built-up areas, but also stresses the potential environmental contributions of controlled seasonal flooding. We feel no solid claims can be made about the extent to which controlled flooding will be fully able to keep 'the engine running', as metaphorically expressed in the opening lines of this article, or to fundamentally reorient the existing development trajectory. Controlled flooding in the upper regions may be capable of addressing a number of challenges associated with unsustainable system trajectories, such as improving agricultural soils and providing water to protected wetland reserves, but at the same time it has its challenges. On a final note, while there is a broad support base for controlled flooding, the interest in eco-floods in the Mekong however does not exclude alternative policy avenues being explored pointing in the opposite direction. 


\section{Chapter 6. Conclusions and discussion}

\subsection{Introduction}

In this thesis I set out to explore controlled flooding initiatives in delta regions, driven by a limited understanding of how very similar initiatives can materialize in very different delta settings. In the introduction of this study the research questions were formulated as follows:

\section{Main research question (MRQ)}

How can the emergence of controlled flooding initiatives in different deltas be explained, and how do these initiatives affect the development trajectories of different deltas?

\section{Sub research questions}

I Which analytical framework of complex delta interaction can help to explain how deltas evolve over time?

II Which socio-political, environmental and technological factors have been critical for the emergence of controlled flooding initiatives in different deltas?

III What are the similarities and differences between controlled flooding initiatives in these three deltas? How can these similarities and differences be explained?

IV How have ideas about controlled flooding been incorporated in long-term delta management plans for these three deltas?

This chapter will summarize the findings to present answers to the main research question and four sub-research questions. Three case studies were conducted to shed light on the critical drivers underlying these contested policy plans or interventions: (1) the Noordwaard de-poldering project in the Netherlands (Chapter 3), (2) the emergence of Tidal River Management in Bangladesh (Chapter 4) and (3) plans for restored seasonal flooding in the Mekong delta (Chapter 5). Based on the collected case study information, the next section will answer RQ2, RQ3, RQ4 and the MRQ.

The findings are then discussed in relation with academic literature on the topic that this study touches upon. A separate section will provide reflexive comments on the employed analytical framework (Chapter 2), which connects to answering RQ1. The chapter closes with a short outlook concerning potential development of future controlled flooding initiatives. 


\subsection{Synthesis of results: case study findings}

This section synthesizes the case study findings of three controlled flooding initiatives located in different deltas. Section 6.2.1 goes into the findings by case study, answering RQ2. Italics highlight the findings in terms of social, technical and environmental factors. Section 6.2.2 presents a cross-case analysis, answering RQ3, and addresses key similarities and differences between the case findings. Section 6.2 .3 consists of a discussion about how ideas about controlled flooding have been incorporated in long-term delta plans, in response to RQ4. The main research question is being discussed in 6.2 .4 , by relating the findings from the controlled flooding initiatives with discussions about how to align delta trajectories with more sustainable development paths.

\subsubsection{Case study findings}

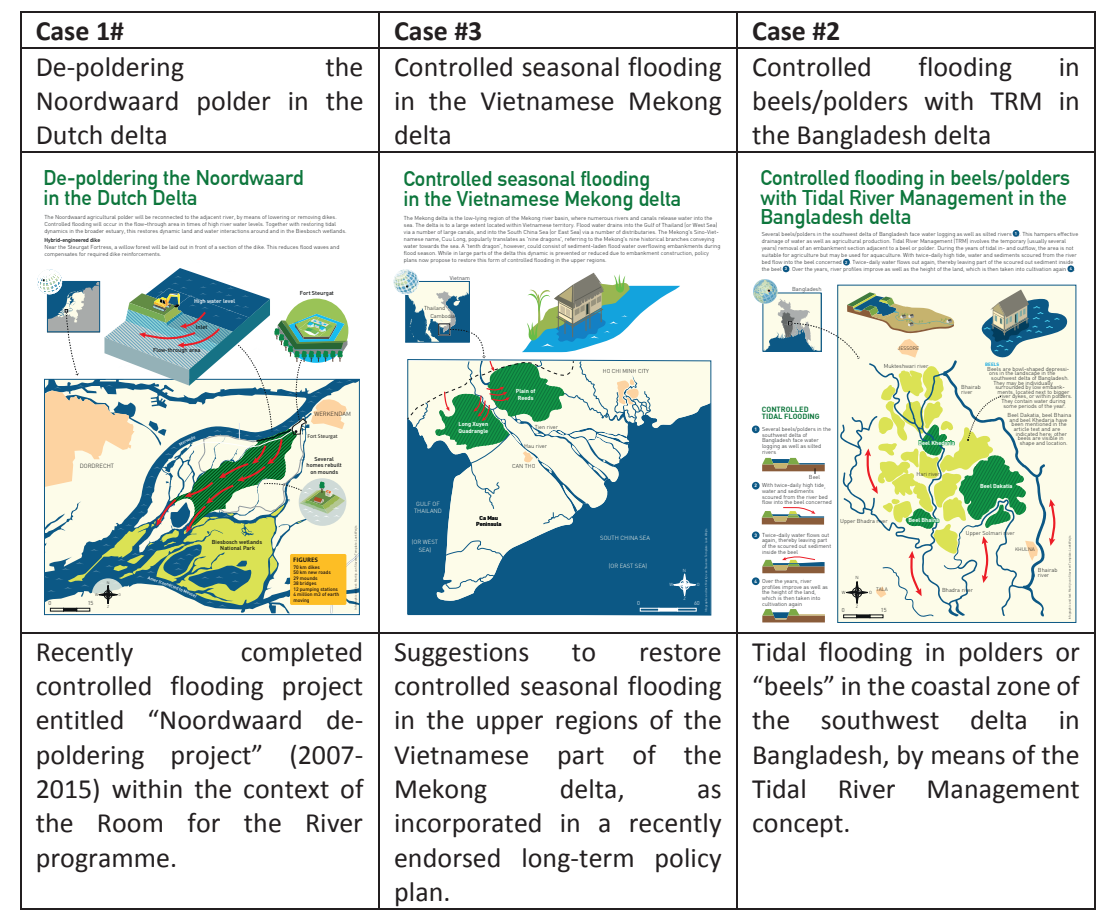

Table 3. Case summaries.

\section{Main findings Dutch case study}

The Noordwaard case study showed how de-poldering took shape in the Dutch delta. Located at a junction of tidal influence and riverine water discharge, the Noordwaard polder was made liable to controlled flooding in October 2015, when the northern river embankments of the 
agricultural polder were lowered (www.ruimtevoorderivier.nl/project/ontpolderingnoordwaard/, accessed June 2017).

While some de-poldering happened unintentionally in this area due to storms (St Elisabeth's flood in 1421, and submersion of the small polder "de Dood" in 1962), a de-poldering discourse was introduced in this area in the 1990s (Van Staveren et al., 2014). The Ministry of Agriculture, Nature and Fisheries (LNV) successfully proposed to de-polder 600 ha of agricultural land for the benefit of nature restoration and enlargement of the Biesbosch wetlands. This intervention acted as a stepping stone a few years later, when unexpected high water caused (near) flooding in the Dutch riverine areas in the mid-1990s, linking debates about flood risk with environmental considerations (Roth et al., 2006). The earlier de-poldering served as an argument for also de-poldering the larger Noordwaard polder (instead of other alternative areas): it was argued to concentrate de-poldering as much as possible, instead of flooding fragmented areas in the wider Biesbosch region (Schut et al., 2010). Such water flows were welcomed in the Biesbosch floodplains, since this also contributed to the (re)development of the wetland.

It would be difficult to predict which future would have unfolded without readily available visionary plans such as Plan Stork (De Bruijn et al., 1986), that presented visual future outlooks based on widened floodplains and nature restoration along the Dutch rivers. The existence of Plan Stork offered water policy makers an immediate answer to high water (and a shocked society) that occurred in the mid-1990s (De Jonge \& Van der Windt, 2007). It gave policy makers the opportunity to formulate a response that addressed environmental issues and flood risk concerns simultaneously (Roth et al., 2006). The subsequently formulated Room for the River programme presented a programmatic environment in which the de-poldering project was implemented.

From a technical point of view, the case study showed that controlled flooding ideas would necessitate new scientific analyses. With hydrologic modelling it was identified which areas within the Noordwaard polder would be liable to which water depth and how often this would occur, where a distinction was made between low-lying sub-polders with a higher flood frequency, and higher polders with a lower flood frequency (Projectbureau Noordwaard, 2010). It was also necessary to calculate the wave attenuating effect of a willow forest, which would make it justifiable to have a lower flood protective embankment in the northeastern part of the area, as there would have been without a forest (De Vries \& Dekker, 2009). 
Furthermore, it was calculated that the reduction in water levels upstream at centimeter scale. By doing so, the seemingly uncontrollability of restoring flooding in the area was met with a process of scientificalization, which means that developing detailed scientific information about water flows, sedimentation rates and structural designs were essential for policy makers to make a decision. This connects to earlier studies, arguing that Room for the River meant "room for the engineer" in both construction work and scientific investigations (Van Hemert, 1999). ${ }^{57}$

The Dutch society is often characterized as being based on negotiations and broad consent the word "polderen" as a verb has come to be indicative of elaborate discussions before a (preferably joint and widely agreed) decision is being made (Wiering \& Immink, 2006). In the early 2000s, so at the time that the first series of Room for the River plans was presented which included removal of embankment and de-poldering, policy makers were confronted by fierce local protests supported by retired water experts. Some of these plans were thereby quickly dropped (Roth et al., 2006). A few years later, the second series of proposals for controlled flooding initiatives in other areas were designed differently, consisting of extensive discussions and exchange of ideas with local inhabitants including de Noordwaard (Schut et al., 2010). These lengthy discussions and issues about representation led to tensions between polder inhabitants and project managers, and in turn to protests (Pleijte et al., 2005). In the end, it required the Vice-Minister of the Ministry of VenW, the Ministry responsible for Public Works and Water Management, to decide that the Noordwaard would be de-poldered, making an end to pending decisions (Min VenW, 2006a).

\section{Main findings Bangladesh case study}

The Bangladesh case study explored the emergence of what has become conceptually labelled as "Tidal River Management." It involves the temporary opening up of polder embankments, which can last up to seven years, by means of broad cuts in the embankment, in the southwest coastal zone of Bangladesh, which makes those areas liable to twice-daily tidal flooding. This scours the adjacent river beds and deposits large amounts of sediment on the opened-up lands.

Against a background of a series of hydraulic interventions to a large extent based on a "closing-off" paradigm, low-lying areas in Bangladesh's coastal zone started to be increasingly

\footnotetext{
${ }^{57}$ The Room for the River programme in itself was supported by extensive scientific studies, for example the "blokkendoos" or "box of bricks" model that could calculate the interrelated hydraulic effects of de-poldering and other measures in the riverine area (Schut et al., 2010).
} 
confronted with drainage problems in polders and silted up rivers (Nowreen et al., 2013). Regional NGOs increasingly challenged the engineered interventions that, according to them, had severely impacted the rural population in negative terms (S. Islam \& Kibria, 2006). They did not only support local communities but also encouraged protests against large scale engineered works, culminating into, as formulated by central water authorities, an illegal embankment breach in September 1990 (A. Rahman, 1995). While soon the TRM concept was considered to bring about positive effects, it took more than 10 years before it was institutionalized in a large water management programme (Van Staveren, Warner, et al., 2017).

The case study showed that the intensity of environmental dynamics in Bangladesh has been very important to demonstrate on a relatively short term scale the negative impacts of large scale engineered works in sediment-rich areas. In polders and beels, water logging hampered agricultural production, and sediments deposited within constrained river beds, since the floodplains could no longer be reached (Awal, 2014). The effects of sediment deposition, which in Bangladesh could be up to decimeters per year, materialized must faster than in for example the Dutch delta. This contributed to a quick aggravation of environmental problems, awareness and community "action" to take risky measures such as re-flooding the polders. The Bangladesh case study showed therefore that controlled flooding is not only about water but also about sediment management (Uttaran, 2013). This calls for a much broader understanding of how flood embankments function: they can be designed for flood prevention (keeping out) but for sediment intake (bringing in).

The technical system consists of polder embankments, sluice gates and other works that have increasingly been expanded in the region since the 1960s (Nowreen et al., 2013). The case study showed that consecutive projects have been physically built on top of, or rehabilitated earlier efforts. The Khulna-Jessore Drainage and Rehabilitation Project (BWDB, 2003) and lately the Coastal Embankment Improvement Project ${ }^{58}$ are exemplary of this. Rehabilitation is challenging because the dynamic muddy environment makes it difficult to stabilize river channels, embankments and smaller hydraulic works. Also, lack of maintenance often leaves hydraulic works in a deplorable state. The latest programmes (e.g. CEIP) have been formulated from the perspective to deal with potential climate change effects and cyclone disasters in

\footnotetext{
${ }^{58}$ See www.worldbank.org/projects/P128276/coastal-embankment-improvement-projectphase1ceip-1?lang=en; and for discussions www.scidev.net/south-asia/environment/news/bangladeshi-expertsdefendcoastal-dikes.html and www.newscientist.com/article/mg22229752.700-bangladeshs-sea-walls-maymake-floods-worse.html\#.VZvLCPmqpBd, all accessed January 2016.
} 
Bangladesh's coastal region. Two major cyclones (Sidr in 2007 and Aila in 2009) have reinforced the desire for flood protection among policy makers and funding institutes, now resulting in embankment strengthening efforts. ${ }^{59}$ Tidal River Management has been included as an element of a long-term policy plan targeting the southwest delta, but clearly within a context dominated by calls for flood prevention and climate change adaptation in the delta (Van Staveren, Warner, et al., 2017).

The TRM case showed that in Bangladesh not only a physical, but also a social opening up materialized, represented by the increasing number of stakeholders in and enforcement of Tidal River Management (Van Staveren, Warner, et al., 2017). Social movements in Bangladesh are quite powerful and their sudden push for TRM was felt strongly among hydrocrats in the capital Dhaka (S. Islam \& Kibria, 2006; Uttaran, 2011). While bottom-up initiative came with socio-political reasons among the side of the NGO community, calls for wider public participation were strong, pushing policy makers and researchers in Dhaka to take such voices seriously (Warner, 2010). At the same time this is no guarantee that stakeholder participation will be pursued in future flood management initiatives.

\section{Main findings Vietnam case study}

The Vietnamese case study focused on analyzing a number of long-term delta plans on their take on flooding in the Mekong delta. While the most recent plan clearly suggests restoring controlled seasonal flooding, it was found in the present study that earlier plans do make mention of such interventions but at the same time their flood policy is strongly based on ideas of flood prevention. This perspective is, however, liable to change, as extensive flooding contributed to new ideas along the policy lines of "Living with Floods," and the intensive rice production system faces long-term sustainability issues.

Environmental concerns have been central to proposing and supporting controlled flooding ideas. The intensive Vietnamese agricultural rice production system requires substantial artificial fertilizers, in order to compensate for reduced nutrient supply on widely embanked floodplains (K. V. Nguyen et al., 2015). Due to the absence of soil-flushing seasonal flooding, the acidity of the soil also becomes a problem (Tong, 2017). While large parts of the delta wetlands have been converted into agricultural area over the last decades, the absence of flooding also puts the last remaining wetland forests at risk: insufficient surface water impacts biodiversity and increases the likeliness of forest fires during summer season (V. X. Nguyen \&

\footnotetext{
${ }^{59}$ See footnote 58.
} 
Wyatt, 2006). Higher embankments upstream lead to higher peak discharges in areas further downstream, such as the city of Can Tho. Using flood retention zones in the upper regions could reduce this (Triet et al., 2017). Another environmental driver, a major flood in 2000, has been instrumental in stimulating further high-dyke construction, but at the same time initiated a Living with Floods paradigm (Truong, 2000).

The case study findings show that there are various framings of what restored controlled flooding entails. To highlight one example (see Chapter 5 for additional examples), for some policy makers it represents a technical, systemic water control measure, predominantly intended to divert flood peaks in order to safeguard downstream areas. Such a functionalist view on the effects of embankment lowering poses the risk that potential environmental benefits, which are multiple and diverse as outlined above, are superseded by water conveyance objectives alone. The technical dimension remains a challenge since flood dynamics are determined by complex water-related interactions in the upper Mekong basin. Upstream rainfall, the effect of water storage behind hydropower dams and the hydrologic connection with Ton Le Sap lake, seasonal peak flows and (sea level rise driven) tidal influences make it challenging to design the hydraulic infrastructure required to support the controlled intake of seasonal flood water (Hung et al., 2012; Tri, 2012).

The case study demonstrated how flood management policies have gradually evolved over time, by analyzing a number a comparable long-term delta policy plans. While earlier plans suggested to allocate some areas for flood retention or flood diversion, in the most recent plans, policy makers emphasized the agricultural and environmental benefits of controlled seasonal flooding (Van Staveren, Van Tatenhove, \& Warner, 2017). The plans were primarily formulated from a top-down perspective, related to the Vietnamese communist state form, and were heavily influenced by the recommendations provided by foreign water experts. Broader stakeholder participation processes, to provide input to such policy processes, have been conducted only to a little extent. It has now been proposed to experiment with or pilot controlled flooding, to test how the ideas are received. Finally, a Living with Floods policy discourse does not imply that this is also conducive for ideas about controlled flooding, since the policy has somewhat contradictory come with extensive embankment heightening (Käkönen, 2008). 


\subsubsection{Cross-case analysis}

The following sections reflect on and draw a number of conclusions based on the findings of the individual case studies. The findings are synthesized based on the three domains: social, environmental and/or technological factors, that have influenced the emergence of controlled flooding initiatives.

\section{Key similarities}

The investigated cases, all located in relatively flat, low-lying deltas, show that environmental dynamics were critical in stimulating ideas and attracting support for restored controlled flooding. These dynamics are in itself different for each delta (see next section) but its similarity lies at the level of how environmental dynamics "triggered" controlled flooding in practice or in relation to policy formulation processes. In the Netherlands, this was represented by (near) flooding, in Bangladesh by prolonged waterlogging and drainage problems, and in Vietnam via questioning the sustainability of intensive rice production and how upstream peak water discharge should be dealt with. While conceptual ideas regarding controlled flooding existed but did not materialize earlier (Kamal, 2006; Santbergen, 2015), the tangible manifestation (or intensification) of the aforementioned events or processes were instrumental in opening up discussions about new types of flood management interventions. This suggests that flood management paradigms and policy formulation processes are influenced by external pressures, formulated here as environmental dynamics. This is not to say that policy change does not happen incrementally, but to emphasize the direct influence of "real world problems" on opening up policy debates. In particular the intensity or speed of environmental dynamics, for example the peak amount of water that needs to be discharged through a delta's rivers, or high sediment deposition rates in a delta's coastal zone, contributes to problem aggravation and is critical in showing the downside of certain flood management approaches.

From the technological perspective, all cases strongly display the "science and technology" dimension of controlled flooding initiatives. This is because water policy makers and planners emphasize the need for a certain level of scientific justification, in order to engage in meaningful policy discussions about or implementation of controlled flooding measures. While early plans or initiatives, such as the community-driven embankment cutting in Bangladesh, were based on more tacit knowledge or general expectations, the institutionalization of controlled flooding necessitated scientific study in terms of hydromorphology and embankment design. In the Netherlands, this was a challenge since flood 
safety norms are incorporated in the law: before embankments could be lowered, it must be proven that the wave-attenuating effects of a compensating willow forest would be sufficient to deliver the same flood safety standard. Bangladesh's policy makers were only willing to institutionalize Tidal River Management in formal water management programmes, when the effectiveness of the intervention was sufficiently supported by scientific studies. The same is also the case for the Mekong delta, where the exact routing and timing of restored seasonal flooding first need to be explored, and pilots are prepared to test the effects on agriculture. Besides the apparent need for scientific justification, also in materialistic terms the initiatives display a need for engineered control. Where, when and how much water flows in, is decided by detailed intake structures designs, although there are obvious differences between the type of hydraulic engineering works in the Netherlands and the Asian deltas. Furthermore, the cases show that the materiality of hydraulic engineering works makes overnight change in policy approaches difficult (although, in the case of Bangladesh, it was exactly night time embankment cuttings that restored flooding in the past [Adnan, 2006]).

From a social system perspective, the investigated case studies show an increasing involvement of a wide( $r$ ) group of stakeholders in flood management. The growing influence of environmentalists and other professional actors in water management has been noted earlier (Disco, 2002; Pahl-Wostl, 2015). The investigated cases show that NGOs, local communities and international policy advisors (supporting flood management policy processes in the Asian deltas) had a strong influence in shaping the debate on controlled flooding. Spatial claims on lands, which is sparse in densely inhabited deltas and in use by farmers, fisher folk or shrimp producers, have sparked local contestation between proponents and antagonist of controlled flooding. This can be explained by water governance transitions: the central position of state hydrocracies and water experts is declining and other actors increasingly influence water management debates (Benedikter, 2013; Huitema \& Meijerink, 2009; Pahl-Wostl, 2015).

At the same time, the centralistic policy processes of long-term delta planning have been instrumental in discussing controlled flooding at the highest policy making levels. The longterm character of delta planning has made it possible to fundamentally question the longterm sustainability of flood management approaches, and created a legitimacy to discuss unconventional approaches. This has resulted in visible incorporation of controlled flooding ideas in the long-term delta plans for the three deltas (Delta Committee, 2008; Socialist Republic of Vietnam and the Kingdom of the Netherlands, 2013; Van Staveren, Warner, et al., 
2017). This does not imply that controlled flooding initiatives will be implemented, but that the topic is incorporated in strategic discussions about flood management policy and longterm delta management.

On a more general note, the controlled flooding cases presented in this thesis strongly connected to historic flood management practices: in the Netherlands, the link between controlled flooding and past flood retention or bypasses stands out (Warner, 2012), in Bangladesh, Tidal River Management bears resemblance to ancient overflow irrigation (Willcocks, 1930), and seasonal flooding in the Mekong delta during the pre-embankment period goes back for centuries (Ehlert, 2012). This resemblance has been revealed due to the historic perspective used in this study. Apparently, historic practices are inspirational and have value in addressing contemporary water management issues.

\section{Key differences}

In terms of environmental dynamics, the cases display differences. Although each case is located in similarly flat delta geographies, the magnitude and speed of change of water, erosion and sedimentation is different (see Table 1). This has resulted, for example in the case of Bangladesh, in much faster deposition of sediments, compared to the Dutch and Vietnamese settings. Extensive flooding in the Mekong (on a seasonal basis, and lasting for several months) takes place much more prominent than in the more "stable" Dutch delta. The manifestation of these environmental dynamics have contributed to the real world challenges, and urged action, to develop responses.

Another key difference is that the hydraulic infrastructure networks are different. The Dutch delta is a densely engineered environment, with major estuarine closure works, meticulously calculated and designed river embankments and smaller water works. This hydraulic density, consisting of works but also the institutional outreach of water management institutes, is also profound in the Mekong (Benedikter, 2013) but compared to the Netherlands less-engineered in physical terms. In Bangladesh major engineering works are found, but also large areas lack the network required to manage water in a detailed and structural way. This means that the technological lock-in of the hydraulic infrastructure is stronger in the Netherlands, compared to the other deltas.

The three cases differ in socio-institutional terms. Without trying to generalize too much, the Dutch society sees itself as more "consensus-based," which means that negotiation and aiming for broad consent in hydraulic engineering projects is usually pursued (but not always 
achieved) (Wiering \& Immink, 2006). In Bangladesh the rural population is characterized by social movements and central hydraulic institutes that do not reach field level everywhere ( $S$. Islam \& Kibria, 2006). In Vietnam the communist party state lays out a relatively top-down, planned economy to which farmers need to align (Huu, 2011). These and other socioinstitutional differences have not been analyzed at nation or full delta scale; rather this study has looked at the way flood management policy debates took shape, concerning the topic of controlled flooding, during which these specific differences surfaced. It appears from the case studies that socio-institutional differences have impacted the way the policy process of developing, implementing or incorporating controlled flooding ideas in policy plans, was organized, comparable to the "policy styles" concept (Knill \& Tosun, 2012).

In each case, policy issue linkage was observed, meaning that initiatives did not only touch upon flood management policies but also related to other domains. In the Mekong, the connection with improving agricultural production was prominently made, which was far less emphasized in the Netherlands: nature restoration and environmental quality were considered more important than improving existing agricultural practices. In Bangladesh, there was a strong link with river siltation management, as the deposition of sediment caused problems with transport and navigation. This has resulted in differences in the way the policy debates took shape, and in which stakeholders participated.

\subsubsection{Controlled flooding in long-term delta planning}

This section discusses how ideas about controlled flooding have been incorporated in longterm delta plans for the Netherlands, Bangladesh and Vietnamese Mekong delta, and thereby answers RQ4.

Each of the case study chapters makes reference to how controlled flooding ideas are included in long-term delta planning initiatives in the respective deltas. In the Netherlands, primarily the Room for the River programme (2005 - 2015) has been instrumental in implementing ideas for controlled flooding along Dutch rivers. It is difficult to say how this interest will evolve after the completion of the Room for the River programme. For the Noordwaard region, studies reveal future plans for increased controlled flooding restoration in areas located in the southwest part of the estuary (Deltaprogramma, 2012, p.61) and on land near the urban area of Dordrecht (Kelder et al., 2013). In the southwest delta of the Netherlands, there are several ongoing controlled flooding projects in which the intake of sediment is an element but not pursued per se (www.waterdunen.com/ and www.perkpolder.nl/, accessed June 2017). Following the introduction of new flood safety norms (as of January 2017) as recommended 
by the Dutch Delta Programme, the so-called High Water Protection Programme (www.hoogwaterbeschermingsprogramma.nl/-default.aspx, accessed June 2017) strengthens the flood prevention paradigm since hundreds of kilometers of embankment sections will need to be reinforced in order to comply with the new norms (Van Alphen, 2016). At the same time, this programme aims to develop innovative ways to deal with riverine or coastal flooding. In that sense it provides a programmatic environment in which environmentinclusive forms of flood management (see for example Kothuis \& Kok [2017]) could develop further.

By means of a TRM Master Plan, the Bangladesh Delta Plan 2100 has taken up Tidal River Management in discussions about the future the Bangladesh's southwest coastal zone, mainly from the perspective of polder rehabilitation or climate change adaptation (Van Staveren, Warner, et al., 2017). Local NGOs concern themselves about how to manage the delta's rivers in the coastal zone in more adaptive ways and applaud the potential of Tidal River Management (Uttaran, 2013). Currently there is one active Tidal River Management initiative in beel Pakhimara, just south of the Khulna-Jessore-Tala triangle, see Figure 7, (Gain et al., 2017). It has been noted that Tidal River Management is evolving conceptually due to social learning processes, which is of interest to adaptive delta management policies (Mutahara et al., 2017).

In the Mekong delta, the Vietnamese government and large international finance institutions have adopted the Mekong Delta Plan as a framework for long-term investment in the delta, and negotiate how to implement the Plan's recommendations (http://www.worldbank.org/en/news/press-release/2016/06/10/vietnam-building-climateresilience-and-ensuring-sustainable-livelihoods-of-farmers-in-the-mekong-delta, accessed June 2017). Small pilot projects have been proposed, but according to the scale of the recommended controlled seasonal flooding, it could affect a much larger area (Van Staveren, Van Tatenhove, et al., 2017).

What can be deducted from these findings is that conceptually, controlled flooding has found its way into long-term policy plans for the respective deltas. This has been driven by a mix of factors. Environmental dynamics have demonstrated some of the downsides of large-scale engineering, ecosystem-based approaches to flood management receive increased attention, and long-term policy processes have acted as a way to "open up" policy debates about longterm delta sustainability and an associated flood management strategy. At the same time, 
suggestions to restore controlled flooding are only minor elements in a context characterized by a dominant flood prevention paradigm. This makes it unclear whether controlled flooding will indeed be implemented. Controlled flooding initiatives are sometimes met by local protests, which presents a constraining factor for implementation (Warner, 2008a). On the other hand, it has been demonstrated that local action can stimulate controlled flooding, despite formal policy plans being absent (Van Staveren, Warner, et al., 2017).

Adaptive delta management has been a leading principle in recent long-term delta planning efforts in the Netherlands (Marchand \& Ludwig, 2014). It has been employed to assist longterm policy planners to develop the delta plans in Bangladesh and Vietnam. Adaptive delta management centers on adaptation and flexibility regarding future flood management challenges, which can be predicted in part but which also comes with uncertainties (Marchand \& Ludwig, 2014). It suggests a conceptual way of thinking in terms of pathways (Haasnoot, 2013). For such a policy environment, controlled flooding (embedded in a wider flood prevention strategy) might be a way to "build in" such adaptive capacities and realign unsustainable pathways. Its potential contribution in relation to long-term, adaptive delta management will be discussed in the next section.

\subsubsection{Controlled flooding and long-term delta trajectory realignment}

This section positions controlled flooding in relation to the development trajectories of the Dutch, Bangladesh and Vietnamese Mekong deltas. It discusses how controlled flooding could contribute to the realignment of unsustainable development trajectories, by addressing both institutional and environmental change or stability. In doing so it answers the $M R Q$, which was formulated as "How can the emergence of controlled flooding initiatives in different deltas be explained, and how do these initiatives affect the development trajectories of different deltas?"

\section{Explaining the emergence of controlled flooding}

This study has found that environmental dynamics have been critical to emphasize the potential of restoring controlled flooding, but that social and technological factors have been important factors (in both enabling and constraining ways) for controlled flooding initiatives to take shape. The previous sections on case study findings and a comparison in terms of similarities and differences, have provided a more elaborate explanation of this. 


\section{Long-term trajectory realignment}

To answer the second element of the MRQ, this section distilled a single, composite delta trajectory, which is more or less representative of, and based on, the trajectories of each of the delta central in this study. Instead of describing the trajectories for each of the deltas separately (see Chapters 2, 4 and 5 for this), the value of formulating a composite trajectory is that it provides a single response to the $M R Q$, and that this necessitates engagement with the synthesized case study findings based on Section 6.2.

For several decades, if not centuries, expanding hydraulic engineering networks and related water management institutions turned the deltas under review into highly engineered and managed environments: a delta trajectory that is based on large-scale flood control. Hydraulic institutes undertook successive cycles of embankment reinforcement to protect increasingly valuable and densely populated areas behind the embankments. This has resulted in technological lock-in and path dependency, in a physical and institutional way (Lach, Ingram, et al., 2005; Van Buuren et al., 2016). Even though long-term trends expose the water-related vulnerability of living in low-lying delta lands, lock-in and path dependency explain the difficulty to fundamentally change these engineered delta systems. Delta systems heading towards unsustainable system states may be realigned with more sustainable development paths, or reoriented towards more sustainable system states.

As mentioned in Section 1.3.1, different yardsticks, such as the effectiveness of current flood management policy extended over longer timescales, the question whether a certain flood management infrastructure network can handle future climate change effects, or the increasing difference between land height and sea level, can be employed to identify or theorize such forms of unsustainability. Realignment of delta trajectories means that a certain (inherited) development path is reoriented towards more sustainable conditions, and in this case the contribution of controlled flooding to such a reorientation is of specific interest. A sustainable system state is not static or an end goal to reach; working towards sustainability is in itself an evolutionary process (Rammel et al., 2007).

The rigidity of hydraulic engineering works and widely dominant paradigm of flood protection in deltas, means that the materialization of restored managed flooding requires gradual modifications to existing embankments, and conceptual turnover time. The next paragraph will adopt an infrastructural perspective, and a socio-institutional perspective, respectively, to discuss how controlled flooding, in its current form, affects the composite delta trajectory. 
From an infrastructural perspective, controlled flooding affects the delta trajectory by providing physical "room to maneuver" for water and tidal dynamics in delta rivers and coasts. The setback, modification or lowering of embankments provides the physical space to redistribute flood water over widened and reconnected floodplains. From the perspective of dealing with future flood risks resulting from climate change (which is argued to come with higher peak discharges) this is a contributive effect, but it remains to be seen whether this sufficiently addresses this challenge. The environmental effects of restored flooding are strongly related to the location and the infrastructural design of controlled flooding initiatives. Taking the unsustainability of an ever-growing difference between land height and sea level as a point of departure (Gerrits \& Marks, 2008), controlled flooding could partially address this point by purposefully capturing the sediment that results from restored (tidal) flood dynamics on delta lands, and raising the height of the land. The thesis shows, however, that there are different views of controlled flooding-induced sedimentation, ranging from unwanted in the Dutch case (Van Staveren et al., 2014) to beneficial in Bangladesh (Van Staveren, Warner, et al., 2017). At the same time Auerbach et al. (2015) rightfully note that Tidal River Management takes place on less than $1 \%$ of the surface area of the southwest delta of Bangladesh. Depoldering in the Netherlands amounts to a similar percentage, while only in the Mekong a larger surface area will become affected. Altogether, the contribution of controlled flooding, in its current form, to address the particular point of land heightening is therefore limited.

From a socio-institutional perspective, controlled flooding represents a relatively minor change in flood management policy, because it is embedded in a context dominated by flood prevention. It therefore represents a niche-development or niche-innovation, which means that it is a local and often radical intervention, that can be considered a (new) element in a broader policy landscape (Geels \& Schot, 2007). Its influence on realigning a delta trajectory is therefore limited, with only a regionally distinct effect in most cases. At the same time, small-scale water innovations have the capacity to open up new development trajectories (Enfors, 2013). If controlled flooding projects successfully address the problems that stimulated their implementation in the first place, they might reach higher-level policy debates at landscape level, and serve as exemplars for other areas dealing with similar challenges. The contribution to reorienting a trajectory of full flood prevention, deemed unsustainable, lies in its potential to provide alternatives for (or additions to) rigid approaches, as well as its suitability with adaptive delta management policies. 


\subsection{Discussion}

This section presents a general discussion, positioning the findings of this study in relation to the literature. It reflects on the use of the conceptual framework (in connection with RQ1), the academic contribution of the thesis, and future outlook regarding the controlled flooding topic.

\subsubsection{Engagement with the literature}

This thesis adds to three bodies of academic scholarship. The first body of literature centers on flood risk management. The study relates to observations about paradigmatic changes in flood risk management. The second body of literature can be classified as "delta research." To this, the study adds new empirical material on a specific topic, which is relevant for also other than the investigated deltas. Finally, the study adds with management ideas to a third body of literature, that focusses on the analysis and management of complex adaptive systems.

This thesis primarily contributes to on-going scientific debates about flood risk management. Since flood management in deltas is and will be a huge future challenge (Hallegatte et al., 2013; Tessler et al., 2015), the present research suggests that adaptive and flexible flood management responses, both in policy and in material terms, are more capable of addressing this challenge than conventional flood protection measures (Borsje et al., 2011; Kothuis \& Kok, 2017; Schanze, 2012). Such proposals are intertwined with calls for change in flood management paradigms. There is a broad consensus that shifts from full flood protection to flood risk management strategies have occurred in policy circles (Pahl-Wostl et al., 2011; Waylen, Holstead, Colley, \& Hopkins, 2017). Flood risk management interventions can consist of flood prevention infrastructure, but also incorporate spatial planning measures and other ways to reduce flood risks. At the same time, it has been argued that this shift happened only "partially": change on institutional and governance level does not necessarily result in fundamental change at the level of project design or implementation (Thomas \& Knüppe, 2016; Wesselink et al., 2015; Wiering \& Arts, 2006).

The chapters in this thesis contribute to this debate in a number of ways. Controlled flooding in itself is regarded as a proxy of a flood risk management paradigm shift. By means of the pendulum swing metaphor, change in flood management policies is most explicitly demonstrated in the Bangladesh case study. But also the cases in the Netherlands and Vietnam confirm a partial shift, as controlled flooding initiatives represent a different or even radical approach towards flooding, positioned in a context characterized by a dominant flood prevention approach. The dominance of flood prevention thinking can be justified, 
considering that extensive flooding in densely populated deltas leads to socio-economic catastrophes. This triggers a fundamental "baseline" of flood control to provide flood protection in deltas (Tessler et al., 2015). This features most prominently in the case of the Dutch and Vietnamese Mekong deltas, where controlled flooding is intended to re-route peak water flows, but also Tidal River Management in Bangladesh, as it contributes to reducing regional flood risks by reshaping silted-up river beds. Controlled flooding is therefore not representative of a full paradigm shift, but instead found to be an element of an overall "systemic" flood risk management strategy.

Paradigm shifts in flood risk management are partly constituted by an interest in "greener" or ecosystem-based forms flood management (see section 1.2.3 and in particular Pahl-Wostl et al., [2011] and Wesselink et al., [2016]). Ecosystem-based approaches have been argued to present alternative options to gray or hard infrastructure, and even can go hand in hand with flood prevention strategies (Borsje et al., 2011). In the literature, the incorporation of this ecosystem-based rationale with existing engineering works can be seen as an ecotechnological add-on (Geels \& Schot, 2007; Van Staveren \& Van Tatenhove, 2016) or hybrid forms of infrastructure (Borsje et al., 2011). This combination of hydraulic engineering with ecosystemic considerations is often presented as a way to deal with future water and flood management challenges (Renaud, Sudmeier-Rieux, et al., 2013; Van Loon-Steensma et al., 2014; Van Wesenbeeck et al., 2014). At the same time, however, a growing interest in large scale hydraulic engineering has been noted recently, seemingly unswayed by the ecological turn which suggests a "swing back" towards full flood control (Crow-Miller, Webber, \& Molle, 2017; Disco, 2002).

The study highlighted that controlled flooding clearly rides this wave. Each conducted case study notes how ecosystems dynamics were an element in controlled flooding initiatives: in the case of Bangladesh, for example, tidal dynamics of TRM make rivers navigable again by redistributing the sediment from the river beds to the beels. At the same time such ecosystembased rationales are not always explicitly mentioned or equally supported by all actors involved. It can therefore be argued that there are different gradations when it comes to defining the way controlled flooding initiatives purposefully incorporate environmental dynamics (see Appendix A) Controlled flooding thereby represents a partial paradigm shift in that it offers a different perspective on flood and ecosystem dynamics, and that it suggests a way to reconcile flood control objectives with objectives to improve ecosystem dynamics. 
The above has raised the question to which extent controlled flooding signifies a more structural change in thinking about flooding in deltas, besides its earlier characterization as a niche-development. Relating back to Figure 2 is helpful here, since this figure discusses the point that moderately controlled flooding can be beneficial. Although it is a radical measure to bring back flooding instead of fully preventing it, the cases have suggested that restoring moderate flooding, even taking place in densely populated deltas, is possible as long as there is a certain level of control in scientific as well as engineering terms. This does not differ much from conventional paradigms of flood control. The investigated controlled flooding initiatives have not really been put to the test yet. Future flood dynamics in the designated areas will show whether controlled flooding addresses the concerns for which the interventions were done in the first place. When this is the case, it can be assessed whether the intervention can generate continued support from various stakeholders involved (flood managers, spatial planners, environmentally concerned actors, inhabitants of the region concerned).

To the literature on flood risk management, this study adds an argument for a more strategic perspective on flooding. Despite attention to integrated perspectives on flood management, which advocate the environmental benefits of flooding (APFM, 2009), most flood risk management literature mostly understands flooding in a rather one-dimensional way: as a threat, or as an environmental "disservice." But recent literature has argued that flooding also comes with environmental benefits (Ehlert, 2012; Nikula, 2008). Besides emphasizing the direct hydraulic capacities of controlled flooding, controlled moderate flooding could also contribute to the agricultural production system, or to a resilient delta system or nature development in deltas in general. Taken a step further, a more strategic perspective on controlled flooding and intentional sediment intake informs discussions about increasing land height and long-term delta survival (De Mesel, Ysebaert, \& Tangelder, 2013; Van Staveren et al., 2014).

This thesis adds to the domain of delta-oriented research. Literature on flood management paradigm shifts and delta-oriented research literature partly overlap since flood risk management in deltas is a key challenge. Academic interests in delta geographies goes way back (UNESCO, 1966), but especially during the last 10 years has received a more "deltafocused" attention. Deltas have been interesting objects for multidisciplinary research (Collins, 2015). ${ }^{60}$ In part due to a simplistic assumption that all deltas are similar (Zegwaard,

\footnotetext{
${ }^{60}$ See http://arkreview.org/, the first academic Journal of Delta Studies (since 1998). Accessed June 2017.
} 
2016), comparative delta research with a focus on flood risk management has stood out in many research endeavors (Bucx et al., 2014; IWR, 2011; Van der Most et al., 2009). Such research found similarities as well as differences between deltas, but this often remains at an abstract delta or nation scale. The particular value of this thesis is that it compares in a detailed way a similar topical case, controlled flooding, embedded in different delta settings. It shows that learning and insights are not only one-way, but that insights from, for example, Bangladesh can be useful for the Netherlands as well (see Section 6.3.4).

Third, this thesis builds on and contributes to the literature on the management of complex, adaptive systems. This literature is primarily concerned with how stability and change occurs in human-environment systems, characterized by complex interaction between different variables. The contribution here is twofold. As a first contribution, the study confirms that human-environment interactions are highly dynamic, with a mutually reciprocal relations that are difficult to disentangle (Gerrits, 2008). Forces of stability and change can come from various "directions" and come with unexpected developments and uncertainty (Frantzeskaki et al., 2016). In particular, the thesis aligns with observations that the physical system heavily, and sometimes more than explicitly acknowledged, influences policy processes. Gerrits (2008, p.204) argues that "...the physical system and the societal environment govern the policy action system rather than the other way around. This challenges the idea that administrators and engineers are decisive in determining the course of the physical system through the attractor basin, i.e. that they are able to fully control the environment they are working in." The intensity of environmental processes, such as flood events or extreme river siltation as identified in the individual case study chapters, exposes the vulnerability of delta inhabitants to living on flood-prone land. As a second contribution, on multiple occasions the thesis has noted path dependency and institutional lock-in mechanisms encountered in water management in complex delta systems. But simultaneously, it discusses how controlled flooding could address this inertia in institutional and physical terms.

\subsubsection{Reflection on the conceptual framework}

In this thesis a social-ecological-technological conceptualization of delta systems has been developed to analyze co-evolutionary development paths, or delta trajectories, of several deltas (Renaud, Syvitski, et al., 2013; Van Staveren \& Van Tatenhove, 2016). Developing this framework is the primary answer to RQ1. This section presents some reflections on the use of the framework. 
A first remark concerning the use of this framework is about systemic abstraction versus systemic specificity. The adopted approach has emphasized interaction between different (relatively open and interconnected) systems (Alessa et al., 2009; Dammers et al., 2013). As a consequence, "internal" dynamics within individual systems have received less attention. Academic disciplines such as policy analysis explore in a much more detailed way how the policy process takes shape, primarily as a social process, influenced by internal and exterior drivers. Various theoretical models and frameworks exist, which can be employed to analyze the dynamics of policy formulation (Thissen \& Walker, 2013). These kinds of analyses go into the details of, for example, changes in policy discourses and the formation of discourse coalitions, dealing with uncertainties regarding policy formulation, and multi-actor policy processes (Hermans \& Thissen, 2009). These theories are well capable of explaining how formal policy change occurs, but in turn, are less specific about how environmental dynamics and technological factors shape policy stability and change directly.

What the use of the framework, and the case study analysis, has highlighted in this regard is that institutional change in the flood management domain can come from various directions. From an institutional perspective, radical change in flood management can be enforced from both top-down as well as bottom-up directions. Whereas it has been possible to identify that, in the case of the Netherlands, there are individual actors that have made a case for controlled flooding and river widening (De Bruijn et al., 1986; Saeijs, 2008), the investigated controlled flooding cases mainly showed that it is typically a broad network of actors, ranging from flood managers to spatial planners, environmentally concerned actors and local residents, that have collectively shaped controlled flooding initiatives. This relates to observations that policy and decision making in flood management has in general become much more complex, with a variety of new stakeholders having (or claiming) a position in the debate. Controlled flooding thereby served as a way to bring together different stakeholders with interests and ideas that aligned to each other, although at the same time there were also negatively affected actors and conflicts about the measure.

The added value of the employed framework lies in emphasizing technological systems dynamics, in relation to environmental dynamics and social processes. While the relevance of, for example, technological aspects in relation with societal dynamics has been noted much earlier (Larkin, 2013; Pinch \& Bijker, 1984; Woolgar, 1991), the used framework reinforces calls for awareness about how (past) technological choices shape social-ecological dynamics. This constitutes a continued interest in studying (large-scale) water management 
infrastructure (Carse, 2012; Crow-Miller et al., 2017) but also the ways in which flood management concepts and technologies are exchanged on a global scale (Bergsma, 2017; Conca, 2005; Stoutjesdijk, 1982). The case study findings show that this perspective has in particular highlighted technological factors exerting influence on how delta systems evolve; insights that would probably have gone unnoticed when adopting, for example, socialecological systems perspectives alone.

The delta trajectory concept has been introduced to describe how delta systems evolve over time. Informed by related concepts of "adaptive policy pathways" (Haasnoot, 2013) and "river basin trajectories" (Molle, 2003; Molle \& Wester, 2009), the concept is concerned with how deltas develop towards the future. But because of its historic perspective, to a large extent instigated by the contemporary effects of hydraulic engineering interventions constructed decades ago, it has a much wider temporal scope: the delta trajectory concept enables an analysis that is rooted in history and acknowledges that past interventions have a long-lasting impact on how delta futures unfold. Flooding, or the absence of flooding, enabled or constrained by hydraulic engineering works, have been allocated a central role in this. Furthermore, compared to the approaches mentioned above, the delta trajectory approach foregrounds long-term flood safety in deltas in combination with environmental sustainability.

\subsubsection{Contribution of the research}

This section discusses the general contribution of this thesis to academic scholarship.

First, this thesis builds on and adds to literature on flood risk management and delta systems analysis. The case study findings are related to debates about changing paradigms about flood risk management. They show that flood risk management has changed, to an extent influenced by new conceptual approaches that have a different take on environmental delta dynamics. Increased attention is being paid to ecosystems dynamics and ecosystem-based flood management concepts, but such approaches are not automatically translated into practice and take shape within a context dominated by large scale engineered flood control (Crow-Miller et al., 2017; Wesselink et al., 2015). Such investigations remain relevant, especially because it has recently been noted that an interest in large scale water infrastructure has taken shape (Crow-Miller et al., 2017). Chapter 2 has developed and used the concept of delta trajectories, which is based on a systemic understanding of deltas as interacting social-ecological-technological systems. 
Second, by means of detailed investigations of controlled flooding initiatives, the study brings together detailed empirical material from three different delta settings. Part of such material has not earlier been analyzed with the objective of the individual chapter in mind (Chapter 5). Chapter 3 concerns a contemporary case that has so far received little attention from academic scholars (Schut et al., 2010). Chapter 4 brings together a number of rather fragmented studies on Tidal River Management, against a background of not easily accessible but relevant historic material.

Finally, the study in itself is a contribution to comparative research. Comparing insights from different cases has yielded insights in case-specific circumstances, but also made it possible to formulate a number of more generalizable findings. For example, the observation that (different) environmental dynamics importantly influenced the emergence of controlled flooding initiatives, stands out. But also that controlled flooding initiatives are likely to lead to local contestation, due to spatial claims on lands that area already fully occupied. The comparative approach has also illustrated that lessons learned in one delta can be useful for other deltas.

\subsubsection{Future outlook: towards strategic controlled flooding in deltas?}

This thesis has explored contemporary controlled flooding initiatives, and has positioned them in relation to long-term delta developments and policy formulation processes. While longterm policies have incorporated ideas about controlled flooding, it is difficult to predict whether this would indeed materialize into new controlled flooding projects, as anything related to future developments comes with uncertainties. However, as controlled flooding in de-poldered areas has been said to be the logical consequence of impoldering (Santbergen, 2015), it can be argued that in many impoldered parts of the world, restored controlled flooding will materialize in the future. The global distribution of controlled flooding initiatives, as shown in the introduction, so far support this expectation.

The case studies but also other studies (Warner, 2008a) have shown that restored controlled flooding projects can cause (local) contestation and fierce conflicts between antagonist and proponents. It is therefore relevant to involve local inhabitants of the region concerned, in such drastic measures. In densely populated delta areas space is scarce, and land targeted for controlled flooding often in use by farmers, fisher folk or shrimp producers. The case studies showed that contestation over projects is likely to be expected, since it radically impacts existing livelihoods and agricultural production systems. 
The concept is promising in the sense that it reconciles ecosystem-based perspectives on water management in deltas with institutionalized flood control approaches. Similarly, it allows for a certain degree of infrastructural flexibility because of the physical modifications to embankments, which is also advocated via calls for flexible, multifunctional flood management infrastructure (Kothuis \& Kok, 2017). In this sense controlled flooding suits adaptive policies for flood management in deltas, since it brings in conceptual and physical "room to manoeuver" for future flood peaks.

The development of controlled flooding is on-going. Findings from Bangladesh, for example, indicate that the intake of sediment intake has not been pursued from the start of Tidal River Management, but that it became a specific objective in later TRM projects once its usefulness came to be acknowledged (Mutahara et al., 2017). This resembles perspectives on capturing sediment in delta polders for heightening land (De Mesel et al., 2013; Stroeken \& Van Winden, 2009) but which go much slower in the Netherlands compared to Bangladesh. Such a strategic view on using currents and erosion processes to contribute to long-term flood risk management has materialized in the field of coastal engineering (Borsje et al., 2011), but a strategic perspective on controlled flooding and associated sedimentation intake has not yet been in evidence. A strategic perspective in this sense means that flood management promotes or takes advantage of environmental opportunities (Sayers et al., 2015).

This thesis has investigated how the absence and presence of flooding impacts delta development trajectories. If deltas without flooding are not deltas at all (N. Islam, 1990; Steenhuis, 2007), many flood-deprived deltas face a severe "identity crisis." Subsequently, the way to give deltas their identity back is by reconsidering the long-term flood dynamics and sedimentation processes, that gave shape to those deltas in the first place. 
$140 \mid$ 


\section{Summary}

This thesis investigates contested initiatives to restore controlled flooding in the deltas of the Dutch, Bangladesh and Vietnamese (Mekong) deltas. Restoring controlled flooding is a seemingly contradictory measure in densely populated delta areas, where approaches based on full flood prevention has been typically dominant for decades. This has instigated the question how the emergence of restored controlled flooding initiatives can be explained. Related, this study reflects on how controlled flooding could contribute to long-term flood risk management and sustainable development in deltas, which are simultaneously attractive and vulnerable places for humans to live in. In order to answer this question, a case study approach has been used to investigate social, environmental and technological factors that have shaped controlled flooding initiatives. Cases have been identified that materialized under different conditions: from very dynamic delta environments to relatively stable ones, and from interventions driven by "top-down" policies to "bottom-up" action to modify or remove embankments. This thesis has an article-based structure, which means that individual chapters (2-5) have been designed for publication with peer reviewed academic journals. Chapter 1 provides the general background information, problem definition, and objectives. Chapter 6 ties together the findings of the individual case study chapters and presents the conclusions.

Chapter 2 conceptualizes deltas as interacting social-ecological-technological systems. It argues that a better understanding of how hydraulic infrastructure influences social processes and environmental dynamics in deltas is critical to understand how deltas evolve over time. By means of the delta trajectories concept, the chapter presents a way to understand this interaction. It also presents a way to understand the sustainability of a delta trajectory, and discusses how new flood management concepts might contribute to "realigning" the development trajectory towards more sustainable system states.

In Chapter 3, the first controlled flooding case is investigated. The Noordwaard is an agricultural polder, located at the junction of tides and riverine discharge in the Netherlands. As part of the Room for the River programme, the northern embankments were lowered which enables the inflow of water during high water levels in the river Merwede. This reduces peak water levels in the river, supports the adjacent freshwater Biesbosch wetland by means of restored water dynamics, but also affects the possibilities for agricultural production. The chapter highlights that a strong coupling can be observed between the domains of water 
safety and nature development objectives, and that a top-down decision concluded a long stakeholder negotiation processes. From the perspective of "subsiding polder lands," controlled flooding is not regarded for its strategic importance, as excessive sedimentation would hamper the intended design discharge of the area.

Chapter 4 explores the Tidal River Management concept. In the coastal zone of Bangladesh, community-enforced embankment breaches have opened up some of the polders or low-lying areas called "beels," and exposed them to tidal influence again. Besides stimulating agricultural production and providing safer places to live in, the extensive network of polder embankments also caused increased sedimentation in the region's rivers, and water logging in enclosed areas due to insufficient drainage possibilities. The chapter highlights that policy debates in Bangladesh have revolved around adopting "open" or "closed" approaches, where TRM represents a hybrid form. The case showed that TRM involves water management and sediment management, and that it represented a "social opening up" for local communities and NGOs to get involved with water projects and embankment removal.

Plans to restore seasonal flooding in the Mekong delta are center stage in Chapter 5. The Mekong delta system is very dynamic and dealing with the delta's water resources, in connection with intensive rice production, have been heavily debated by Vietnamese and international policy makers. This chapter investigates a number of older and more recent longterm development plans for the Mekong delta. This analysis highlights how ideas about controlled flooding and flood control have gradually evolved over time. The most recent delta management plan suggests to restore seasonal flooding in some parts of the delta, as a way to safeguard downstream urban areas from peak flows, and as a way to improve the conditions for agricultural production.

Chapter 6 summarizes the findings of the case study chapters one by one, and concisely answers the research questions. It highlights key similarities and differences when it comes to social, environmental and technological dimensions, and discusses these findings with the literature on flood risk management policy, complex adaptive systems research, and delta studies. The findings demonstrate that environmental dynamics have been critical to emphasize the potential of restoring controlled flooding, but that social and technological factors have been important enablers or constrainers for controlled flooding initiatives to take shape. In itself, controlled flooding reconciles ecosystem-based ideas about flood management with more mainstream policies based on flood control. For this reason 
controlled flooding can be seen as a "niche-development" with limited influence on how flood management policies, and environmental delta systems, evolve. At the same time, controlled flooding has been acknowledged for its strategic opportunities, for example when it comes to diverting peak water discharges, land heightening by means of capturing suspended sediment, and by providing nutrient for agricultural. This offers opportunities for further thinking about and conceptual development of controlled flooding. 


\section{Bibliography}

ADB. (2004). Project Completion Report on the Khulna-Jessore Drainage Rehabilitation Project. Dhaka: Author.

Addams-Williams, C. (1919). History of the Rivers in the Gangetic delta 1750-1918. Calcutta \& Dhaka: Bengal Secretariat Press.

Adnan, S. (1992). People's participation, NGOs, and the Flood Action Plan: an independent review. Dhaka: Research \& Advisory Services.

Adnan, S. (2006). Explaining the retreat from flood control in the Ganges-Brahmaputra-Meghna delta of Bangladesh. Hérodote. Menaces Sur Les Deltas, 2, 95-118.

Ahmed, S. (2013). Integrated water resources management: from policy to practice through an comprehensive national water management plan. In A. Prakash, S. Singh, C. G. Goodrich, \& S. Janakarajan (Eds.), Water resources policies in southeast Asia (pp. 115-133). New Delhi: Routledge.

Alessa, L., Kliskey, A., \& Altaweel, M. (2009). Toward a typology for social-ecological systems. Sustainability: Science, Practice, \& Policy, 5(1), 31-41.

Ali, M. L. (2002). An Integrated Approach for the Improvement of Flood Control and drainage schemes in the coastal belt of Bangladesh. Wageningen University, PhD thesis.

Anderies, J. M., Janssen, M. A., \& Ostrom, E. (2004). A framework to analyze the robustness of socialecological systems from an institutional perspective. Ecology and Society, 9(1), 18. Retrieved from http://www.ecologyandsociety.org/vol9/iss1/art18/

Anvarifar, F., Zevenbergen, C., Thissen, W., \& Islam, T. (2016). Understanding flexibility for multifunctional flood defences: A conceptual framework. Journal of Water and Climate Change, 7(3), 467-484. http://doi.org/10.2166/wcc.2016.064

APFM. (2009). Integrated Flood Management. Concept paper. Geneva: WMO.

Arthington, A. H., Bunn, S. E., Poff, N. L., \& Naiman, R. J. (2006). The challenge of providing environmental flow rules to sustain river ecosystems. Ecological Applications, 16(4), 1311-1318. http://doi.org/10.1890/1051-0761(2006)016[1311:TCOPEF]2.0.CO;2

Auerbach, L. W., Goodbred, S. L., Mondal, D. R., Wilson, C. A., Ahmed, K. R., Roy, K., ... Ackerly, B. A. (2015). Reply to "Tidal river management in Bangladesh." Nature Climate Change, 5, 492-493. http://doi.org/10.1038/nclimate2620

Awal, M. (2014). Water logging in south-western coastal region of Bangladesh: local adaptation and policy options. Science Postprint, 1(1). http://doi.org/10.14340/spp.2014.12A0001

Bandyopadhyay, J. (2009). Water, ecosystems and society. New Delhi: Sage Publications.

Barry, J. M. (1998). Rising Tide: The Great Mississippi Flood of 1927 and How It Changed America. New York: Simon \& Schuster.

Bates, M. E., \& Lund, J. R. (2013). Delta subsidence reversal, levee failure, and aquatic habitat - A cautionary tale. San Francisco Estuary and Watershed Science. Retrieved from https://escholarship.org/uc/item/9pp3n639

Bayley, P. (1991). The flood pulse advantage and the restoration of river-floodplain systems. Regulated Rivers: Research \& Management, 6, 75-86. http://doi.org/10.1002/rrr.3450060203/abstract

Becker, G., Huitema, D., \& Aerts, J. C. J. H. (2015). Prescriptions for adaptive comanagement: the case of flood management in the German Rhine basin. Ecology and Society, 20(3), 1. Retrieved from http://www.ecologyandsociety.org/vol20/iss3/art1/

Begum, U. K. M. (2011). Modernization, vulnerability and climate change in the southwest Bangladesh. University of Arizona, PhD thesis.

Benedikter, S. (2013). The Vietnamese hydrocracy and the Mekong delta. Water resources development from state socialism to bureacratic capitalism. ZEF Development Studies (Vol. 25). Münster: LIT Verlag.

Bentley, C. A. (1925). Malaria and agriculture in Bengal: How to reduce malaria in Bengal by irrigation. Calcutta: Government of Bengal. 
Bergsma, E. (2017). From flood safety to risk management. The rise and demise of engineers in the Netherlands and the United States? University of Amsterdam, PhD thesis.

Berkes, F., Colding, J., \& Folke, C. (Eds.). (2008). Navigating social-ecological systems: Building resilience for complexity and change. Cambridge, UK: Cambridge University Press.

Berkes, F., Folke, C., \& Colding, J. (Eds.). (2000). Linking social and ecological systems: Management practices and social mechanisms for building resilience. Cambridge, UK: Cambridge University Press.

Bhattacharyya, K. (2011). The Lower Damodar River, India. Understanding the Human Role in Changing Fluvial Environment. Dordrecht Heidelberg London New York: Springer.

Biesbosch National Park Authority. (2004). Management and Layout Plan. 's-Hertogenbosch.

Biggs, D. A. (2010). Quagmire. Nation-building and nature in the Mekong Delta. Seattle: University of Washington Press.

Biggs, D. A., Miller, F., Chu Thai, H., \& Molle, F. (2009). The delta machine: water management in the Vietnamese Mekong Delta in historical and contemporary perspectives. In F. Molle, T. Foran, \& M. Kakonen (Eds.), Contested waterscapes in the Mekong region: hydropower, livelihoods and governance (pp. 203-225). London: Earthscan.

Bijker, W. E. (2002). The Oosterschelde storm surge barrier: a test case for Dutch water technology, management, and politics. Technology and Culture, 43(3), 569-584. http://doi.org/10.1353/tech.2002.0104

Bijker, W. E. (2007). Dikes and Dams, Thick with Politics. Isis, 98(1), 109-123. http://doi.org/10.1086/512835

Bijker, W. E., Hughes, T. P., \& Pinch, T. (Eds.). (1987). The Social Construction of Technological Systems. Cambridge MA \& London: MIT Press.

Blackbourn, D. (1997). The Conquest of Nature: Water, Landscape, and the Making of Modern Germany. New York \& London: W.W. Norton \& Company Inc.

Borsje, B. W., van Wesenbeeck, B. K., Dekker, F., Paalvast, P., Bouma, T. J., van Katwijk, M. M., \& de Vries, M. B. (2011). How ecological engineering can serve in coastal protection. Ecological Engineering, 37(1), 113-122. http://doi.org/10.1016/j.ecoleng.2010.11.027

Bosch Slabbers, Van de Goor, L., Lagendijk, O., \& Rijsdorp, R. (2005). Noordwaard. Ontwerpen met cultuurhistorie. Arnhem.

Brabants Dagblad. (2002). "Noordwaard afstaan aan water" - prijsgeven landbouwgebied in Biesbosch houdt groene rivier Altena mogelijk buiten deur.

Brammer, H. (2010). After the Bangladesh Flood Action Plan: Looking to the future. Environmental Hazards-Human and Policy Dimensions, 9(1), 118-130. http://doi.org/10.3763/ehaz.2010.SI01

Brammer, H. (2014). Bangladesh's dynamic coastal regions and sea-level rise. Climate Risk Management, 1, 51-62. http://doi.org/10.1016/j.crm.2013.10.001

Brocheux, P. (1995). The Mekong Delta: ecology, economy, and revolution, 1860-1960. Michigan: University of Michigan.

Brugnach, M., Dewulf, A., Pahl-Wostl, C., \& Taillieu, T. (2008). Toward a relational concept of uncertainty: About knowing too little, knowing too differently, and accepting not to know. Ecology and Society, 13(2), 30. Retrieved from https://www.ecologyandsociety.org/vol13/iss2/art30/

Bubeck, P., Kreibisch, H., Penning-Rowsell, E. C., Botzen, W. J. W., de Moel, H., \& Klijn, F. (2013). Explaining differences in flood management approaches in Europe and the USA: A comparative analysis. In F. Klijn \& T. Schweckendiek (Eds.), Comprehensive Flood Risk Management (pp. 11991209). London: Taylor \& Francis Group.

Bucx, T., Van Driel, W., De Boer, H., Graas, S., Langenberg, V., Marchand, M., \& Van de Guchte, C. (2014). Comparative assessment of the vulnerability and resilience of deltas. Extended version with 14 deltas. Synthesis report. Wageningen: Delta Alliance.

Bureau Benedenrivieren. (2004). Benedenrivieren in Samenhang: stand van zaken regionale voorkeuren Ruimte voor de Rivier. Rotterdam.

BWDB. (2003). KJDRP. Monitoring and Integration of the Environmental and Socio-economic impacts of implementing the Tidal River Management option to solve the problem of drainage congestion in KJDRP area. Final report, part C. Dhaka: Author. 
Carse, A. (2012). Nature as infrastructure: Making and managing the Panama Canal watershed. Social Studies of Science, 42(4), 539-563. http://doi.org/10.1177/0306312712440166

Carson, R. (1962). Silent spring. Boston: Houghton Miflfin.

CEGIS. (2012). Master plan of haor region. Dhaka.

Chadwick, M., \& Datta, A. (2001). Water Resource Management in Bangladesh. A Policy Review. London: Dfid.

Chowdhury, N. T. (2010). Water management in Bangladesh: An analytical review. Water Policy, 12(1), 32-51. http://doi.org/DOI: 10.2166/wp.2009.112

Clark, M. J. (2002). Dealing with uncertainty: Adaptive approaches to sustainable river management. Aquatic Conservation: Marine and Freshwater Ecosystems, 12(1), 347-363. http://doi.org/10.1002/aqc.531

Coastal Development Partnership. (2008). People's alternative water resource management. A case study on Tidal River Management in Bangladesh. Khulna.

Collins, J. (Ed.). (2015). Defining the Delta. Multidisciplinary perspectives on the lower Mississippi delta. Fayetteville: The University of Arkansas Press.

Commissie Luteijn. (2000). Eindrapport Commissie Noodoverloopgebieden. Den Haag: Projectsecretariaat Commissie Noodoverloopgebieden.

Conca, K. (2005). Governing Water. Cambridge MA \& London: MIT Press.

Consultant Team BanDuDeltAS. (2014). Bangladesh Delta Plan 2100. Inception report.

Cook, B. R. (2010). Knowledges, controversies and floods: national-scale flood management in Bangladesh. Durham University, PhD thesis.

Cox, T., Maris, T., de Vleeschauwer, P., de Mulder, T., Soetaert, K., \& Meire, P. (2006). Flood control areas as an opportunity to restore estuarine habitat. Ecological Engineering, 28(1), 55-63. http://doi.org/10.1016/j.ecoleng.2006.04.001

Crow-Miller, B., Webber, M., \& Molle, F. (2017). The (Re)turn to Infrastructure for Water Management. Water Alternatives, 10(2), 195-207.

Cumming, G. S. (2011). The resilience of big river basins. Water International, 36(1), 63-95. http://doi.org/10.1080/02508060.2011.541016

D'Souza, R. (2006). Drowned and dammed: colonial capitalism and flood control in Eastern India. New Delhi: Oxford University Press.

Dammers, E., Bregt, A. K., Edelenbosch, J., Meyer, H., \& Pel, B. (2013). Urbanized deltas as Complex Adaptive Systems: Implications for planning and design. Built Environment, 40(2), 156-168.

Danh, V. T., \& Mushtaq, S. (2011). Living with Floods: An Evaluation of the Resettlement Program of the Mekong Delta of Vietnam. In P. A. Coclanis \& M. A. Stewart (Eds.), Environmental Change and Agricultural Sustainability in the Mekong Delta (pp. 181-206). Dordrecht Heidelberg London New York: Springer.

Day, J. W., Boesch, D. F., Clairain, E. J., Kemp, G. P., Laska, S. B., Mitsch, W. J., ... Whigham, D. F. (2007). Restoration of the Mississippi Delta: Lessons from Hurricanes Katrina and Rita. Science, 315(5819), 1679-1684. http://doi.org/10.1126/science.1137030

De Bruijn, D., Hamhuis, D., Van Nieuwenhuijze, L., \& Overmars, W. (1986). Ooievaar. De toekomst van het rivierengebied. Arnhem: Stichting Gelderse Milieufederatie.

De Gast, C. (2005). Van Boerenland tot doorstroomgebied. Werkendam: Stichting Geschiedschrijving Noordwaard.

De Jonge, J., \& Van der Windt, N. (2007). Doorbraken in het Rivierengebied. Wageningen.

De Kraker, A. (2015). Flooding in river mouths: human caused or natural events? Hydrology and Earth System Sciences, 19, 1-12. http://doi.org/10.5194/hess-19-1-2015

De Mesel, I., Ysebaert, T., \& Tangelder, M. (2013). Klimaatbestendige dijken: het concept wisselpolders. Yerseke: IMARES.

De Schipper, P. (2008). De slag om de Oosterschelde. Amsterdam: Atlas-contact.

De Schipper, P. (2010). De Biesbosch. Gisteren, vandaag en morgen. Werkendam: Vèrse Hoeven.

De Stoop, C. (2015). Dit is mijn hof. Amsterdam: De Bezige Bij.

De Vriend, H. J., \& Van Koningsveld, M. (2012). Building with Nature: thinking, acting and interacting differently. Dordreccht: Ecoshape, Building with Nature. 
De Vries, M., \& Dekker, F. (2009). Golfremmende dijk Noordwaard. Verkennende studie.

Deelprogramma Rivierengebied. (2014). Voorkeursstrategie Waal en Merwedes. Arnhem. Retrieved from http://www.gelderland.nl/4/Home/Voorkeursstrategie-Waal-en-Merwedes.html

Deelprogramma Zuidwestelijke Delta. (2014). Synthesedocument Zuidwestelijke Delta. Achtergronddocument B8. Den Haag. Retrieved from http://www.deltacommissaris.nl/binaries/deltacommissaris/documenten/publicatie/2014/09/1 6/deltaprogramma-2015-achtergronddocumentb8/DP2015+B8+Synthesedocument+Zuidwestelijke+Delta_tcm309-358059.pdf

Delta Committee. (2008). Working together with Water. A living land builds for its future. Findings of the Delta Committee 2008. Den Haag. Retrieved from http://www.deltacommissie.com/doc/deltareport_full.pdf

Delta Program. (2015). Working on the delta. Den Haag. Retrieved from http://deltacommissaris.nl/english/Images/Delta Programme 2015 English_tcm310-358177.pdf

Deltaprogramma. (2012a). Rijn-Maasdelta. Kansen voor de huidige waterveiligheidsstrategie in 2100. Rotterdam.

Deltaprogramma. (2012b). Werk aan de delta. Den Haag.

Dewan, C. (2012). Review of the historical evolution of policies and institutions of community based management in coastal Bangladesh. Colombo: IMWI.

Dewulf, A. (2013). Contrasting frames in policy debates on climate change adaptation. Wiley Interdisciplinary Reviews: Climate Change, 4(4), 321-330. http://doi.org/10.1002/wcc.227

Disco, C. (2002). Remaking "nature": The Ecological Turn in Dutch Water Management. Science Technology \& Human Values, 27(2), 206-235. http://doi.org/10.1177/016224390202700202

Disco, C., \& Van den Ende, J. C. M. (2003). "Strong, Invincible Arguments"? Tidal Models as Management Instruments in Twentieth-Century Dutch Coastal Engineering. Technology and Culture, 44(3), 502-535. http://doi.org/10.1353/tech.2003.0108

Domptail, S., Easdale, M. H., \& Yuerlita. (2013). Managing socio-ecological systems to achieve sustainability: A study of resilience and robustness. Environmental Policy and Governance, 23(1), 30-45. http://doi.org/10.1002/eet.1604

Dreze, J., Samson, M., \& Singh, S. (1997). The Dam and the Nation. Oxford New York: Oxford University Press.

Duel, H., Ellis Penning, W., Haasnoot, M., \& Klijn, F. (2003). Ecological Flood Management strategies for the rivers Rhine and Meuse in the Netherlands. In Proceedings of the International Conference "Torwards natural flood reduction strategies." Warsaw.

Duyne, F. (1998). People's Water Management Practices in Rural Bangladesh. Development Policy Review, 16(3), 264-280. http://doi.org/10.1111/1467-7679.00064

Edelenbos, J., Van Meerkerk, I., \& Van Leeuwen, C. (2015). Vitality of Complex Water Governance Systems: Condition and Evolution. Journal of Environmental Policy \& Planning, 17(237-261). http://doi.org/10.1080/1523908X.2014.936584

Eden, S. E., \& Tunstall, S. (2006). Ecological versus social restoration? How urban river restoration challenges but also fails to challenge the science-policy nexus in the United Kingdom. Environment and Planning C: Government and Policy, 24(5), 661-680. http://doi.org/10.1068/c0608j

EGIS. (1998). Environmental and social impact assessment of the Khulna-Jessore Drainage and Rehabilitation Project, BWDB. Dhaka.

Ehlert, J. (2012). Beautiful floods. Environmental knowledge and agrarian change in the Mekong delta, Vietnam. ZEF Development Studies (Vol. 19). Münster: LIT Verlag.

Ekbladh, D. (2002). "Mr. TVA": Grass-Roots Development, David Lilienthal, and the Rise and Fall of the Tennessee Valley Authority as a Symbol for U.S. Overseas Development, 1933-1973. Diplomatic History, 26(3), 335-374. http://doi.org/10.1111/1467-7709.00315

Ellul, J. (1964). The technological society. New York: Vintage.

Enfors, E. (2013). Social-ecological traps and transformations in dryland agro-ecosystems: Using water system innovations to change the trajectory of development. Global Environmental Change, 23(1), 51-60. http://doi.org/10.1016/j.gloenvcha.2012.10.007

Enserink, B. (2004). Thinking the unthinkable - the end of the Dutch river dike system? Exploring a new 
safety concept for the river management. Journal of Risk Research, 7(7-8), 745-757. http://doi.org/10.1080/13669870210166185

Faaland, J. (1995). Flood and Water management. Towards a Public Debate. Report by the Independent FAP Review Mission. Dhaka: UNDP.

Falkenmark, M. (2003). Freshwater as shared between society and ecosystems: from divided approaches to integrated challenges. Philosophical Transactions of the Royal Society B: Biological Sciences, 358(1440), 2037-2049. http://doi.org/10.1098/rstb.2003.1386

Feddes, Y. (2012). Met de stroom mee - de landschappelijke betekenis van NURG projecten. Den Haag: College van Rijksadviseurs.

Feenberg, A. (2010). Between reason and experience. Essays in technology and modernity. Cambridge MA \& London: MIT Press.

Fischer-Kowalski, M., \& Rotmans, J. (2009). Conceptualizing, observing, and influencing socialecological transitions. Ecology and Society, 14(2), 3. Retrieved from http://www.ecologyandsociety.org/vol14/iss2/art3/

Flood, R. J. (2001). The Relationship of "Systems Thinking" to Action Research. Systemic Practice and Action Research, 23(4), 269-284. http://doi.org/10.1007/s11213-010-9169-1

Flyvbjerg, B. (2006). Five Misunderstandings About Case-Study Research. Qualitative Inquiry, 12(2), 219-245. http://doi.org/10.1177/1077800405284363

Folke, C., Carpenter, R., Walker, B., Scheffer, M., Chapin, T., \& Rockström, J. (2010). Resilience thinking: Integrating resilience, adaptability and transformability. Ecology and Society, 15(4), 20. Retrieved from https://www.ecologyandsociety.org/vol15/iss4/art20/

Folke, C., Hahn, T., Olsson, P., \& Norberg, J. (2005). Adaptive governance of social-ecological systems. Annual Review of Environment and Resources, 30(1), 441-473. http://doi.org/10.1146/annurev.energy.30.050504.144511

Fox, C. A., Magilligan, F. J., \& Sneddon, C. S. (2016). "You kill the dam, you are killing a part of me": Dam removal and the environmental politics of river restoration. Geoforum. http://doi.org/10.1016/j.geoforum.2016.02.013

Frantzeskaki, N., Thissen, W., \& Grin, J. (2016). Drifting between transitions. Lessons from the environmental transition around the river Acheloos Diversion project in Greece. Technological Forecasting and Social Change, 102, 275-286. http://doi.org/10.1016/j.techfore.2015.09.007

French, P. W. (2006). Managed realignment - The developing story of a comparatively new approach to soft engineering. Estuarine, Coastal and Shelf Science, 67(3), 409-423. http://doi.org/10.1016/j.ecss.2005.11.035

Gain, A. K., Benson, D., Rahman, R., Datta, D. K., \& Rouillard, J. J. (2017). Tidal river management in the southwest Ganges-Brahmaputra delta in Bangladesh: Moving towards a transdisciplinary approach? Environmental Science and Policy, 75, 110-120. http://doi.org/10.1016/j.envsci.2017.05.020

Galat, D. D. L., Fredrickson, L. H. L., Humburg, D. D., Bataille, K. J., Bodie, J. R., Dohrenwend, J., ... Semlitsch, R. D. (1998). Flooding to Restore Connectivity of Regulated, Large-River Wetlands. BioScience, 48(9), 721-733. Retrieved from http://www.jstor.org/stable/1313335?origin=crossref

Gallopín, G. C. (2006). Linkages between vulnerability, resilience, and adaptive capacity. Global Environmental Change-Human and Policy Dimensions, 16(3), 293-303. http://doi.org/DOI 10.1016/j.gloenvcha.2006.02.004

Garrelts, H., \& Lange, H. (2011). Path dependencies and path change in complex fields of action: climate adaptation policies in Germany in the realm of flood risk management. Ambio, 4O(2), 200-209. http://doi.org/10.1007/s13280-010-0131-3

Garschagen, M. (2010). Crises prevention and climate change adaptation in the coupled socialecological systems of the Mekong delta, Vietnam: The need for rethinking concepts and policies. In X. Shen, T. E. Downing, \& M. Hamza (Eds.), Tipping points in humanitarian crisis: from hot spots to hot systems. Bonn: UNU-EHS.

Geels, F. W. (2005). Technological Transitions and System Innovations: A Co-evolutionary and SocioTechnical Analysis. Technological Forecasting and Social Change. Edward Elgar Publishing Ltd.

Geels, F. W., \& Schot, J. W. (2007). Typology of sociotechnical transition pathways. Research Policy, 36(3), 399-417. http://doi.org/10.1016/j.respol.2007.01.003 
Geertz, C. (1972). The Wet and the Dry: Traditional Irrigation in Bali and Morocco. http://doi.org/10.1007/BF01791279

Gerrits, L. M. (2008). The Gentle Art of Co-Evolution: A Complexity Theory Perspective on Decision Making over Estuaries in Germany, Belgium and the Netherlands. Erasmus University Rotterdam, $\mathrm{PhD}$ thesis.

Gerrits, L. M., \& Marks, P. (2008). Complex bounded rationality in dyke construction. Path-dependency, lock-in in the emergence of the geometry of the Zeeland delta. Land Use Policy, 25(3), 330-337. http://doi.org/10.1016/j.landusepol.2007.09.001

Ghosh, A. (2004). The hungry tide. New York: Harper Collins.

Giddens, A. (1990). The Consequences of Modernity. Stanford: Stanford University Press.

Glaser, M., Krause, G., Ratter, B., \& Welp, M. (2008). Human-nature interaction in the Anthropocene. Potential of social-ecological systems analysis. Gaia-Ecological Perspectives for Science and Society, 17(1), 77-80. Retrieved from http://www.dg-humanoekologie.de/pdf/DGHMitteilungen/GAIA200801_77_80.pdf

Gleick, P. H. (2003). Global Freshwater Resources: Soft-Path Solutions for the 21st Century. Science, 302(5650), 1524-1528. http://doi.org/10.1126/science.1089967

Goeller, B. F., Abrahamse, A. F., Bigelow, J. H., Bolten, G. J., de Ferranti, D. M., De Haven, J. C., ... Petruschell, R. L. (1977). Protecting an estuary from floods - A policy analysis of the Oosterschelde. Volume 1, Summary report. Santa Monica CA: Rand Corporation.

Government of the Netherlands. (2009). National Water Plan 2009 - 2015. Den Haag.

Grontmij. (2002). Natuurontwikkeling Noordwaard - inrichtingsplan. Eindhoven.

Grontmij. (2012). Balance Island. Retrieved from http://www.grontmij.com/MediaCenter/Press releases/Publishinglmages/Balance island_12 ENG-01.pdf

Gunderson, L. H., Garmestani, A., Rizzardi, K. W., Ruhl, J., \& Light, A. (2015). Escaping a rigidity trap: governance and adaptive capacity to climate change in the Everglades social ecological system. Idaho Law Review, 51(1), 127-156.

Haasnoot, M. (2013). Anticipating change. Sustainable water policy pathways for an uncertain future. Twente University, PhD thesis.

Hajer, M., \& Versteeg, W. (2005). A decade of discourse analysis of environmental politics: Achievements, challenges, perspectives. Journal of Environmental Policy \& Planning, 7(3), 175184. http://doi.org/10.1080/15239080500339646

Hallegatte, S., Green, C., Nicholls, R. J., \& Corfee-Morlot, J. (2013). Future flood losses in major coastal cities. Nature Climate Change, (3), 802-806. http://doi.org/10.1038/nclimate1979

Halliday, A., \& Glaser, M. (2011). A management perspective on social-ecological systems: A generic system model and its application to a case study from Peru. Human Ecology Review, 18(1), 1-18.

Haque, K. N. H., Chowdhury, F. A., \& Khatun, K. R. (2014). Participatory environmental governance and climate change adaptation: Mainstreaming of Tidal River Management in southwest Bangladesh. In H. Ha (Ed.), Land and Disaster Management Strategies in Asia (pp. 189-208). Kyoto: Springer Japan.

Harden, C. P. (2012). Framing and reframing questions of human-environment interactions. Annals of the Association of American Geographers, 102(4), 737-747. http://doi.org/10.1080/00045608.2012.678035

Harrison, H. L. (1875). The Bengal embankment manual. Calcutta: Bengal Secretariat Press.

Hartmann, T. (2010). Reframing Polyrational Floodplains: Land Policy for Large Areas for Temporary Emergency Retention. Nature and Culture, 5(1), 15-30. http://doi.org/10.3167/nc.2010.050102

Hashimoto, T. (2001). Environmental issues and recent infrastructure development in the Mekong delta: review, analysis and recommendations with particular reference to large-scale water control projects and the development of coastal areas. Sydney: AMRC.

Haskoning. (1993). Second Coastal Embankment Rehabilitation Project - Volume I: executive summary. Dhaka: BWDB.

Hermans, L. M., \& Thissen, W. A. H. (2009). Actor analysis methods and their use for public policy analysts. European Journal of Operational Research, 196(2), 808-818. http://doi.org/10.1016/j.ejor.2008.03.040

Hieu, T. V. (2010). Understanding farmer production strategies in context of policies for adaptation to 
floods in Vietnam. Case study at two communes, An Giang province, Vietnam. Uppsala.

Howie, C. A. (2011). Co-operation and contestation: farmer-state relations in agricultural transformation, An Giang Province, Vietnam. University of London, PhD thesis.

Hughes, R., Adnan, S., \& Dalal-Clayton, B. (1994). Floodplains of flood plans? A review of approaches to water management in Bangladesh. London/Dhaka: IIED.

Hughes, T. P. (1983). Networks of power: Electrification in Western society, 1880-1930. Baltimore \& London: The Johns Hopkins University Press.

Hughes, T. P. (1987). The evolution of Large Technological Systems. In W. E. Bijker, T. P. Hughes, \& T. J. Pinch (Eds.), The social construction of technological systems. Cambridge MA \& London: MIT Press.

Huitema, D., \& Meijerink, S. (2009). Understanding and managing water transitions: a policy science perspective. In D. Huitema \& S. Meijerink (Eds.), Water policy entrepreneurs (pp. 23-36). Cheltenham \& Massachusetts: Edward Elgar Publishing Ltd.

Huitema, D., \& Meijerink, S. (2010). Realizing water transitions: The role of policy entrepreneurs in water policy change. Ecology and Society, 15(2), 26. Retrieved from http://www.ecologyandsociety.org/vol15/iss2/art26/

Hung, N. N., Delgado, J. M., Tri, V. K., Hung, L. M., Merz, B., Bárdossy, A., \& Apel, H. (2012). Floodplain hydrology of the mekong delta, Vietnam. Hydrological Processes, 26(5), 674-686. http://doi.org/10.1002/hyp.8183

Huu, P. C. (2011). Floods and Farmers: Politics, Economics and Environmental Impacts of Dyke Construction in the Mekong Delta/Vietnam. ZEF Development Studies (Vol. 18). Münster: LIT Verlag.

Ibne Amir, M. S. I., Khan, M. S. A., Kamal Khan, M. M., Golam Rasul, M., \& Akram, F. (2013). Tidal river sediment management - a case study in southwestern Bangladesh. International Journal of Civil Science and Engineering, 7(3). Retrieved from http://scholar.waset.org/1999.6/17122

IFRC. (2016). World Disasters Report. Geneva: International Federation of Red Cross and Red Crescent Societies.

Ingram, H., \& Fraser, L. (2006). Path dependency and Adroit Innovation: The Case of California Water. In R. Repetto (Ed.), Punctuated equilibrium and the dynamics of U.S. environmental policy. New Haven \& London: Yale University Press.

Institute for Right View. (2010). Hanging garden. A voice for people's perspective. Khulna.

IOV (Operations Review Unit). (1993). Flood Action Plan, Bangladesh. A study on the debate on flood control in Bangladesh. Den Haag: IOV.

Iqbal, I. (2010). The Bengal delta. Hampshire: Palgrave Macmillan.

Islam, M. R., Begum, S. F., Yamaguchi, Y., \& Ogawa, K. (1999). The Ganges and Brahmaputra rivers in Bangladesh: Basin denudation and sedimentation. Hydrological Processes, 13(17), 2907-2923. http://doi.org/10.1002/(SICI)1099-1085(19991215)13:17<2907::AID-HYP906>3.0.CO;2-E

Islam, N. (1990). Let the delta be the delta. Journal of Social Studies, 48, 18-41.

Islam, N. (2001). The open approach to flood control: the way to the future in Bangladesh. Futures, 33(8-9), 783-802. http://doi.org/10.1016/S0016-3287(01)00019-2

Islam, S., \& Kibria, Z. (2006). Unraveling KJDRP. ADB financed project of mass destruction in southwest coastal region of Bangladesh. Khulna: Uttaran.

IWR. (2011). Flood Risk Management Approaches. As being practiced in Japan, Netherlands, United Kingdom, and United States. IWR on behalf of USACE, Rijkswaterstaat, MLIT and the Environmental Agency.

Jansen, J. (2015). Living with the Mekong. Wageningen: Blauwdruk Publishers.

Janssen, S. K. H. (2015). Greening flood protection in the Netherlands. A knowledge arrangement approach. Wageningen University, PhD thesis.

Janssen, S. K. H., Van Tatenhove, J. P. M., Otter, H. S., \& Mol, A. P. J. (2015). Greening flood protection - An interactive knowledge arrangement perspective. Journal of Environmental Policy \& Planning, 17(3), 309-331. http://doi.org/10.1080/1523908X.2014.947921

Kaijser, A. (2002). System building from below: Institutional change in Dutch water control systems. Technology and Culture, 43(3), 521-548. http://doi.org/10.1353/tech.2002.0120

Kaijser, A. (2004). The dynamics of infrasystems. Lessons from history. In Proceedings of the 6th 
International Summer Academy on Technology Studies (pp. 153-165).

Käkönen, M. (2008). Mekong Delta at the crossroads: more control or adaptation? Ambio, 37(3), 205212. http://doi.org/10.1579/0044-7447(2008)37[205:MDATCM]2.0.CO;2

Kamal, A. (2006). Living with water: Bangladesh since ancient times. In T. Tvedt \& E. Jakobsson (Eds.), A History of Water, Volume 1: Water Control and River Biographies (pp. 194-213). London: I.B. Tauris \& Co.

Kelder, E., Gersonius, B., \& Hulsebosch, M. (2013). Concept Gebiedsrapportage Eiland van Dordrecht. Deltaprogramma Rijnmond-Drechtsteden.

Kemp, R., \& Rotmans, J. (2005). The management of the co-evolution of technical, environmental and social systems. In M. Weber \& J. Hemmelskamp (Eds.), Towards Environmental Innovation Systems (pp. 33-56). Heidelberg: Springer Germandy.

Klaassen, G. J. (2009). Preferred development of Bangladesh main rivers: from bank protection to land reclamation. In Proceedings of the 2nd International Conference on Water \& Flood Management (pp. 69-82). Dhaka.

Kleinen, J., Van der Zwan, B., Moors, H., \& Van Zeeland, T. (2007). Leeuw en draak. Vier eeuwen Nederland en Vietnam. Amsterdam: Boom Publishers.

Kleinhans, M. G., Cohen, K. M., \& Weerts, H. J. T. (2010). Avulsion in action: Reconstruction and modelling sedimentation pace and upstream flood water levels following a Medieval tidal-river diversion catastrophe (Biesbosch, The Netherlands, 1421-1750AD). Geomorphology, 118(1-2), 65-79. http://doi.org/10.1016/j.geomorph.2009.12.009

Klingensmith, D. (2007a). "Decadence" and Ecological Change: Environmental Crisis and Political Ideology in Late Colonial Bengal. Calcutta Historical Journal, 27(1), 31-51.

Klingensmith, D. (2007b). One valley and a thousand. Dams, nationalism, and development. Delhi: Oxford University Press.

Klingensmith, D. (2008). Of "Ancient Irrigation" and modern dams: orientalism, nationalism and water policy in late colonial Bengal, 1925-1947. In New Interdisciplinary Perspectives on Water and Society (pp. 1-29).

Knill, C., \& Tosun, J. (2012). Public Policy: A New Introduction. London: Palgrave Macmillan.

Korbee, D. (2015). Greening the construction of marine infrastructure: A governance approach. Wageningen University, PhD thesis.

Korbee, D., \& Van Tatenhove, J. P. M. (2013). Environmental governance for marine infrastructure: Enabling and constraining conditions for ecodynamic development and design in marine infrastructural projects. Journal of Environmental Policy \& Planning, 15(4), 533-550. http://doi.org/10.1080/1523908X.2013.807211

Kothuis, B., \& Kok, M. (Eds.). (2017). Integral Design of Multifunctional Flood Defenses: Multidisciplinary Approaches and Examples. Delft: Delft University Publishers.

Kundzewicz, Z. W. (2002). Non-structural Flood Protection and Sustainability. Water International, 27(1), 3-13. http://doi.org/10.1080/02508060208686972

Kvaløy, F. (1994). NGOs and people's participation in relation to the Bangladesh Flood Action Plan. Oslo: Mankodi.

Lach, D., Ingram, H., \& Rayner, S. (2005). Maintaining the status quo: How institutional norms and practices create conservative water organizations. Texas Law Review, 83, 2027-53. Retrieved from https://ssrn.com/abstract $=874797$

Lach, D., Rayner, S., \& Ingram, H. (2005). Taming the waters: Strategies to domesticate the wicked problems of water resource management. International Journal of Water, 3(1), 1-17. http://doi.org/10.1.1.475.5764\&rep=rep1\&type=pdf

Lahiri-Dutt, K., \& Samanta, G. (2013). Dancing with the river: people and life on the chars of South Asia. New Haven, Connecticut, USA; London, UK: Yale University Press.

Landman, T. (2000). Issues and Methods in Comparative Politics : An Introduction. Human Rights. New York: Routledge.

Larkin, B. (2013). The Politics and Poetics of Infrastructure. Annual Review of Anthropology, 42, 327343. http://doi.org/10.1146/annurev-anthro-092412-155522

Lary, D. (2001). Drowned earth: the strategic breaching of the Yellow River dyke, 1938. War in History, 8(2), 191-207. Retrieved from http://wih.sagepub.com/content/8/2/191.short 
Le, T. V. H., Nguyen, H. N., Wolanski, E., Tran, T. C., \& Haruyama, S. (2007). The combined impact on the flooding in Vietnam's Mekong River delta of local man-made structures, sea level rise, and dams upstream in the river catchment. Estuarine, Coastal and Shelf Science, 71(1-2), 110-116. http://doi.org/10.1016/j.ecss.2006.08.021

Leach, M., Scoones, I., \& Stirling, A. (2007). Pathways to Sustainability: an overview of the STEPS Centre approach. Brighton. Retrieved from http://steps-centre.org/wpcontent/uploads/final_steps_overview.pdf

Lebel, L., Anderies, J. M., Campbell, B., Folke, C., Hatfield-dodds, S., Hughes, T. P., \& Wilson, J. (2006). Governance and the capacity to manage resilience in regional social-ecological systems. Ecology and Society, 11(1), 19. Retrieved from http://www.ecologyandsociety.org/vol11/iss1/art19/

Leedshill-De Leuw Engineers. (1968). Coastal Embankment Project: engineering and economic evaluation. Volume 1. Dhaka: BWDB.

Lilienthal, D. (1944). Democracy on the March. New York: Harper and Brothers.

Ludwig, F., van Slobbe, E., \& Cofino, W. (2014). Climate change adaptation and Integrated Water Resource Management in the water sector. Journal of Hydrology, 518(B), 235-242. http://doi.org/10.1016/j.jhydrol.2013.08.010

Lund, J. R., Hanak, E., Fleenor, W., Howitt, R., Mount, J., \& Moyle, P. (2008). Envisioning futures for the Sacramento-San Joaquin delta. San Fransisco, California: Public Policy Institute of California.

Majumdar, S. C. (1938). River problems in Bengal. In Proceedings of the National Institute of Science India (pp. 441-476). Calcutta: National Institute of Science.

Manh, N. V., Dung, N. V., Hung, N. N., Merz, B., \& Apel, H. (2014). Large-scale suspended sediment transport and sediment deposition in the Mekong Delta. Hydrology and Earth System Sciences, 18(8), 3033-3053. http://doi.org/10.5194/hess-18-3033-2014

Marchand, M., Long, T., \& Sawarendo. (2012). Adaptive Water Management for Delta Regions: Towards GREEN Water Defense in East Asia. Delft. Retrieved from http://publications.deltares.nl/1205471_000.pdf

Marchand, M., \& Ludwig, F. (2014). Towards a Comprehensive Framework for Adaptive Delta Management. Delft/Wageningen, the Netherlands: Delta Alliance. Retrieved from http://www.delta-alliance.org/gfx_content/documents/documentation/Towards a Comprehensive Framework for Adaptive Delta Management.pdf

Marchand, M., Pham, D. Q., \& Le, T. (2014). Mekong delta: Living with water, but for how long? Built Environment, 40(2), 230-243.

Marchand, M., \& Toornstra, F. (1986). Ecological guidelines for river basin development. Leiden.

Maris, T., Cox, T., Temmerman, S., De Vleeschauwer, P., Van Damme, S., De Mulder, T., ... Meire, P. (2007). Tuning the tide: Creating ecological conditions for tidal marsh development in a flood control area. Hydrobiologia, 588(1), 31-43. http://doi.org/10.1007/s10750-007-0650-5

MEA. (2005). Millennium Ecosystem Assessment. Ecosystems and human well-being: synthesis. Washington: Island Press.

Merz, B., Elmer, F., Kunz, M., Mühr, B., Schröter, K., \& Uhlemann-Elmer, S. (2014). The extreme flood in June 2013 in Germany. La Houille Blanche, 1, 5-10. http://doi.org/10.1051/lhb/2014001

Meyer, H. (2009). Reinventing the Dutch Delta: Complexity and Conflicts. Built Environment, 35(4), 432-451. http://doi.org/10.2148/benv.35.4.432

Middleton, B. A. (2002). The Flood Pulse Concept in Wetland Restoration. In B. A. Middleton (Ed.), Flood Pulsing in Wetlands: Restoring the Natural Hydrological Balance (pp. 1-10). New Jersey: John Wiley \& Sons.

Miller, F. (2003). Society-Water Relations in the Mekong Delta: A Political Ecology of Risk. University of Sydney, PhD thesis.

Miller, F. (2006). Environmental Risk in Water Resources Management in the Mekong Delta: A Multiscale Analysis. In T. Tvedt \& E. Jakobsson (Eds.), A History of Water, Volume 1: Water Control and River Biographies (pp. 172-193). London: I.B. Tauris \& Co.

Min LNV. (1990). Natuurbeleidsplan. Den Haag.

Min VenW. (1985). Omgaan met Water. Den Haag.

Min VenW. (1998). Vierde Nota Waterhuishouding. Den Haag.

Min VenW. (2000a). Discussienotitie Ruimte voor de Rivier. Den Haag. 
Min VenW. (2000b). Kabinetsstandpunt Ruimte voor de Rivier. Den Haag.

Min VenW. (2006a). PKB Ruimte voor de Rivier - toelichting. Brief aan de Tweede Kamer der Staten General, 23 maart 2006. Den Haag: Author.

Min VenW. (2006b). PKB Ruimte voor de Rivier deel 4 - nota van toelichting. Den Haag.

Min VenW, \& Min LNV. (2001). Natuur aan het werk. een verkenning van mogelijkheden voor grootschalige natuurontwikkeling langs rijkswateren en rijkswegen. Den Haag.

Mitchell, T. (1991). America's Egypt: discourse of the development industry. Middle East Report, 169, 18-34. Retrieved from http://www.jstor.org/stable/3012949?seq=1\#page_scan_tab_contents

Molle, F. (2003). Development trajectories of river basins: A conceptual framework. Colombo, Sri Lanka: IWMI (research report 72). $\quad$ Retrieved from http://www.iwmi.cgiar.org/Publications/IWMI_Research_Reports/PDF/pub072/Report72.pdf

Molle, F., \& Wester, P. (Eds.). (2009). River basin trajectories: Societies, environments and development. Oxfordshire \& Cambridge MA: CAB International.

Mollinga, P., \& Gondhalekar, D. (2012). Theorizing structured diversity. an approach to comparative research on water resources management. ICCWaDS Working Paper No. 1.

Mollinga, P., \& Gondhalekar, D. (2014). Finding structure in diversity: a stepwise small-N/medium-N qualitative comparative analysis for water resources management research. Water Alternatives, 7(1), 187-198.

Mutahara, M., Warner, J., Wals, A., Khan, M. S. A., \& Wester, P. (2017). Social learning for adaptive delta management: Tidal River Management in the Bangladesh Delta. International Journal of Water Resources Development, 1-21. http://doi.org/10.1080/07900627.2017.1326880

NEDECO. (1993). Master plan for the Mekong delta in Vietnam. A perspective for sustainable development of land and water resources. Arnhem/Nijmegen: Author.

Nelson, R. R., \& Winter, S. G. (1982). An evolutionary theory of economic change. Cambridge MA: Harvard University Press.

Netherlands Delta Development Team. (1974). Recommendations concerning agricultural development with improved water control in the Mekong delta. Bangkok: Committee for the coordination of investigations of the Lower Mekong Basin.

Nguyen, K. V., \& James, H. (2013). Measuring household resilience to floods: A case study in the Vietnamese Mekong River Delta. Ecology and Society, 18(3), 13. Retrieved from http://www.ecologyandsociety.org/vol18/iss3/art13/

Nguyen, K. V., Vo, O. V., \& Huynh, D. N. (2015). Comparing the costs and benefits of floating rice-based and intensive rice-based farming systems in the Mekong delta. Asian Journal of Agriculture and Rural Development, 5(9), 202-217. Retrieved from http://www.aessweb.com/download.php?id=3286

Nguyen, V. X., \& Wyatt, A. B. (2006). Situation Analysis Plain of Reeds, Viet Nam. Vientiane: Mekong Wetlands Biodiversity Conservation and Sustainable Use Programme.

Nienhuis, P. (2008). Environmental History of the Rhine-Meuse Delta. An Ecological Story on Evolving Human-environmental Relations Coping with Climate Change and Sea-level Rise.

Nikula, J. (2008). Is harm and destruction all that floods bring? In M. Kummu, M. Keskinen, \& O. Varis (Eds.), Modern myths of the Mekong. A critical review of water and development concepts, principles and policies (pp. 23-38). Helsinki: Helsinki University of Technology.

Norgaard, R. B. (1994). Development betrayed: The end of progress and a coevolutionary revisioning of the future. London: Routledge.

Norgaard, R. B., Kallis, G., \& Kiparsky, M. (2009). Collectively engaging complex socio-ecological systems: Re-envisioning science, governance, and the California delta. Environmental Science Policy, 12(6), 644-652. http://doi.org/10.1016/j.envsci.2008.10.004

Nowreen, S., Rashed Jalal, M., \& Khan, M. S. A. (2013). Historical analysis of rationalizing South West coastal polders of Bangladesh. Water Policy, 16(2), 264-279. http://doi.org/10.2166/wp.2013.172

Ozden, C. (2014). The Pontifex Minimus: William Willcocks and Engineering British Colonialism. Annals of Science, 71(2), 183-205. http://doi.org/10.1080/00033790.2013.808378

Pahl-Wostl, C. (Ed.). (2015). Water governance in the face of global change. From understanding to transformation. Dordrecht Heidelberg London New York: Springer. 
Pahl-Wostl, C., Jeffrey, P., Isendahl, N., \& Brugnach, M. (2011). Maturing the New Water Management Paradigm: Progressing from Aspiration to Practice. Water Resources Management, 25, 837-856. http://doi.org/10.1007/s11269-010-9729-2

Parker, D. J. (1992). Six Comments on the Bangladesh Flood Action Plan. Natural Hazards, 6(3), 290291. http://doi.org/10.1007/BF00129514

Paul, B. K. (1984). Perception of and agricultural adjustment to floods in Jamuna floodplain, Bangladesh. Human Ecology, 12(1), 3-19. http://doi.org/10.1007/BF01531281

Paul, B. K. (1995). Farmers Responses to the Flood Action Plan (FAP) of Bangladesh - an Empirical Study. World Development, 23(2), 299-309. http://doi.org/10.1016/0305-750X(94)00119-J

Pel, B., Verkerk, J., Van Buuren, A., \& Edelenbos, J. (2014). Intersections in delta development: Analyzing actors for complexity-sensitive spatial concepts. Complexity Governance and Networks, 1(2), 79-97. http://doi.org/10.7564/14-CGN18

Perkins, R. (2003). Technological "lock-in." Retrieved from http://isecoeco.org/pdf/techlkin.pdf

Pethick, J. (2002). Estuarine and tidal wetland restoration in the United Kingdom: Policy versus practice. Restoration Ecology, 10(3), 431-437. http://doi.org/10.1046/j.1526-100X.2002.01033.x

Pethick, J., \& Orford, J. D. (2013). Rapid rise in effective sea-level in southwest Bangladesh: Its causes and contemporary rates. Global and Planetary Change, 111, 237-245. http://doi.org/10.1016/j.gloplacha.2013.09.019

Pierson, P. (2000). Increasing Returns, Path Dependence, and the Study of Politics. American Political Science Review, 94(2), 251-267. http://doi.org/10.2307/2586011

Pinch, T. J., \& Bijker, W. E. (1984). The Social Construction of Facts and Artifacts - or How the Sociology of Science and the Sociology of Technology Might Benefit Each Other. Social Studies of Science, 14(3), 399-441. http://doi.org/10.1177/030631284014003004

Pleijte, M., \& During, R. (2006). Ruimte voor alternatieven ? Ruimte voor de rivier in de Noordwaard. Landschap: Tijdschrift Voor Landschapsecologie En Milieukunde, 23(4), 187-191.

Pleijte, M., During, R., Gerritsen, A., \& Stuyt, L. (2005). Noordwaard: over stromingen in denken over hoogwater en natuur. Wageningen: Wetenschapswinkel.

Priscoli, J. D., \& Stakhiv, E. (2015). Water-related disaster risk reduction (DRR) management in the United States: Floods and storm surges. Water Policy, 17, 58-88. http://doi.org/10.2166/wp.2015.004

ProAct network. (2008). The role of environmental management and eco-engineering in disaster risk reduction and climate change adaptation. Tannay: Author. Retrieved from http://www.preventionweb.net/files/4148_emecoengindrrcca1.pdf

Projectbureau Noordwaard. (2009). Inrichtingsplan Noordwaard. Rotterdam: Author.

Projectbureau Noordwaard. (2010). Milieueffectrapport Ontpoldering Noordwaard. Rotterdam: Author.

Projectbureau Noordwaard. (2011). Ontpoldering Noordwaard op hoofdlijnen. Rotterdam: Author.

Provincie Gelderland. (2004). Grensoverschrijdende effecten van extreem hoogwater op de Niederrhein. Arnhem: Author.

Quassem, M. A., \& van Urk, A. (2006). Participatory flood management: Comparative study of the Dutch and Bangladesh experience. In J. van Alphen, E. van Beek, \& M. Taal (Eds.), Proceedings of the International Symposion "Floods, from Defence to Management," Nijmegen, 2005 (pp. 133146). Oxford NY: Taylor \& Francis.

Ragin, C. (1997). Turning the Tables: How Case-oriented Research challenges Variable-oriented Research. Comparative Social Research, 16, 27-42. Retrieved from http://www.suz.uzh.ch/dam/jcr:6b4dc263-2922-464e-b9a1-18414c0e0841/Text_6.pdf

Rahman, A. (1995). Beel Dakatia. The environmental consequences of a development disaster. Dhaka: University Press Limited.

Rahman, R., \& Salehin, M. (2013). Flood Risks and Reduction Approaches in Bangladesh. In R. Shaw, F. Mallick, \& A. Islam (Eds.), Disaster Risk Reduction Approaches in Bangladesh (pp. 65-90). Tokyo: Springer Japan.

Ramachandran, R., Ramachandran, P., \& Lakshmi, A. (2010). Deltas. Coastal Vulnerability and Management. In Proceedings of the International Workshop "Deltas. Coastal Vulnerability and Management," Chennai, 2009. Retrieved from 
https://www.hzg.de/imperia/md/content/loicz/report/delta_workshop_report_final_15may20 10.pdf

Rammel, C., Stagl, S., \& Wilfing, H. (2007). Managing complex adaptive systems - A co-evolutionary perspective on natural resource management. Ecological Economics, 63, 9-21. http://doi.org/10.1016/j.ecolecon.2006.12.014

Rashid, S., \& Rahman, R. (Eds.). (2010). Water resources development in Bangladesh: Historical documents. Dhaka: The University Press Limited.

Redeker, C., \& Kantoush, S. A. (2014). The Nile delta: Urbanizing on diminishing resources. Built Environment, 40(2), 201-212.

Rein, M., \& Schön, D. (1996). Frame-critical policy analysis and frame-reflective policy practice. Knowledge \& Policy, 9(1), 85-104. http://doi.org/10.1007/BF02832235

Renaud, F. G., \& Kuenzer, C. (Eds.). (2012). The Mekong delta system. Interdisciplinary analyses of a river delta. Dordrecht Heidelberg London New York: Springer.

Renaud, F. G., Sudmeier-Rieux, K., \& Estrella, M. (Eds.). (2013). The role of ecosystems in Disaster Risk Reduction. Bonn: United Nations University Press.

Renaud, F. G., Syvitski, J. P. M., Sebesvari, Z., Werners, S. E., Kremer, H., Kuenzer, C., ... Friedrich, J. (2013). Tipping from the Holocene to the Anthropocene: How threatened are major world deltas? Current Opinion in Environmental Sustainability, 5(6), 644-654. http://doi.org/10.1016/j.cosust.2013.11.007

Rijke, J., Farrelly, M., Brown, R., \& Zevenbergen, C. (2013). Configuring transformative governance to enhance resilient urban water systems. Environmental Science and Policy, 25, 62-72. http://doi.org/10.1016/j.envsci.2012.09.012

Rijkswaterstaat. (2005). De 5 levens van de Noordwaard. Lelystad: Author.

Rijkswaterstaat. (2008). Verminderd getij. Verkenning naar mogelijke maatregelen om het verlies van platen, slikken en schorren in de Oosterschelde te beperken. Middelburg: Author.

Rijkswaterstaat. (2013). Nieuwsbrief Ontpoldering Noordwaard, June 2013. Author.

RIZA. (2001). Advies integrale verkenning benedenrivieren. Lelystad.

Rogers, P., Lydon, P., \& Seckler, D. (1989). Easter Waters Study: Strategies to manage flood and drought in the Ganges-Brahmaputra Basin. Arlington: ISPAN.

Roth, D., \& Warner, J. F. (2007). Flood risk, uncertainty and changing river protection policy in the Netherlands: the case of "calamity polders." Tijdschrift Voor Economische En Sociale Geografie, 98(4), 519-525. http://doi.org/10.1111/j.1467-9663.2007.00419.x

Roth, D., Warner, J. F., \& Winnubst, M. (2006). Een noodverband tegen hoog water. Wageningen: Wageningen UR.

Rotmans, J., Kemp, R., \& Van Asselt, M. (2001). More evolution than revolution. Foresight, 3(1), 1531. http://doi.org/10.1108/14636680110803003

Sadoff, C., Harshadeep, N. R., Blackmore, D., Wu, X., O’Donnell, A., Jeuland, M., ... Whittington, D. (2013). Ten fundamental questions for water resources development in the Ganges: Myths and realities. Water Policy, 15(SUPPL.1), 147-164. http://doi.org/10.2166/wp.2013.006

Saeed Khan, R. K., Nawaz, K., Van Steenbergen, F., Nizami, A., \& Ahmad, S. (2014). The Dry Side of the Indus: Exploring Spate Irrigation in Pakistan. Lahore: Vanguard Books.

Saeijs, H. L. F. (2008). Turning the tide. Essays on Dutch ways with water. Delft: Delft Academic Press.

Sage, W., Simms, F., \& M'Clelland, J. (1846). Report on the embankments of the rivers of Bengal. Calcutta: Military Orphan Press.

Saleh, F., \& Weinstein, P. (2016). The role of Nature-Based Infrastructure (NBI) in coastal resiliency planning: A literature review. Journal of Environmental Management, 183(3), 1088-1098. http://doi.org/10.1016/j.jenvman.2016.09.077

Santbergen, L. (2015). Henk Saeijs, Stormloper in een delta. Delft: Eburon.

Sarker, M. H., Akter, J., \& Rahman, M. M. (2013). Century-scale dynamics of the Bengal delta and future development. In Conference Proceedings of the "4th International Conference on Water \& Flood Management", Dhaka (pp. 91-104).

Savenije, H. H. G., Hoekstra, A. Y., \& Van Der Zaag, P. (2014). Evolving water science in the Anthropocene. Hydrology and Earth System Sciences, 18, 319-332. http://doi.org/10.5194/hess18-319-2014 
Sayers, P., Galloway, G., Penning-Rowsell, E., Yuanyuan, L., Fuxin, S., Yiwei, C., ... Guan, Y. (2015). Strategic flood management: ten "golden rules" to guide a sound approach. International Journal of River Basin Management, 13(2), 137-151. http://doi.org/10.1080/15715124.2014.902378

Schanze, J. (2012). Dealing with future change in flood risk management. Journal of Flood Risk Management, 5(1), 1-2. http://doi.org/10.1111/j.1753-318X.2011.01129.x

Schut, M., Leeuwis, C., \& Van Paassen, A. (2010). Room for the River: Room for Research? The case of depoldering De Noordwaard, the Netherlands. Science and Public Policy, 37(8), 611-627. http://doi.org/10.3152/030234210X12767691861173

Seidl, R., \& Stauffacher, M. (2013). Evaluation of river restoration by local residents. Water Resources Research, 49(10), 7077-7087. http://doi.org/10.1002/2013WR013988

Seijger, C., Douven, W., van Halsema, G., Hermans, L., Evers, J., Phi, H. L., ... Hoang, V. T. M. (2016). An analytical framework for strategic delta planning: negotiating consent for long-term sustainable delta development. Journal of Environmental Planning and Management, 60, 1485-1509. http://doi.org/10.1080/09640568.2016.1231667

Shampa, \& Pramanik, M. I. M. (2012). Tidal River Management (TRM) for selected coastal area of Bangladesh to mitigate drainage congestion. International Journal of Scientific \& Technology Research, 1(5), 1-6. http://doi.org/10.1.1.298.2254

SIWRP. (2016). Project on flood control planning in the Mekong delta by 2020, vision to 2030. Summary report. Ho Chi Minh City: SIWRP.

Smith, A., \& Stirling, A. (2010). The politics of social-ecological resilience and sustainable sociotechnical transitions. Ecology and Society, 15(1), 11. Retrieved from http://www.ecologyandsociety.org/vol15/iss1/art11/

Smith, M. R., \& Marx, L. (1994). Does Technology Drive History?: The Dilemma of Technological Determinism. Cambridge MA \& London: MIT Press.

Socialist Republic of Vietnam and the Kingdom of the Netherlands. (2013). Mekong Delta Plan. Longterm vision and strategy for a safe, prosperous and sustainable delta. Ho Chi Minh City \& Den Haag: Author.

Steenhuis, A. (2007). Stemmen van Groninger dijken. Amsterdam: Pandora Pockets.

Stijnen, J. W., Kanning, W., Jonkman, S. N., \& Kok, M. (2014). The technical and financial sustainability of the Dutch polder approach. Journal of Flood Risk Management, 7(1), 3-15. http://doi.org/10.1111/jfr3.12022

Stoutjesdijk, J. A. (1982). Compendium of polder projects: documentation on existing and proposed polder projects in various countries of the world. Delft: TU Delft.

Stratelligence. (2012). Handreiking Adaptief Deltamanagement. Leiden: Author.

Stroeken, F., \& Van Winden, A. (2009). Oppolderen. 's-Hertogenbosch: InnovatieNetwerk.

Suddeth, R. (2011). Policy Implications of Permanently Flooded Islands in the Sacramento-San Joaquin Delta. San Francisco Estuary and Watershed Science, 9(2), 1-18. http://doi.org/10.15447/sfews.2011v9iss2art5

Sultana, P., Johnson, C., \& Thompson, P. (2008). The impact of major floods on flood risk policy evolution: Insights from Bangladesh. International Journal of River Basin Management, 6(4), 339348. http://doi.org/10.1080/15715124.2008.9635361

Syvitski, J. P. M. (2008). Deltas at risk. Sustainability Science, 3(1), 23-32. http://doi.org/10.1007/s11625-008-0043-3

Syvitski, J. P. M., Kettner, A. J., Overeem, I., Hutton, E. W. H., Hannon, M. T., Brakenridge, G. R., ... Nicholls, R. J. (2009). Sinking deltas due to human activities. Nature Geoscience, 2(10), 681-686. http://doi.org/10.1038/NGEO629

Syvitski, \& Saito, Y. (2007). Morphodynamics of deltas under the influence of humans. Global and Planetary Change, 57(3-4), 261-282. http://doi.org/10.1016/j.gloplacha.2006.12.001

Sze, J., London, J., Shilling, F., Gambirazzio, G., Filan, T., \& Cadenasso, M. (2009). Defining and contesting environmental justice: Socio-natures and the politics of scale in the delta. Antipode, 41(4), 807-843. http://doi.org/10.1111/j.1467-8330.2009.00698.x

TeBrake, W. H. (2002). Taming the waterwolf: Hydraulic engineering and water management in the Netherlands during the Middle Ages. Technology and Culture, 43(3), 475-499. http://doi.org/10.1353/tech.2002.0141 
Tenner, E. (1997). Why things bite back: Technology and the revenge of unintended consequences. London: Vintage.

Tessler, Z. D., Vorosmarty, C. J., Grossberg, M., Gladkova, I., Aizenman, H., Syvitski, J. P. M., \& FoufoulaGeorgiou, E. (2015). Profiling risk and sustainability in coastal deltas of the world. Science, 349(6248), 638-643. http://doi.org/10.1126/science.aab3574

Thissen, W. A. H., \& Walker, W. E. (2013). Public Policy Analysis. New developments. Dordrecht Heidelberg London New York: Springer.

Thomas, F., \& Knüppe, K. (2016). From Flood Protection to Flood Risk Management: Insights from the Rhine River in North Rhine-Westphalia, Germany. Water Resources Management, 30, 27852800. http://doi.org/10.1007/s11269-016-1323-9

Tinh, D. Q., \& Hang, P. T. (2003). Living with floods in the Mekong river delta of Vietnam. Contribution to the "3rd World Water Forum, Poverty and Flood Theme," Kyoto. Retrieved from http://www.alnap.org/resource/10099

Tong, Y. D. (2017). Rice Intensive Cropping and Balanced Cropping in the Mekong Delta, Vietnam Economic and Ecological Considerations. Ecological Economics, 132, $205-212$. http://doi.org/10.1016/j.ecolecon.2016.10.013

Tran, T., \& James, H. (2017). Transformation of household livelihoods in adapting to the impacts of flood control schemes in the Vietnamese Mekong Delta. Water Resources and Rural Development, 9, 67-80. http://doi.org/10.1016/j.wrr.2017.04.002

Tri, V. K. (2012). Hydrology and hydraulic infrastructure systems in the Mekong Delta, Vietnam. In F. G. Renaud \& C. Kuenzer (Eds.), The Mekong Delta System. Interdisciplinary analyses of a river delta (pp. 49-81). Dordrecht Heidelberg London New York: Springer.

Triet, N. V. K., Dung, N. V., Fujii, H., Kummu, M., Merz, B., \& Apel, H. (2017). Has dyke development in the Vietnamese Mekong Delta shifted flood hazard downstream? Hydrology and Earth System Sciences Discussions. http://doi.org/10.5194/hess-2017-123

Trung, N. H., Tuan, L. A., Trieu, T. T., Bastakoti, R., \& Lebel, L. (2013). Multi-level governance and adaptation to floods in the Mekong delta. In R. Daniel, L. Lebel, \& K. Manorom (Eds.), Governing the Mekong. Engaging in the politics of knowledge (pp. 111-126). Petaling Jaya: Strategic Information and Research Development Centre.

Truong, T. V. (2000). Referring to the historic flood in the year 2000 and flood control strategies and measures in the Mekong Delta. Ho Chi Minh City: SIWRP.

TU Delft. (2004). Project Noordwaard. Delft: TU Delft.

Tuan, L. A., Hoanh, C. T., Miller, F., \& Sinh, B. T. (2007). Floods and Salinity Management in the Mekong Delta, Vietnam. In T. T. Be, B. T. Sinh, \& F. Miller (Eds.), Challenges to sustainable development in the Mekong delta: regional and national policy issues and research needs (pp. 15-68). Bangkok: The Sustainable Mekong Research Network.

UNDP. (1989). Bangladesh Flood Policy Study. Final report. Dhaka: Author.

UNESCO. (1966). Scientific Problems of the Humid Tropical Zone Deltas and their Implications. In Proceedings of the Symposium "Scientific Problems of the Humid Tropical Zone Deltas and their Implications," Dacca. Paris: Firmin-Didot.

United Nations. (1957). Report of a United Nations Technical Assistance Mission ('Krug mission'). In S. Rashid \& R. Rahman (Eds.), Water resources development in Bangladesh. Historical documents (pp. 157-278). Dhaka: University Press Limited.

United Nations. (1966). Appraisal of some aspects of the Coastal Embankment Project of East Pakistan. New York: Author.

Uttaran. (2011). Tidal River Management. Climate change adaptation and community based river basin management in southwest coastal region of Bangladesh. Dhaka: Author.

Uttaran. (2013). People's plan of action for management of rivers in southwest coastal region of Bangladesh. Dhaka: Author.

Van Alphen, J. (2016). The Delta Programme and updated flood risk management policies in the Netherlands. Journal of Flood Risk Management, 9, 310-319. http://doi.org/10.1111/jfr3.12183

Van Alphen, J., \& Lodder, Q. (2006). Integrated flood management: Experiences of 13 countries with their implementation and day-to-day management. Irrigation and Drainage, 55, S159-S171. http://doi.org/10.1002/Ird.251 
Van Buuren, A., Ellen, G. J., \& Warner, J. F. (2016). Path-dependency and policy learning in the dutch delta: Toward more resilient flood risk management in the Netherlands? Ecology and Society, 21(4), 43. Retrieved from https://www.ecologyandsociety.org/vol21/iss4/art43/

Van Cruyningen, P. (2014). From disaster to sustainability: floods, changing property relations and water management in the south-western Netherlands, c.1500-1800. Continuity and Change, 29(2), 241-265. http://doi.org/10.1017/S0268416014000149

Van Dam, P. J. J. M. (2002). Ecological Challenges, Technological Innovations: The Modernization of Sluice Building in Holland, 1300-1600. Technology and Culture, 43(3), 500-520. http://doi.org/10.1353/tech.2002.0144

Van de Ven, G. (Ed.). (2004). Man-made lowlands. History of water management and land reclamation in the Netherlands. Utrecht: Matrijs.

Van den Berg, A. E., \& Koole, S. L. (2006). New wilderness in the Netherlands: An investigation of visual preferences for nature development landscapes. Landscape and Urban Planning, 78(4), 362-372. http://doi.org/10.1016/j.landurbplan.2005.11.006

Van den Brink, M. (2009). Rijkswaterstaat on the horns of a dilemma. Delft: Eburon.

Van der Brugge, R. (2007). Transition Dynamics in Social-Ecological Systems. The Case of Dutch Water Management. Erasmus University Rotterdam, PhD thesis, Rotterdam.

Van der Ham, W. (2009). Hollandse polders. Amsterdam: Boom.

Van der Meulen, Y. (2007). Ontpoldering Noordwaard is omvangrijkste maatregel. Land+Water, 8284.

Van der Most, H., Marchand, M., Bucx, T., Nauta, T., \& Van Staveren, M. F. (2009). Towards sustainable development of deltas, estuaries and coastal zones. Delft: Deltares.

Van der Vleuten, E. (2013). Large Technological Systems. In J. K. B. F. Olsen, S. A. Pedersen, \& V. E. Hendricks (Eds.), A companion to the philosophy of technology (pp. 218-222). Chichester: Blackwell Publishing Ltd.

Van der Vleuten, E., \& Disco, C. (2004). Water wizards: Reshaping wet nature and society. History and Technology, 20(3), 291-309. http://doi.org/10.1080/0734151042000287014

Van Heezik, A. (2008). Battle over the rivers. Two hundred years of river policy in the Netherlands. Haarlem: VHB and Rijkswaterstaat.

Van Hemert, M. (1999). Ruimte voor de ingenieur. Rivierbeheer in Nederland eind jaren negentig. K\&M, Tijdschrift Voor Empirische Filosofie, 361-387.

Van Hemert, M. (2008). Making rivers modular. Emerging river science 1980 - 2005. Twente University, PhD thesis.

Van Loon-Steensma, J. M. (2014). Salt marshes for flood protection. Long-term adaptation by combining functions in flood defences. Wageningen University, PhD thesis.

Van Loon-Steensma, J. M., Slim, P. A., Decuyper, M., \& Hu, Z. (2014). Salt-marsh erosion and restoration in relation to flood protection on the Wadden Sea barrier island Terschelling. Journal of Coastal Conservation, 18(4), 415-430. http://doi.org/10.1007/s11852-014-0326-z

Van Rooy, P. (2015). Overdiepse polder. Vijftien jaar overheidsparticipatie. Den Haag: NederLandBovenWater.

Van Schendel, W. (2010). A history of Bangladesh (3rd ed.). New York: Cambridge University Press.

Van Slobbe, E., de Vriend, H. J., Aarninkhof, S., Lulofs, K., de Vries, M., \& Dircke, P. (2013). Building with Nature: In search of resilient storm surge protection strategies. Natural Hazards, 65, 947-966. http://doi.org/10.1007/s11069-012-0342-y

Van Staveren, M. F., \& Van Tatenhove, J. P. M. (2016). Hydraulic engineering in the social-ecological delta: understanding the interplay between social, ecological, and technological systems in the Dutch delta by means of "delta trajectories." Ecology and Society, 21(1), 8. Retrieved from http://www.ecologyandsociety.org/vol21/iss1/art8/

Van Staveren, M. F., Van Tatenhove, J. P. M., \& Warner, J. F. (2017). The tenth dragon: controlled seasonal flooding in long-term policy plans for the Vietnamese Mekong delta. Journal of Environmental Policy \& Planning, (Online first). http://doi.org/10.1080/1523908X.2017.1348287

Van Staveren, M. F., Warner, J. F., \& Khan, M. S. A. (2017). Bringing in the tides. From closing down to opening up delta polders via Tidal River Management in the southwest delta of Bangladesh. Water Policy, 19(3), 147-164. http://doi.org/10.2166/wp.2016.029 
Van Staveren, M. F., Warner, J. F., Van Tatenhove, J. P. M., \& Wester, P. (2014). Let's bring in the floods: De-poldering in the Netherlands as a strategy for long-term delta survival? Water International, 39(5), 686-700. http://doi.org/10.1080/02508060.2014.957510

Van Stokkom, H. T. C., Smits, A. J. M., \& Leuven, R. S. E. W. (2005). Flood defense in the Netherlands A new era, a new approach. Water International, 30(1), 76-87. http://doi.org/10.1080/1523908X.2017.1348287

Van Veen, J. (1962). Dredge, drain, reclaim. The art of a nation (5th ed.). Den Haag: Martinus Nijhoff.

Van Wesenbeeck, B. K., Mulder, J. P. M., Marchand, M., Reed, D. J., De Vries, M. B., De Vriend, H. J., \& Herman, P. M. J. (2014). Damming deltas: A practice of the past? Towards nature-based flood defenses. Estuarine, Coastal and Shelf Science, 140, 1-6. http://doi.org/10.1016/j.ecss.2013.12.031

Vikolainen, V., Van Buuren, A., Warner, J. F., Lulofs, K., \& Bressers, H. (2015). Negotiated Space for the River Scheldt in Flanders. A longitudinal reconstruction of the policy debate to realize multifunctional retention capacity. International Journal of Water Governance, 3, 101-120. http://doi.org/10.7564/13-IJWG31

Vis, F., Klijn, F., \& Van Buuren, M. (Eds.). (2001). Living with floods - resilience strategies for flood risk management and multiple land use in the lower Rhine river basin. Delft: NCR.

Voß, J. P., \& Bornemann, B. (2011). The politics of reflexive governance: Challenges for designing adaptive management and transition management. Ecology and Society, 16(2), 9. Retrieved from http://www.ecologyandsociety.org/vol16/iss2/art9/

Walker, B., Gunderson, L., Kinzig, A., Folke, C., Carpenter, S., \& Schultz, L. (2006). A handful of heuristics and some propositions for understanding resilience in social-ecological systems. Ecology and Society, 11(1), 13. Retrieved from http://www.ecologyandsociety.org/vol11/iss1/art13/

Walker, W. E., Rahman, S. A., \& Cave, J. (2001). Adaptive policies, policy analysis, and policy-making. European Journal of Operational Research, 128(2), 282-289. http://doi.org/10.1016/S03772217(00)00071-0

Wallace, H. (2000). The policy process. A moving pendulum. In H. Wallace \& W. Wallace (Eds.), Policymaking in the European Union (4th ed., pp. 39-64). Oxford NY: Oxford University Press.

Warner, J. F. (2008a). Emergency river storage in the Ooij polder - A bridge too far? Forms of participation in flood preparedness policy. International Journal of Water Resources Development, 24(4), 567-582. http://doi.org/10.1080/07900620801923153

Warner, J. F. (2008b). The politics of flood insecurity. Framing contested river management projects. Wageningen University, PhD thesis.

Warner, J. F. (2010). Integration through Compartmentalization? Pitfalls of "Poldering" in Bangladesh. Nature + Culture, 5(1), 65-83. http://doi.org/10.3167/nc.2010.050105

Warner, J. F. (2012). The Shadow of the Past in Dutch Flood Management: The Rediscovery and Politicisation of Best Practices. In V. Acosta, J. Audefroy, \& F. Briones (Eds.), Strategies for Prevention and Adaptation (pp. 25-47). Mexico: CIESAS

Warner, J. F., Van Buuren, A., \& Edelenbos, J. (Eds.). (2013). Making space for the river. Governance experiences with multifunctional river flood management in the US and Europe. London: IWA Publishing.

Waterman, R. E. (2008). Integrated coastal policy via building with nature. Delft: Author.

Waylen, K. A., Holstead, K. L., Colley, K., \& Hopkins, J. (2017). Challenges to enabling and implementing Natural Flood Management in Scotland. Journal of Flood Risk Management. http://doi.org/10.1111/jfr3.12301

Wescoat, J. L. (2009). Comparative international water research. Journal of Contemporary Water Research \& Education, (142), 61-66. http://doi.org/10.1111/j.1936-704X.2009.00055.x

Wesselink, A. J. (2006). Safety from flooding in low countries. Position paper Katrina workshop. In Contribution to the "Katrina workshop," New Orleans.

Wesselink, A. J. (2007). Flood safety in the Netherlands: The Dutch response to Hurricane Katrina. Technology in Society, 29(2), 239-247. http://doi.org/10.1016/j.techsoc.2007.01.010

Wesselink, A. J., Bijker, W. E., de Vriend, H. J., \& Krol, M. (2007). Dutch dealings with the delta. Nature and Culture, 2(2), 188-209. http://doi.org/10.3167/nc.2007.020206

Wesselink, A. J., \& Warner, J. F. (2010). Reframing Floods: Proposals and Politics. Nature + Culture, 5(1), 
1-14. http://doi.org/10.3167/nc.2010.050101

Wesselink, A. J., Warner, J. F., Abu Syed, M., Chan, F., Tran, D. D., Huq, H., ... Zegwaard, A. (2015). Trends in flood risk management in deltas around the world: Are we going "soft"? International Journal of Water Governance, 4, 25-46. http://doi.org/10.7564/15-IJWG90

Westerman, F. (2015). De Graanrepbliek. Amsterdam: Athenaeum.

Wiering, M. A., \& Arts, B. J. M. (2006). Discursive shifts in Dutch river management: "deep" institutional change or adaptation strategy? Hydrobiologia, 565, 327-338. http://doi.org/10.1007/s10750005-5923-2

Wiering, M. A., \& Driessen, P. (2001). Beyond the art of diking: interactive policy on river management in the Netherlands. Water Policy, 3(4), 283-296. http://doi.org/10.1016/S1366-7017(01)000757

Wiering, M. A., \& Immink, I. (2006). When water management meets spatial planning: A policyarrangements perspective. Environment and Planning C: Government and Policy, 24(3), 423-438. http://doi.org/10.1068/c0417j

Willcocks, W. (1930). Lectures on the ancient system of irrigation in Bengal and its application to modern problems. In S. Rashid \& R. Rahman (Eds.), Water resources development in Bangladesh. Historical documents (pp. 101-112). Dhaka: University Press Limited.

Wolff, W. J. (1992). The end of a tradition: 1000 years of embankment and reclamation of wetlands in the Netherlands. Ambio, 21(4), 287-291.

Wolters, M., Bakker, J., \& Garbutt, A. (2005). Salt-marsh restoration: evaluating the success of deembankments in north-west Europe. Biological Conservation, 123(2), 249-268. http://doi.org/10.1016/j.biocon.2004.11.013

Wood, G. (1999). Contesting water in Bangladesh: Knowledge, rights and governance. Journal of International Development, 11(5), 731-754. http://doi.org/10.1002/(SICI)10991328(199907/08)11:5<731::AID-JID567>3.0.CO;2-Z

Woolgar, S. (1991). The Turn to Technology in Social Studies of Science. Science, 16(1), 20-50. http://doi.org/10.1177/016224399101600102

World Bank. (2012). Grow in Concert with Nature. Green Water Defense for Flood Risk Management in East Asia. Washington DC: Author.

World Commission on Environment and Development. (1987). Our Common Future. Oxford: Oxford University Press.

Yin, R. K. (2014). Case study research. Design and methods. Los Angeles: Sage Publications.

Young, O. R., Berkhout, F., Gallopín, G. C., Janssen, M. a., Ostrom, E., \& van der Leeuw, S. (2006). The globalization of socio-ecological systems: An agenda for scientific research. Global Environmental Change, 16(3), 304-316. http://doi.org/10.1016/j.gloenvcha.2006.03.004

Zegwaard, A. Z. (2016). Mud. Deltas dealing with uncertainties. Free University Amsterdam, PhD thesis.

Zevenbergen, C., van Herk, S., Rijke, J., Kabat, P., Bloemen, P., Ashley, R., ... Veerbeek, W. (2013). Taming global flood disasters. Lessons learned from Dutch experience. Natural Hazards, 65, 1217-1225. http://doi.org/10.1007/s11069-012-0439-3

Zwarts, L., Van Beukering, P., Kone, B., \& Wymenga, E. (2005). The Niger, a lifeline. Effective water management in the Upper Niger Basin. Lelystad: RIZA. 
162 | 


\section{Appendix A Shades of green in flood management concepts}

The table below does not aim to propose a formal classification of different types of green flood management concepts, but to show that the extent to which ecosystems dynamics are incorporated in flood management engineering. Some concepts could be placed in multiple categories.

\begin{tabular}{|c|c|c|}
\hline Shade & Term/concept & Sources \\
\hline \multirow{6}{*}{$\begin{array}{l}\text { Ecosystem-integrative } \\
\text { Flood management } \\
\text { engineering designs } \\
\text { (or mode of operation } \\
\text { of infrastructure) that } \\
\text { incorporate greener } \\
\text { aspects }\end{array}$} & $\begin{array}{l}\text { Ecological engineering in coastal } \\
\text { projects }\end{array}$ & $\begin{array}{l}\text { (Borsje et al., 2011; ProAct network, } \\
\text { 2008) }\end{array}$ \\
\hline & $\begin{array}{l}\text { Green infrastructure/nature-based } \\
\text { flood defense }\end{array}$ & $\begin{array}{l}\text { (Saleh \& Weinstein, 2016; Van } \\
\text { Wesenbeeck et al., 2014) }\end{array}$ \\
\hline & Flood pulse concept & (Bayley, 1991; Middleton, 2002) \\
\hline & Green Flood Protection & (Janssen, 2015) \\
\hline & Green Water Defenses & $\begin{array}{l}\text { (Marchand, Long, \& Sawarendo, } \\
\text { 2012; World Bank, 2012) }\end{array}$ \\
\hline & $\begin{array}{l}\text { Salt marshes as foreshore } \\
\text { protection }\end{array}$ & (Van Loon-Steensma, 2014) \\
\hline \multirow{7}{*}{$\begin{array}{l}\text { Ecosystem- } \\
\text { anticipative } \\
\text { Flood management } \\
\text { engineering that is } \\
\text { flexible and aims to } \\
\text { cater for } \\
\text { environmental } \\
\text { dynamics, primarily } \\
\text { from a control } \\
\text { perspective }\end{array}$} & $\begin{array}{l}\text { Emergency retention areas, de- } \\
\text { poldering, green rivers or bypass, } \\
\text { Room for the River }\end{array}$ & $\begin{array}{l}\text { (Roth et al., 2006; Van Staveren, } \\
\text { Van Tatenhove, et al., 2017; Van } \\
\text { Staveren et al., 2014; Warner, } \\
\text { 2008a) }\end{array}$ \\
\hline & Controlled restoration flooding & (Galat et al., 1998) \\
\hline & Multifunctional flood defenses & (Kothuis \& Kok, 2017) \\
\hline & Managed coastal realignment & (French, 2006; Pethick, 2002) \\
\hline & Controlled Reduced Tide (CRT) & (Cox et al., 2006) \\
\hline & Rotational polder concept & $\begin{array}{l}\text { (De Mesel et al., 2013; Vikolainen, } \\
\text { Van Buuren, Warner, Lulofs, \& } \\
\text { Bressers, 2015) }\end{array}$ \\
\hline & Living with floods & $\begin{array}{l}\text { (Kamal, 2006; Tinh \& Hang, 2003; } \\
\text { Vis, Klijn, \& Van Buuren, 2001) }\end{array}$ \\
\hline \multirow{5}{*}{$\begin{array}{l}\text { Ecosystem-based } \\
\text { Flood management } \\
\text { engineering that } \\
\text { builds on ecosystem } \\
\text { dynamics as a } \\
\text { (strategic) element of } \\
\text { designing flood } \\
\text { management } \\
\text { approaches }\end{array}$} & Building with Nature & $\begin{array}{l}\text { (De Vriend \& Van Koningsveld, } \\
\text { 2012; Waterman, 2008) }\end{array}$ \\
\hline & Ecosystem-based DRR measures & $\begin{array}{l}\text { (Renaud, Sudmeier-Rieux, et al., } \\
\text { 2013) }\end{array}$ \\
\hline & Tidal River Management & $\begin{array}{l}\text { (Gain et al., 2017; Mutahara et al., } \\
\text { 2017; Van Staveren, Warner, et al., } \\
\text { 2017) }\end{array}$ \\
\hline & Natural Flood Management & (Waylen et al., 2017) \\
\hline & Strategic flood management & (Sayers et al., 2015) \\
\hline
\end{tabular}




\section{Appendix B Interview list}

\begin{tabular}{|c|c|c|}
\hline \multicolumn{3}{|l|}{ De-poldering the Noordwaard polder in the Dutch delta } \\
\hline Organization & Date & Type \\
\hline Former chairman residents association Noordwaard polder & 14-11-2013 & Report \\
\hline Senior project manager Water Board Rivierenland & $15-11-2013$ & Report \\
\hline Researcher Wageningen University & $15-11-2013$ & Recording \\
\hline Historian, Land van Heusden en Altena area & 28-11-2013 & Report \\
\hline Senior programme manager Water Board Rivierenland & 28-11-2013 & Report \\
\hline EIA Expert Consultancy Firm & $5-12-2013$ & Report \\
\hline Project manager Rijkswaterstaat & $6-12-2013$ & Recording \\
\hline Former director IJsselmeer Polder Development Authority & $22-2-2014$ & Report \\
\hline Civil engineer TU Delft & $24-4-2014$ & Report \\
\hline Senior programme managers WWF & $29-4-2014$ & Recording \\
\hline Agricultural extension officer new polders (retired) & $6-2-2016$ & Recording \\
\hline \multicolumn{3}{|l|}{ Tidal River Management in the coastal zone of the Bangladesh's delta } \\
\hline Organization & Date & Type \\
\hline Senior Specialist DRR World Bank * & $1-3-2015$ & Recording \\
\hline Addition Director General BWDB (retired) & 28-11-2012 & Report \\
\hline Employee IRV * & $28-1-2015$ & Recording \\
\hline Project Scientist IRRI $*$ & $2-2-2015$ & Recording \\
\hline Senior Water Expert, Dutch Embassy Dhaka * & $3-2-2015$ & Recording \\
\hline Consultant Water and Agriculture, KJDRP $*$ & $4-2-2015$ & Report \\
\hline Blue Gold, former KJDRP consultant participation * & $5-2-2015$ & Recording \\
\hline Deputy Team Leader Blue Gold Programme * & $5-2-2015$ & Recording \\
\hline Technical Director WARPO * & $5-2-2015$ & Report \\
\hline Senior researcher Deltares * & $6-2-2016$ & Recording \\
\hline Deputy Component Leader WRM Blue Gold * & $9-2-2015$ & Recording \\
\hline Deputy Executive Director CEGIS * & $15-2-2015$ & Recording \\
\hline Project Director, CEIP $*$ & $16-2-2015$ & Recording \\
\hline Deputy Team Leader BDP2100* & $23-2-2015$ & Recording \\
\hline UNDP Bangladesh * & $25-2-2015$ & Recording \\
\hline Participatory Water Management Specialist LGED * & $25-2-2015$ & Recording \\
\hline Specialist Geology IWM * & $26-2-2015$ & Recording \\
\hline Director Uttaran * & $22-3-2015$ & Recording \\
\hline Team Leader BDP2100 \# & $22-3-2015$ & Recording \\
\hline \multicolumn{3}{|l|}{ Restoring controlled seasonal flooding in the Vietnamese Mekong delta } \\
\hline Organization & Date & Type \\
\hline Department of Agriculture and Rural Development, An Giang Province & $27-3-2016$ & Recording \\
\hline Hydraulic engineer Consultancy Firm & $22-2-2014$ & Report \\
\hline Research Center for Rural Development, An Giang University & $24-2-2014$ & Report \\
\hline IUCN Vietnam * & $4-4-2016$ & Recording \\
\hline Can Tho University * & $4-4-2016$ & Recording \\
\hline Deputy Director Mekong Delta Development Research Institute * & $12-4-2016$ & Recording \\
\hline Senior advisor, World Bank * & $15-4-2016$ & Recording \\
\hline Senior researcher, Deltares * & $22-4-2016$ & Report \\
\hline Project Manager GIZ * & $27-4-2016$ & Recording \\
\hline
\end{tabular}

* interviews carried out by/together with research assistant 
166 | 
WASS Certificate

Martijn Floris van Staveren

Wageningen School of Social Sciences (WASS)

Completed Training and Supervision Plan

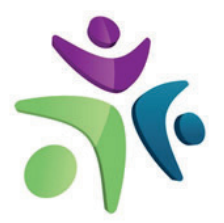

Wageningen School of Social Sciences

\section{Name of the learning activity \\ A) Project related competences}

Department/Institute

Year

ECTS*

Joint proposal development

Stakeholder workshop

Research proposal writing

Designing Innovative Governance

Arrangements, PAP30306

Delta Lessons Seminar Dhaka

Summer School Sustainable

Governance of Land and Water

MOOC Disasters and Ecosystems:

Resilience in a Changing Climate

MOOC Building with Nature

$\mathrm{PhD}$ discussion groups (Marine

Meetings)
WRM

WRM

DIS, WRM

WUR

Institute for Water and Flood

Management, BUET

Utrecht University

UNEP, Cologne University of Applied

Sciences, GUPES, CNRD

Deltares

ENP
2011

2011

2012

2012

2012

2013

2015

2016

2012 - 2016
2

1

0.5

6

6

1

2

1

0.5

\section{B) General research related competences}

Introduction course
QCA for Water Studies Training
'Blue-green convergence in the Dutch
delta'

WASS

2012

1

WRM

2012

0.5

WASS PhD day

2013

1

'Ecosystem-based approaches to flood WPC PhD day

2014

0.5

management in the Dutch delta'

Summer School Science \&

Linköping University, Sweden

2014

Technology Studies

\section{C) Career related competences/personal development}

Global Platform on Disaster Risk

Reduction, delegation member
Global Facility for Disaster Risk

Reduction, United Nations institutes 
'Shades of green: examples of greener approaches to water and flood management in the Bangladesh and Dutch deltas'

Research visit Stockholm

Environmental Institute

Student co-supervision (4x MSc)

ENP PhD Trip Germany \& Switzerland

Guest lectureships

'Using infographics in research'

'Social-ecological deltas and green

infrastructure: lessons from the Dutch

and Paraná deltas'

Course coordination Water

ENP, SDC, WRM, PAP

SEI, Stockholm International Water

2015

2 Institute (SIWI), Global Water

Partnership (GWP)

ENP

ENP

UNESCO-IHE, SDC

Urbanizing Delta of the World Conference, Ho Chi Minh City

Stockholm World Water Week

Governance and co-coordination

Governance \& Policy Change

Total

* One credit according to ECTS is on average equivalent to 28 hours of study load 


\section{About the author}

Martijn van Staveren was born on October 10, 1981 in Amsterdam. After attending pre-university education he studied Civil Engineering at Delft Technical University (2000-01), but completed the study at the Amsterdam University of Applied Sciences (2001-05), specialization water management. His internship in Kenya sparked his interest in the international

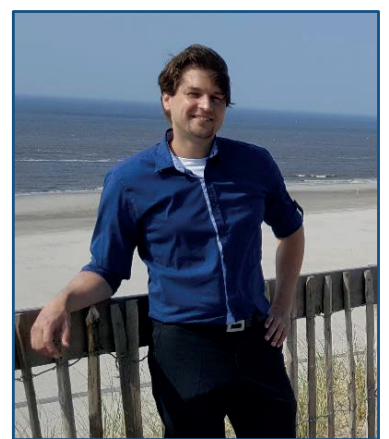
dimensions of land and water management. Subsequently, at Wageningen University, Martijn followed the MSc International Land and Water Management, with a specialisation in flood management (2005-07). He spent several months in Vietnam and Mali, studying water and flood management policy and practices in the Red River delta and Inner Niger delta.

After a student assistant position at the (now) Water Resources Management group, he was hired by the Netherlands Water Partnership. This has enabled him to travel to and work with a variety of water management organizations in Vietnam, Bangladesh, Mozambique and Japan. Via NWP Martijn was involved with various delta-oriented initiatives, from the Innovation Network Delta Technology, the initiation of the Water Mondiaal programme (Dutch international development cooperation on delta management), to the first outlines of the Urbanizing Deltas of the World research programme (NWO-UDW). In 2011 Martijn took on the invitation of the WRM group to contribute to a proposal for a PhD research project. When funding for this proposal was granted by NWO-Wotro, he commenced on this PhD journey from 2012 onwards.

Besides conducting the PhD research, Martijn (co-)supervised a number of BSc and MSc students, delivered guest lectures and coordinated (Water Governance, 2016-17) and cocoordinated (Governance and Policy Change, 2016-17) two courses at Wageningen University. He has been one of the initiators of the Infographics Committee at ENP, contributing to innovative ideas about research dissemination, and member of IUCN-CEM's Ecosystem-based DRR thematic group.

From August 2017 onwards, he is part of the All-Risk research programme, funded by NWOSTW, as a postdoc researcher. He will conduct research in the field of water governance and science-policy interface dynamics regarding riverine and coastal flood management measures. 


\section{Publications}

Van Staveren, M. F., Van Tatenhove, J. P. M., \& Warner, J. F. (2017). The tenth dragon: controlled seasonal flooding in long-term policy plans for the Vietnamese Mekong delta. Journal of Environmental Policy \& Planning. http://doi.org/10.1080/1523908X.2017.1348287

Van Staveren, M. F., Warner, J. F., \& Khan, M. S. A. (2017). Bringing in the tides. From closing down to opening up delta polders via Tidal River Management in the southwest delta of Bangladesh. Water Policy, 19(3), 147-164. http://doi.org/10.2166/wp.2016.029

Van Staveren, M. F., \& Van Tatenhove, J. P. M. (2016). Hydraulic engineering in the socialecological delta: understanding the interplay between social, ecological, and technological systems in the Dutch delta by means of "delta trajectories." Ecology and Society, 21(1), 8. Retrieved from http://www.ecologyandsociety.org/vol21/iss1/art8/

Wesselink, A. J., Warner, J. F., Abu Syed, M., Chan, F., Tran, D. D., Huq, H., Huthoff, F., Tran, D.D., Thuy, N.L., Pinter, N., van Staveren, M., Zegwaard, A. (2015). Trends in flood risk management in deltas around the world: Are we going "soft"? International Journal of Water Governance, 4, 25-46. http://doi.org/10.7564/15-IJWG90

Van Staveren, M. F., Warner, J. F., Van Tatenhove, J. P. M., \& Wester, P. (2014). Let's bring in the floods: De-poldering in the Netherlands as a strategy for long-term delta survival? Water International, 39(5), 686-700. http://doi.org/10.1080/02508060.2014.957510

Boomsma, C., Dijkshoorn, B., van den Horn, P., Jeuken, A., van Staveren, M., Ovink, H., Wisniewska, E., Lamoree, B., de Groot, K., Nauta, T., van Halsema, G., Tonneijck, M., Dronkers, J., Coenen, V., Wissink, J. (2014). The Delta Approach. Preconditions for sustainable delta management. $\quad$ https://www.dutchwatersector.com/uploads/2014/11/140209-01-deltaapproach-a4-web-07.pdf

Van Staveren, M. (2014). Governance of 'long term delta planning' in Bangladesh, Vietnam and the Netherlands. Water Governance Tijdschrift, 4, 50-51. http://watergovernance.nl/bookshelf/2014/

Van der Most, H., Marchand, M., Bucx, T., Nauta, T., \& Van Staveren, M. F. (2009). Towards sustainable development of deltas, estuaries and coastal zones. Delft: Deltares. 


\section{Acknowledgements}

This $\mathrm{PhD}$ has been, like probably many other PhD trajectories, a rough ride. During those years I am indebted primarily to my supervisors: a PhD endeavour is not only a multi-annual commitment from the candidate, but also from the supervisors. I would like to take this opportunity to thank them for their support. First, Jeroen Warner for his enthusiasm, encouragement and critical questions along the way as daily (hourly?) supervisor and copromotor. Jan van Tatenhove, I would like to thank you for taking on this project as promotor when it was already well underway. Now things are completed, I understand why you have been always repeated that 'this is your party!' Flip Wester (co-promotor): thanks for starting off all of this by inviting me to join the writing stage of the award winning proposal. Thea Hilhorst, I also would like to thank you for your support in the first year and for giving me the space to pursue the topic that took shape along the way.

With the core team of other PhD candidates and close supervisors I enjoyed interesting discussions and adventurous journeys on various occasions and in various (delta) countries. To fellow PhD mates Arjen Zegwaard, Farhana Ahmed, Mahmuda Mutahara: thanks for sharing this lifetime experience and unique rollercoaster. Hamidul Huq, William Veerbeek, Berry Gersonius, Shah Alam Khan and Chris Zevenbergen: thanks for riding along on this journey and the adventures we had, from Zeeland to Bangladesh and Vietnam (in mixed combinations of individuals). I also would like to thank Rik Heinen, who spent quite some time of his study in support of our/my project in Bangladesh and Vietnam (2015-16), and Leendert de Die and Jan van Minnen for their involvement with Bangladesh related research (2013).

The Environmental Policy Group (ENP) has been a fantastic place of work, both from a professional and a social perspective. A great mix of young and less-young researchers, Dutch and international staff, it was a pleasure to have been (and remain) part of you. It never required effort to spend time at the office, in an environment where professionalism, personal motivation and fun are in great balance. Corry Rothuizen: thanks for answering countless questions regarding the administrative and financial dimension of the management of a PhD project. Roommates Robin and Frank: thanks for being paranymphs on this special occasion.

It was also very nice to share experiences with PhD candidates outside ENP: from other groups within Wageningen University (WRM, WSGC, PAP), and with those working at other universities in the Netherlands (Delft, Rotterdam, Utrecht and Nijmegen). Special word of 
thanks to Dung Duc Tran and Thi Minh Hoang Vo (both WRM) for conducting some research together in Vietnam.

I had the privilege to undertake various adventurous activities over the last years: from conducting international fieldwork in Bangladesh and Vietnam to attending summer schools on Science and Technology Studies in Sweden and on delta spatial planning in Utrecht. Conferences in Ho Chi Minh City (Urbanizing Deltas of the World Conference), Rotterdam (Deltas in Times of Climate Change), London (Royal Geographical Society annual conference), Stockholm (Stockholm Water Week and a research visit at the Stockholm Environmental Institute), Geneva (Global Platform on Disaster Risk Reduction), and Amsterdam (Amsterdam International Water Week) were great places to present work and discuss work with international delta researchers from various geographical and professional perspectives. A highlight was also the ENP PhD Trip we undertook with about 15 PhD candidates to Germany and Switzerland early 2016.

During the PhD years I highly appreciated the support from my former full-time colleagues at the Netherlands Water Partnership. Especially Lennart Silvis, Peter van den Horn (now with Hoogheemraadschap Hollands Noorderkwartier), Joris van Oppenraaij, Paul van Koppen and Sandra Borst: thanks for keeping me informed about and involved in the diverse range of activities of the internationally operating Dutch water sector.

To my closest (study) friends I promise that now this project is officially completed, there will be much meetings, dinners and other fun stuff that has gradually reduced in number a bit over the years. Thijs Bergsma (and Hiltje), Twan Brinkhof, Krystel Stevens, Simon Chevalking, Cathelijne Melissen, Erwin Nijsingh, Yamile Julio, Jochum Goede, Jet Sneep, Ronald Kruizenga, Carlos Preciado, John-Paul (and Shiarra) van der Ham: thanks for being such a close group of friends.

Formal and more extended family: thanks to my grandmother (oma oma), my parents Gert and Marion, sister Sarina (and Jeffrey - Leanna and Elias), and Jet and Boud Elsenburg, Boudewijn (and Nicole - Finn) for being an extended family. This also includes Daisy, Wilfredo, Eduardo (Rosa - Adriana and Rosangela), Anthony (Norka - Mariano) in Peru for your support and encouragement. Although conducting this PhD work must sometimes looked like a black box and a never-ending story, you never failed to encourage me (and Milagros) to keep going. 
Finally, on page 173, I can start to thank Milagros Sosa Landeo (forever $\operatorname{Dr} \# 1$ in our household) for your support and motivation. I am foremost very proud of you since you never gave up with your project and kept going: by now you mastered not only to raise a great little companion (FERNANDO), but you also managed to finish your PhD despite having a similar "rough ride." I look forward very much to our "new life," with different kinds of weekends and holidays together. 
The research described in this thesis was financially supported by NWO, the Dutch Organization for Scientific Research, under grant number W.01.65.339.00.

Cover design by Bregje Jaspers

Infographic design by Loek Weijts/Martijn van Staveren

Printed by Digiforce 